San Jose State University

SJSU ScholarWorks

Master's Theses

Master's Theses and Graduate Research

1992

\title{
The effect of varied plasma etching parameters on adhesion of copper plating to ABS plastic
}

\author{
Earl Steven Gurley \\ San Jose State University
}

Follow this and additional works at: https://scholarworks.sjsu.edu/etd_theses

\section{Recommended Citation}

Gurley, Earl Steven, "The effect of varied plasma etching parameters on adhesion of copper plating to ABS plastic" (1992). Master's Theses. 391.

DOI: https://doi.org/10.31979/etd.wwr2-pqfn

https://scholarworks.sjsu.edu/etd_theses/391

This Thesis is brought to you for free and open access by the Master's Theses and Graduate Research at SJSU ScholarWorks. It has been accepted for inclusion in Master's Theses by an authorized administrator of SJSU ScholarWorks. For more information, please contact scholarworks@sjsu.edu. 


\section{INFORMATION TO USERS}

This manuscript has been reproduced from the microfilm master. UMI films the text directly from the original or copy submitted. Thus, some thesis and dissertation copies are in typewriter face, while others may be from any type of computer printer.

The quality of this reproduction is dependent upon the quality of the copy submitted. Broken or indistinct print, colored or poor quality illustrations and photographs, print bleedthrough, substandard margins, and improper alignment can adversely affect reproduction.

In the unlikely event that the author did not send UMI a complete manuscript and there are missing pages, these will be noted. Also, if unauthorized copyright material had to be removed, a note will indicate the deletion.

Oversize materials (e.g., maps, drawings, charts) are reproduced by sectioning the original, beginning at the upper left-hand corner and continuing from left to right in equal sections with small overlaps. Each original is also photographed in one exposure and is included in reduced form at the back of the book.

Photographs included in the original manuscript have been reproduced xerographically in this copy. Higher quality $6 "$ " 9 9" black and white photographic prints are available for any photographs or illustrations appearing in this copy for an additional charge. Contact UMI directly to order.

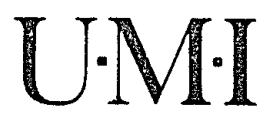

University Microflims Internatıonal

A Bell \& Howell Information Company 300 North Zeeb Road. Ann Arbor. MI 48106-1346 USA 

Order Number 1350085

The effect of varied plasma etching parameters on adhesion of copper plating to ABS plastic

Gurley, Earl Steven, M.S.

San Jose State University, 1992

Copyright $(1993$ by Gurley, Earl Steven. All rights reserved.

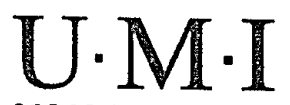

300 N. Zeeb Rd.

Ann Arbor, MI 48106 
- 


\title{
THE EFFECT OF VARIED PLASMA ETCHING PARAMETERS ON ADHESION OF COPPER PLATING TO ABS PLASTIC
}

\author{
A Thesis \\ Submitted In Partial Fulfillment \\ of the Requirements for the Degree \\ Master of Science \\ in Chemical Engineering
}

By

Earl Steven Gurley

August, 1992 
APPROVED FOR THE DEPARTMENT OF CHEMICAL ENGINEERING

Reset P Rani

Dr. Robert Romig, Chairperson

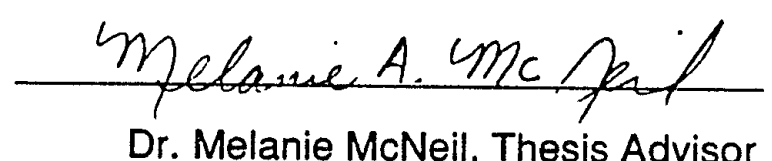

Dr. Melanie McNeil, Thesis Advisor

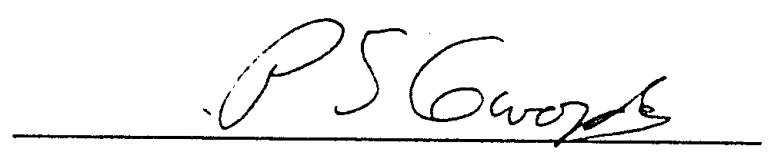

Dr. Peter Gwordz

APPROVED FOR THE UNIVERSITY Serena It. Stanford 


\begin{abstract}
THE EFFECT OF VARIED PLASMA ETCHING PARAMETERS ON ADHESION OF COPPER PLATING TO ABS PLASTIC

by Earl Steven Gurley
\end{abstract}

This thesis addresses the effect of varying plasma etch conditions on the adhesion of copper plating to Acrylonitrile-Butadiene-Styrene (ABS) plastic. Oxygen gas was used for the plasma etching experiments. The main objective was to determine the effect of varied plasma etching parameters on the relative peel strength of copper plating. Taguchi experimental design was used to characterize a subscale electroless and electrolytic copper plating line and to study the effect of four plasma etch parameters, oxygen flowrate, time, radio frequency power, and chamber pressure, on relative peel strength. In addition, Scanning Electron Microscope (SEM) photographs were taken of selected etched samples to record their topography.

Results showed that of the plasma etch parameters studied those parameters most effecting the adhesion of copper plating to ABS plastic are flowrate of oxygen, and to a lesser extent, chamber pressure. Ultimate peel strength increased as oxygen flow decreased and also as the chamber pressure decreased. For plasma etched samples, data showed that excellent adhesion could be attained outside the previously reported critical pore size regime . 


\section{ACKNOWLEDGMENTS}

I would like to thank the following people for their help and cooperation in this project:

Dr. Melanie McNeil

Ms. Marissa Vidal

Dr. Peter Gwordz

Dr. Pat Pizzo

Mr. Jerry Eveland 


\section{TABLE OF CONTENTS}

\subsection{INTRODUCTION TO PLATING ON PLASTICS}

1.1 Introduction 1

1.2Industry Size 1

1.3Electroless Plating 2

1.4Plasma Etching 5

2.0 LITERATURE REVIEW OF THE COMPARISON OF CHROMIC ACID ETCH AND PLASMA ETCH AND THEIR EFFECTT ON ADHESION

2.1 Mechanical Interlocking 14

2.2Formation of Chemical Bonds 20

2.3Surface Effects 22

3.0 RESEARCH HYPOTHESIS AND OBJECTIVE

3.0Hypothesis 24

3.1 Justification 24

3.2Objective 24

\subsection{EXPERIMENTAL PROCEDURE}

4.1 Taguchi Methods 26

4.2Experimental Procedure and Apparatus 32 
TABLE OF CONTENTS (Cont'd)

\subsection{RESULTS}

5.1 Introduction 38

5.2Acid Etch Experiment 38

5.3Acid Etch "Standard" Topography 41

5.4Plasma Etch Experiment 47

5.5Plasma Etch Topography 55

5.6One Variable Testing 61

5.7 Attribute Data 71

5.8Repeatability and Reproducibility 78

6.0 DISCUSSION

6.1 Chromic Acid Main Effects 80

6.2 Plasma Etch Main Effects 81

6.3 Confirmation Run $\quad 84$

6.4 One Variable Testing: The Main Objective 88

$\begin{array}{lll}7.0 & \text { CONCLUSIONS } & 92\end{array}$

$\begin{array}{ll}\text { REFERENCES } & 94\end{array}$ 


\section{APPENDICES}

Appendix A: Equipment Description 96

Appendix B: Chromic Acid Taguchi Calculations 101

Appendix C: $\quad$ Plasma Etch Taguchi Calculations 104

Appendix D Tables of Raw Data for One Variable Testing 113

$\begin{array}{lll}\text { Appendix E Error Analysis } & 117\end{array}$ 


\section{LISTS OF FIGURES}

Figure 1. Effective Range of the High Performance System. 4

Figure 2. Flow Diagram of the Experiment Equipment 6

Figure 3. Diagram of Plasma Etching of Plastics 8

Figure 4. Flow Diagram for Plasma Etching 10

Figure 5. Contact Angle $\quad 12$

Figure 6. Diagram of Mechanical Interlocking Mechanism 15

Figure 7. Interaction Curve for Power and Chamber Pressure 18

Figure 8. Anisotropic Recombination 19

Figure 9. Linear Graph Chromic Acid: Acid Etch Time 39

Figure 10. Linear Graph Chromic Acid: Catalyst Time 39

Figure 11. Linear Graph Chromic Acid: Accelerator Time 40

Figure 12. Linear Graph Chromic Acid: Electroless Time 40

Figure 13. Linear Graph Plasma Etch: Flowrate 49

Figure 14. Linear Graph Plasma Etch: Time 49

Figure 15. Linear Graph Plasma Etch: Power 50

Figure 16. Linear Graph Plasma Etch: Chamber Pressure 50

Figure 17. S/N Response Graphs and Mean Peel Strength: Flowrate 51

Figure 18. S/N Response Graphs and Mean Peel Strength: Time 52

Figure 19. S/N Response Graphs and Mean Peel Strength: Power 53

Figure 20. S/N Response Graphs and Mean Peel Strength:

Chamber Pressure 54

Figure 21. Interaction Response Graphs 56 


\section{LISTS OF FIGURES (Cont'd)}

Figure 22. One Variable Testing: Varied Flowrate 62

Figure 23. One Variable Testing: Varied Chamber Pressure, $80 \mathrm{ml} / \mathrm{min} .68$

Figure 24. One Variable Testing: Varied Chamber Pressure, $20 \mathrm{ml} / \mathrm{min} .70$

Figure 25. Film Thickness: Experimental Control 74

Figure 26. Interaction Response Graph (B X D) 87

Figure 27. Flowrate Versus Adhesion: Calculated Results 89 


\section{LIST OF TABLES}

Table I: Taguchi L L $_{8}$ Orthogonal Array

Table II: Results of the Villamizer Experiment: The Critical Pore Size Theory $\quad 29$

Table III: Taguchi Design Experiment: Chromic Acid Etch 33

Table IV: Effect of Etching Period on Topography; Gurley 44

Table V: Taguchi Design Experiment: Plasma Etch 48

Table VI: Effect of Flowrate on Peel Strength 113

Table VII: Effect of Chamber Pressure Results: $80 \mathrm{ml} / \mathrm{min}$. 114

Table VIII:Effect of Chamber Pressure Results: $20 \mathrm{ml} / \mathrm{min}$. 115

Table IX: Copper Film Thickness $\quad 116$

Table X: Confirmation Run $\quad 85$ 


\section{LIST OF PLATES}

Photograph 1. Standard Etch Topography ("Blank") 42

Photograph 2. Sample Etched 6 Minutes: Chromic Acid Array 42

Photograph 3. Sample Etched 8 Minutes: Chromic Acid Array 43

Photograph 4. Sample Etched 10 Minutes: Chromic Acid Array 43

Photograph 5. Sample Etched 2 Minutes: Chromic Acid 45

Photograph 6. Sample Etched 5 Minutes: Chromic Acid 45

Photograph 7. Sample Etched 10 Minutes: Chromic Acid 46

Photograph 8. Sample Etched 20 Minutes: Chromic Acid 46

Photograph 9. Sample 1: Plasma Etch Array 57

Photograph 10. Sample 2: Plasma Etch Array 57

Photograph 11. Sample 3: Plasma Etch Array 58

Photograph 12. Sample 4: Plasma Etch Array 58

Photograph 13. Sample 5: Plasma Etch Array 59

Photograph 14. Sample 6: Plasma Etch Array 59

Photograph 15. Sample 7: Plasma Etch Array 60

Photograph 16. Sample 8: Plasma Etch Array 60

Photograph 17. Flowrate $100 \mathrm{ml} / \mathrm{min}$. @ 380 milltorr, 50 Watts, $10 \mathrm{~min} .63$

Photograph 18. Flowrate $80 \mathrm{ml} / \mathrm{min}$. @ 380 milltorr, 50 Watts, $10 \mathrm{~min} .64$

Photograph 19. Flowrate $60 \mathrm{ml} / \mathrm{min}$. @ 380 milltorr, 50 Watts, $10 \mathrm{~min} .65$

Photograph 20. Flowrate $40 \mathrm{ml} / \mathrm{min}$. @ 380 millitorr, 50 Watts, $10 \mathrm{~min}$. 66

Photograph 21. Flowrate $20 \mathrm{ml} / \mathrm{min}$. @ 380 millitorr, 50 Watts, $10 \mathrm{~min}$. 67

Photograph 22. Pressure 380 millitorr @ $20 \mathrm{ml} / \mathrm{min} ., 50$ Watts, $10 \mathrm{~min} .72$ 


\section{LIST OF PLATES (Cont'd)}

Photograph 23. Pressure 270 millitorr @ $20 \mathrm{ml} / \mathrm{min} ., 50$ Watts, $10 \mathrm{~min} .72$

Photograph 24. Pressure 170 millitorr @ $20 \mathrm{ml} / \mathrm{min} ., 50$ Watts, $10 \mathrm{~min} . \quad 73$

Photograph 25. Cross Section: 45 micrometer Film Thickness 76

Photograph 26. Cohesive Failures: Acid 76

Photograph 27. Partial Cohesive Failures: Chromic Acid 77

Photograph 28. Cohesive Failures: Plasma 77 


\subsection{INTRODUCTION TO THE PROBLEM: \\ PLATING ON PLASTICS INDUSTRY}

\subsection{Introduction}

Over the past 40 years industry has been rapidly replacing metal parts with low cost and low weight molded plastic parts. These plastic parts have been metal plated when it has been necessary to retain anti-static, electromagnetic force resistive, conductive or decorative properties. In order to metal plate plastic a complicated cycle is used in which the plastic is first etched and then electrolessly plated before electrolytic plating can be achieved. A mixed acid solution of chromic and sulfuric acids is currently used in industry to etch plastic parts. The elimination of the use of chromic acid is desirable due to chromic acid's impact on the environment. Plasma etch has been proposed as an alternative etch method to replace the acid etch system and thus, eliminate the use of chromic acid in the plating on plastics industry.

\subsection{Industry Size}

The plating on plastics, POP, industry has evolved from a method of mass producing printed circuit boards in the 1950's (Krulik, 1978), to extensive automotive exterior and interior trim application during the first oil crisis in 1973 (Jameson, 1973), and these materials are now common place in the 1990's. Since plastics, such as acrylonitrile-butadiene-styrene (ABS) terpolymer, are 
non-conductive, they require a pretreatment to make them electrically conductive. This pretreatment is known as electroless plating and was discovered in 1944 by A Brenner and G. Riddel (Krulik, 1978). The two most common applications for electroless plating are: (1) electroless copper on printed circuit boards, (2) electroless copper or nickel on plastics. The electroless plating functions only as an initial conductive film. Further layers of metal are electrolytically deposited. Since a large majority of POP is for decorative automotive applications, most of the deposited metal is subsequently chrome electroplate. Sales for automobiles in 1991 were approximately 6.5 million units. Therefore, the extent of application for these plated products is quite large as demonstrated by this one industry alone.

This investigation focused on electroless plating of ABS plastic, since ABS plastics are the most common plastics commercially plated (Saubestre et al. 1978). Well over $90 \%$ of POP is done on ABS, as it is the easiest to process (Krulik, 1978). Electroless copper and electrolytic copper were used due to the copper being substantially cheaper to use than chrome. The use of copper plating did not change the results of the experiment, since chrome is electrolytically plated over electroless copper in industry.

\subsection{Electroless Plating}

As with any bonding system, it is necessary to prepare or modify the surface of the plastic in order to obtain good adhesion. Typical molded plastic surfaces 
are not well suited for deposition of metals. Plastics typically have smooth surfaces and are usually hydrophobic. These two characteristics lead to poor wetability and thus weak chemical bonds.

A complicated processing cycle is needed to plate plastics. Most plating lines consist of the following chemical baths: (1a) optional pre-etch, (1b) etch, (1c) etch neutralizer, (2) predip, (3) catalyst, (4) accelerator, (5) electroless copper, (6) sulfuric acid, and (7) electroplating. The electroless plating process, step (5), is the most important part of the process (Brockmann, 1989). Adhesion of the electroless plating must be flawless in order to remain durable. Delaminations, blistering, burn-off and flaking are common problems associated with electroless plating. These problems are exposed by further processing such as electrolytic plating. Adequate etching is necessary to give good metal-to-plastic adhesion (Krulik, 1978).

The above described system is called in industry a high performance system, and has been in use since 1973 (Jameson, 1973). This high performance system is used for ABS applications requiring exceptional performance or for extending pre-plate capabilities to other substrates. The primary difference between the high performance system and systems used prior to 1973 is the addition of a pre-etch and the etch system composition. Most etchants are essentially three component solutions of chromium trioxide, sulfuric acid and water. Figure 1 shows the ternary etchant system commonly used. This figure also shows the effective range of each etchant. Note that for the ternary system, 


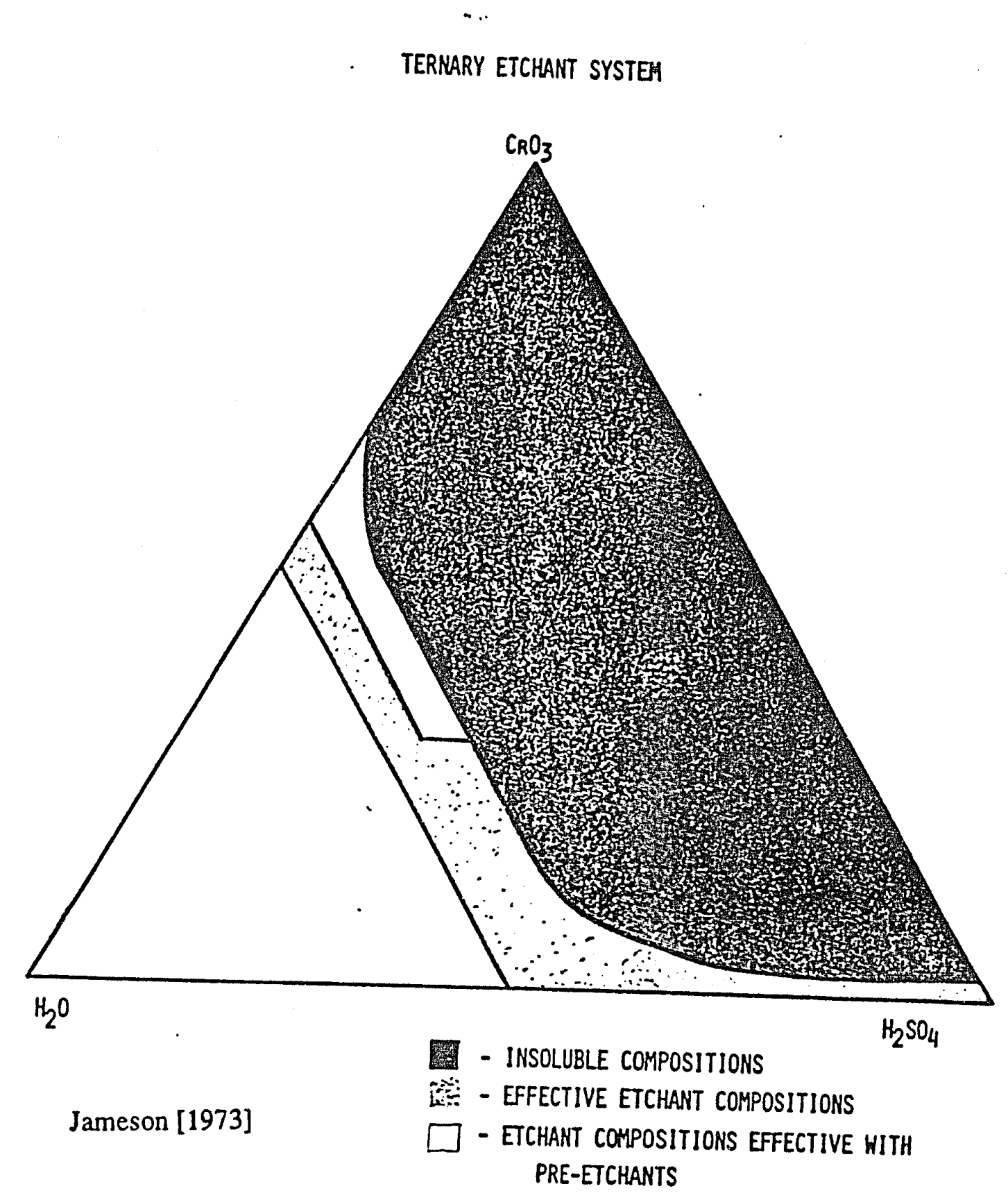

Figure 1: Effective Range of the "High Performance System." 
there are restrictions as to the chemical composition due to solubility limitations (Jameson, 1973 and Krulik, 1978).

\subsection{Plasma Etching}

Plasma etching has been proposed to replace the first three steps numbered (1a), (1b), and (1c), as shown in Figure 2. The replacement of acid etching by plasma was first prompted by bonding problems with certain plastics, such as Teflon. This replacement is more desirable due to the environmental problems associated with the use of chromic acid. Plasma etching and micromachining have been used in the semiconductor industry for over 3 decades. The use of plasma etching to improve bondability of plastics (Hansen, 1989) in secondary bonding applications has been in use since the early 1960's. Later this etch method was used successfully with metalizing in 1981 (Villamizer, 1981).

Plasma treating of plastics to increase adhesion has several advantages. These advantages include, but aren't limited to the following:

- Ablation -- The removal by evaporation of surface material. Ablation is desirable since it is this action that will remove surface material from the plastic surface and lead to improved etching.

- Crosslinking - A connecting of two or more parallel polymer chains. This crosslinking is desired since crosslinking can stiffen the surface making the top layer of the plastic stronger due to these additional bonds thus giving better peel strength. 


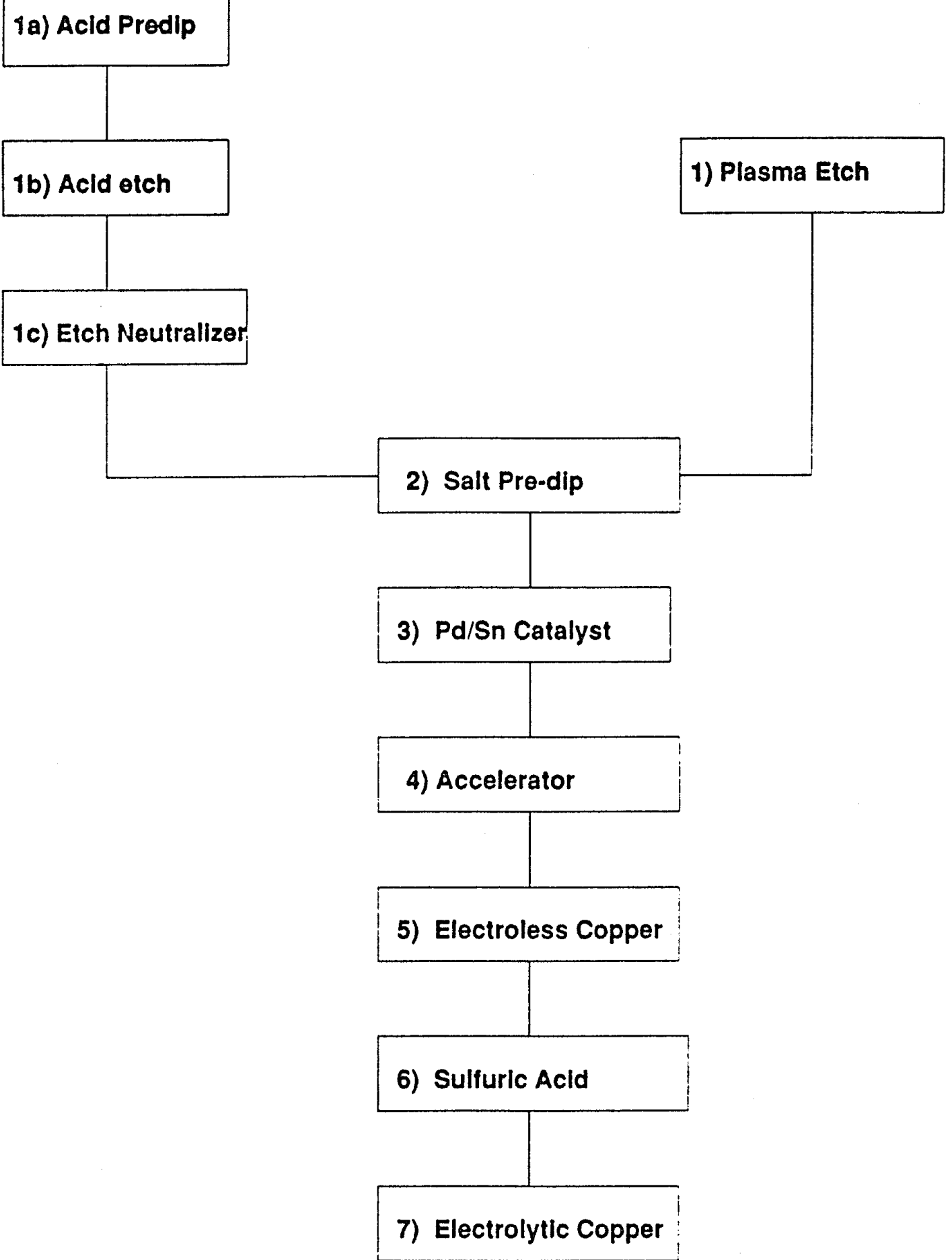

Figure 2. Flow Dlagram for the Experiment 
- Activation -- The act of substituting atoms in the plastic with chemical groups from the plasma gas. Activation is desired since addition of polar groups have been attributed to increased bonding.

Use of the above techniques have significantly increased bondability of Teflon materials. It is expected that some of the same methods used to engineer improvements in the Tefzel 200 (Hansen, 1989) bonding problem could also be employed in the metalization of $A B S$.

Plasmas can be made by ionizing a gas with an electromagnetic field of sufficient power. Useful gas plasmas are formed by introducing a gas, such as $\mathrm{O}_{2}$, into a reaction chamber at pressures between 0.10 and 10 torr, and then exciting the contents of the chamber with radio frequency (RF) power. A schematic of a typical plasma etching chamber is shown in Figure 3. The ionized gas species react with the surfaces they contact. The physical and chemical properties of the formed plasma are dependent on the gas(es) used, RF power, and frequency (although frequency is somewhat restricted), reactor geometries, electrode design, gas flow rates, and temperature.

Although there are several types of plasma, cold plasma was used in this experiment. In cold plasmas the bulk gas is at room temperature, but the temperature of the free electrons in the ionized gas can be 1000 times higher (as hot as $23,000^{\circ} \mathrm{C}$ ) (Chapman, 1980). Cold plasmas are used in commercial lighting, for processing semiconductors, and etching polymers. 


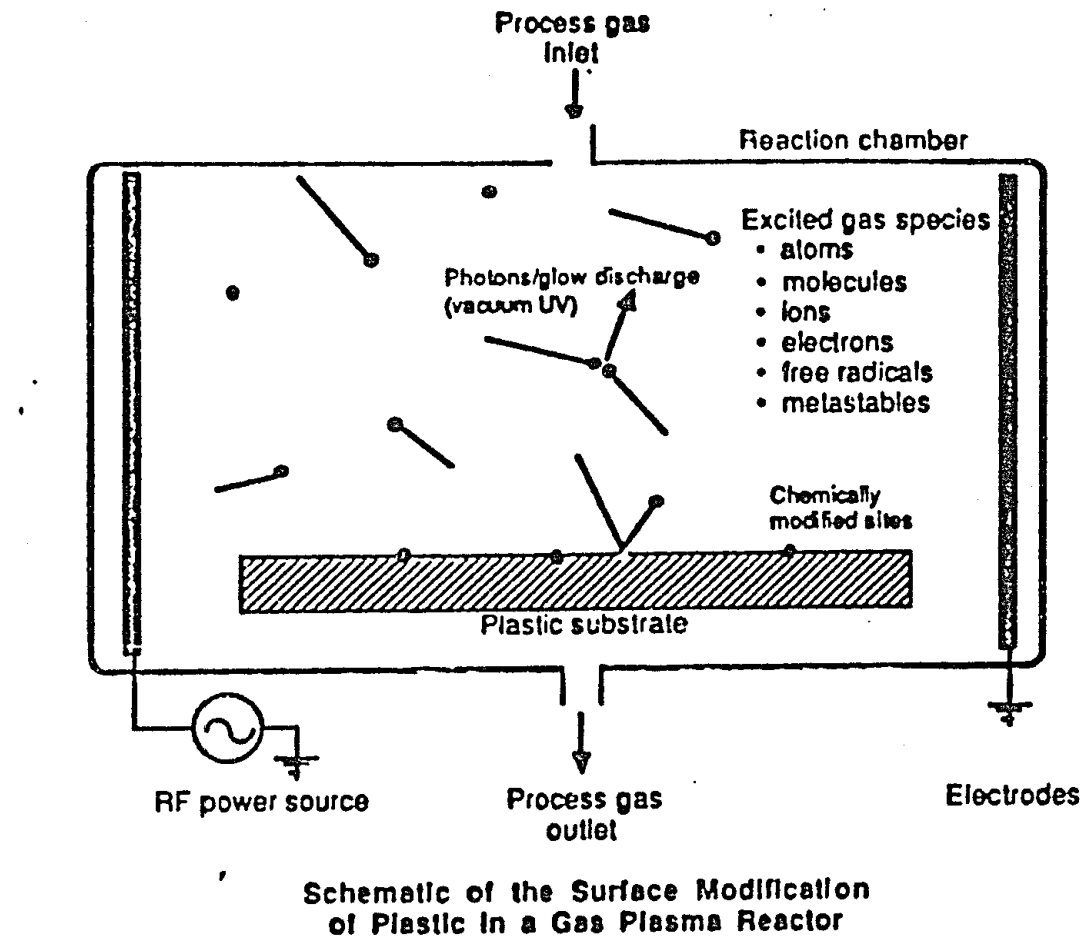

Kaplan [1988]

Figure 3: Diagram of Plasma Etching of Plastics 
There are two types of cold plasma. A primary plasma is generated directly by the RF power and appears between the electrodes of the plasma chamber. A secondary plasma exists outside of the generator's energy field. This plasma is carried by the gas flow.

At the atomic level, plasma contains the following: (1) ions, (2) electrons, and (3) various neutral species. All these subatomic parts exist at different energy levels. The free electrons gain their energy from the electromagnetic field, and transfer that energy by colliding with neutral gas molecules. These collisions and the resultant energy transfer forms free radicals, atoms and ions. These particles interact with plastic surfaces placed in the plasma stream leading to drastic modification of the structure and properties of the surface of the plastic. The plasma process causes these changes to a depth of several monolayers within plastic. Additional time within the plasma chamber will not change this depth since additional time will only ablate the surface away. Plasma may change the molecular weight of the substrate surface layer by scissioning, branching and crosslinking. The type of surface modification depends on the composition of the surface and the gas used.

Figure 4 represents a typical plasma processing system. Depending on the chemistry of the polymer and the gas used for generating the plasma, substitution can make polymers wetable or totally non-wetable. This is an indirect method of measuring the surface energy and relative reactivity of the plastic surface. The type of groups that can be substituted determines how the surface will behave. If polar groups can be substituted on the substrate, then the 


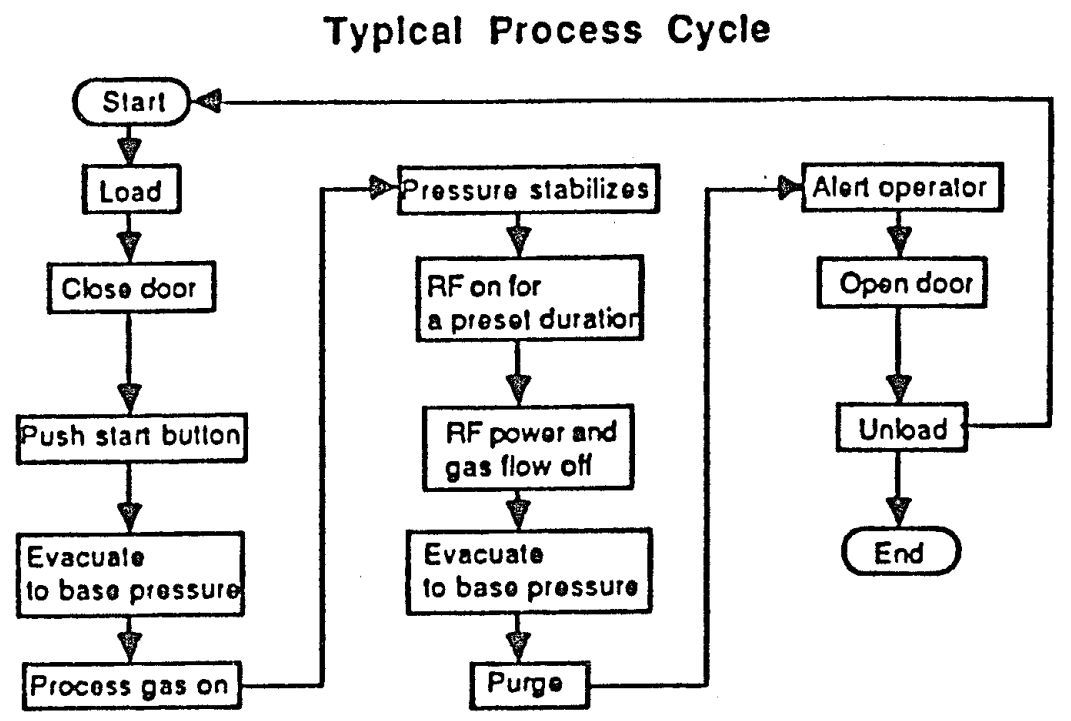

Kaplan [1988]

Figure 4: Flow Diagram for Plasma Etching 
surface will be more wetable. For example, if hydrogen groups result when freeradicals, created by the rupturing of carbon-hydrogen bonds in the polymer combine with any oxygen radical present in an $\mathrm{O}_{2}$ plasma (Villamizer, 1981) to form a hydroxyl group, then these polar groups can be added to the surface. Greater surface energy translates to greater chemical reactivity and can essentially act as a primer for adhesives, paints and deposited metallic films. This modified surface energy can be measured in the lab by water wetability. A common method for determining wetability is by measuring the contact angle between a liquid drop and the surface. Figure 5 shows a comparison between the contact angle of untreated plastic and plasma treated plastic. Contact angle decreases with increasing surface energy.

Oxygen is a commonly used gas for plasma etching and was used in this study. Oxygen plasma contains over 24 different activated species (Hollahan et al., 1974). As the components of the plasma recombine, they release energy and photons, emitting a faint blue glow and UV radiation. The photons in the UV region have enough energy to break the polymer's carbon-carbon and carbonhydrogen bonds. All of the generated active species reacts with the polymer, in addition to bombarding the surface with photons, ions and neutral particles. The oxygen reacts with the released carbon and hydrogen from the polymer surface to form by-products such as $\mathrm{CO}_{2}, \mathrm{CO}, \mathrm{H}_{2} \mathrm{O}$ and low molecular weight hydrocarbons. 


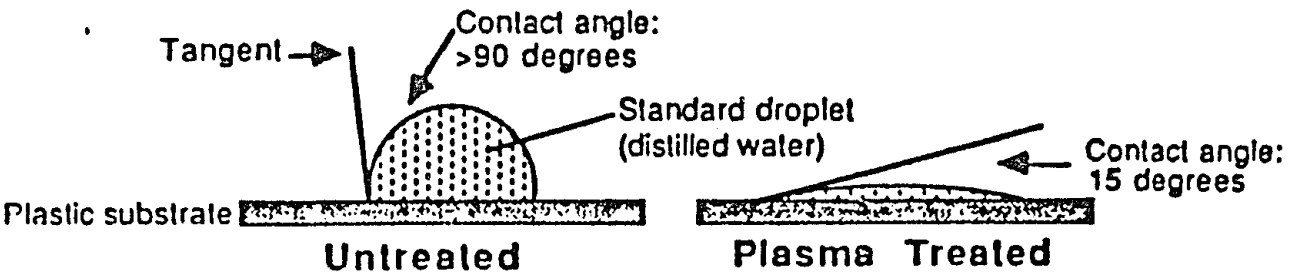

Kaplan [1988]

Figure 5: Contact Angle 
The purpose of this study is to use plasma to engineer the plating system to an environmentally acceptable process. Improvement in this process involves the replacement of chromic acid etching by plasma etching. This study will use oxygen plasma to etch sample coupons made from ABS. These coupons will then be copper plated and tested per standard testing methods to determine adhesion strength of this plating. A statistical method, called Taguchi experimental design, will be used to determine the effect of four etch parameters, namely: flowrate of oxygen, time, power and chamber pressure on the adhesion of copper plating. From this experiment, further experiments will be performed on the parameters which most affect adhesion. 


\subsection{Literature Review of the Effect of Chromic Acid Etch and Plasma Etch and Their Effect on Adhesion.}

\subsection{Mechanical Interlocking}

It has been shown by SEM by Villamizar (1981) and Poa (1977) that mechanical interlocking is the predominant controlling factor in the adhesion of metal to plastics, specifically ABS. Figure 6 shows an idealized diagram of the adhesion of metal to ABS and a real structure verified by SEM (Heymann et al., 1970). From these studies the critical pore size theory has evolved. Villamizer (1981) studied acid etching and plasma showed that the number and the diameter of etched cavities on the plastic surface played a very important role in determining the adhesion property between the metal and plastic. He writes that "There appears to be a critical pore size at which the etching solution gives an optimum peel strength." The critical pore size opening has been reported, in separate sources (Villamizer, 1981, as shown on Table I; Ho, 1989), to be $0.3 \mathrm{x}$

$10^{-3}$ to $2 \times 10^{-5} \mathrm{~cm}$. The critical pore size has been reported to be the same regardless of etching method.

Chromic acid/sulfuric acid etching is preferential to substrate chemistry and is controlled by $\mathrm{CrO}_{3}$ concentration, with the optimum ratio being $20 \%$ volume $\mathrm{H}_{2} \mathrm{SO}_{4}$ with $400 \mathrm{~g} / \mathrm{L} \mathrm{CrO}_{3}$ (Ghorashi, 1977). The chemical etch system preferentially attacks polybutadiene sites. Although the size has been determined and measured by mercury porosity, no specifics of the shape or pattern of these pores are mentioned. 


\section{Figure 7}

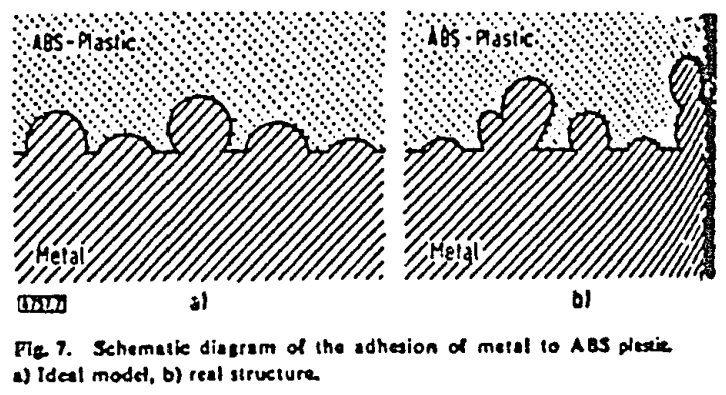

Heymann [1970]

Figure 6. Diagram of Mechanical Interlocking Mechanism 


\section{Table I: Results of the Villamizer Experiment: \\ The Critical Pore Size Theory}

Table 1a Effoct of Elching Portod of Chromic Acld Solution 3 on Adresion Propertios ol Copper To ABS

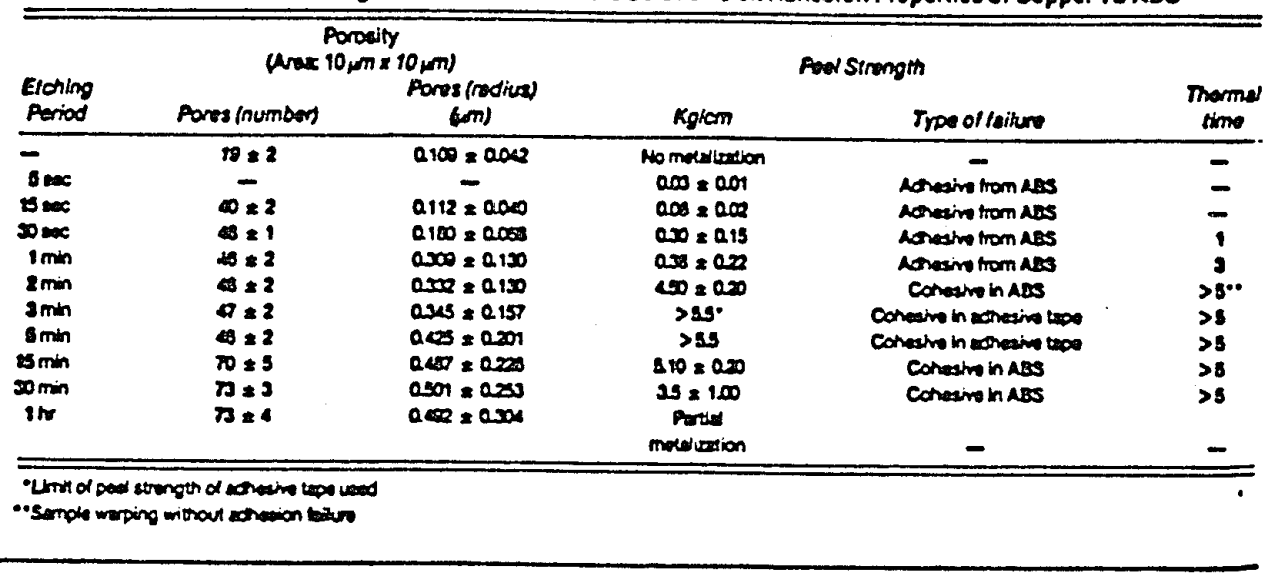

Table Ib EHect of Etcting Pariod ol Oxyoen Plosms on Adheston Properties of Copper to ABS

\begin{tabular}{|c|c|c|c|c|c|}
\hline \multirow[b]{2}{*}{$\begin{array}{l}\text { Elching } \\
\text { Poriod }\end{array}$} & \multicolumn{2}{|c|}{$\begin{array}{l}\text { Porosity } \\
\text { (Ans: } 10, m \times 10 \mu m)\end{array}$} & \multirow{2}{*}{\multicolumn{2}{|c|}{ Pret Strength }} & \multirow[b]{2}{*}{$\begin{array}{l}\text { Thermel } \\
\text { cyode }\end{array}$} \\
\hline & Pores (number) & $\begin{array}{l}\text { Pone (rodiva) } \\
(m)\end{array}$ & & & \\
\hline $\operatorname{lic}$ & - & $0.14=000$ & $05=0.1$ & Antening tromass & - \\
\hline 0 & $\bar{x}=2$ & $0.13=000$ & as at & Aorveshe from ABS & 1 \\
\hline $\operatorname{limin}_{\min }$ & $\begin{array}{l}30=2 \\
30 \pm 2\end{array}$ & $\begin{array}{l}0.13=0.000 \\
0.160=0.098\end{array}$ & 2202 & Cotesin in ADS & 9 \\
\hline $\operatorname{limin}$ & $51=2$ & $\begin{array}{l}0.00=0.18 \\
0240=0.46\end{array}$ & $\begin{array}{l}4=0.0 \\
>10^{\circ}\end{array}$ & Corratinnas & 4 \\
\hline $9 \mathrm{~min}$ & $\theta=3$ & $0.250=0.25$ & $>35$ & 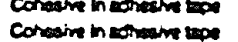 & $\begin{array}{l}38.0 \\
>8\end{array}$ \\
\hline $5 \mathrm{~min}$ & $\pi \times 3$ & $0200 \times 2200$ & $>85$ & 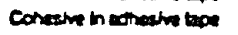 & ss \\
\hline : Smin & 200.5 & $0.518=0.500$ & $>25$ & Cohasin in molveain ine & $>5$ \\
\hline $90 \min$ & $2=3$ & $0001=0.013$ & $>25$ & Conavin in womatin to & $>8$ \\
\hline comin & omen & $>1$ & SSS & Conectre in coresine tripe & $>5$ \\
\hline
\end{tabular}

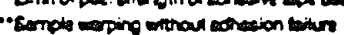

Villamizer [1981] 
Plasma etching is believed to be non-preferential to any of the monomers or conjugation of alike monomers (i.e., polybutadiene, polystyrene, etc.). However, there is general agreement that etch times over 2 minutes do not result in much more adhesion strength (Villamizer, 1981). It is noteworthy, although not mentioned by Villamizer (1981), that the numbers of pores per unit of surface area and the pore size are the same for both etch systems. Much work remains to be done. The shape of the pores, whether dovetail, fir tree or some other geometry could be beneficial to adhesion. The pattern of which the pores appear on the surface could be significant to adhesion, such as along the edges, or maybe even the pore size to surface area could change. Plasma has been demonstrated to be anisotropic, as well as isotropic. These two characteristics seem, as of yet, to be unexplored.

Diffusion of activated species, from the primary plasma to the substrate, is very dependent on pressure; the higher the pressure, the shorter the mean free path. The mean free path is the distance active species can most likely travel before undergoing collisions that deactivate radicals or neutralize ions. Low pressure and lower frequency increase the energy of ions bombarding a substrate, see Figure 7. Low flow rate has been shown to increase what is called recombinant anisotropy. This recombinant mechanism is essentially the combining of molecules initially removed from the surface with other molecules from the plasma, or with one another. As shown in Figure 8, these molecules not only recombine in the plasma, but also reattach themselves back onto the substrate surface. 


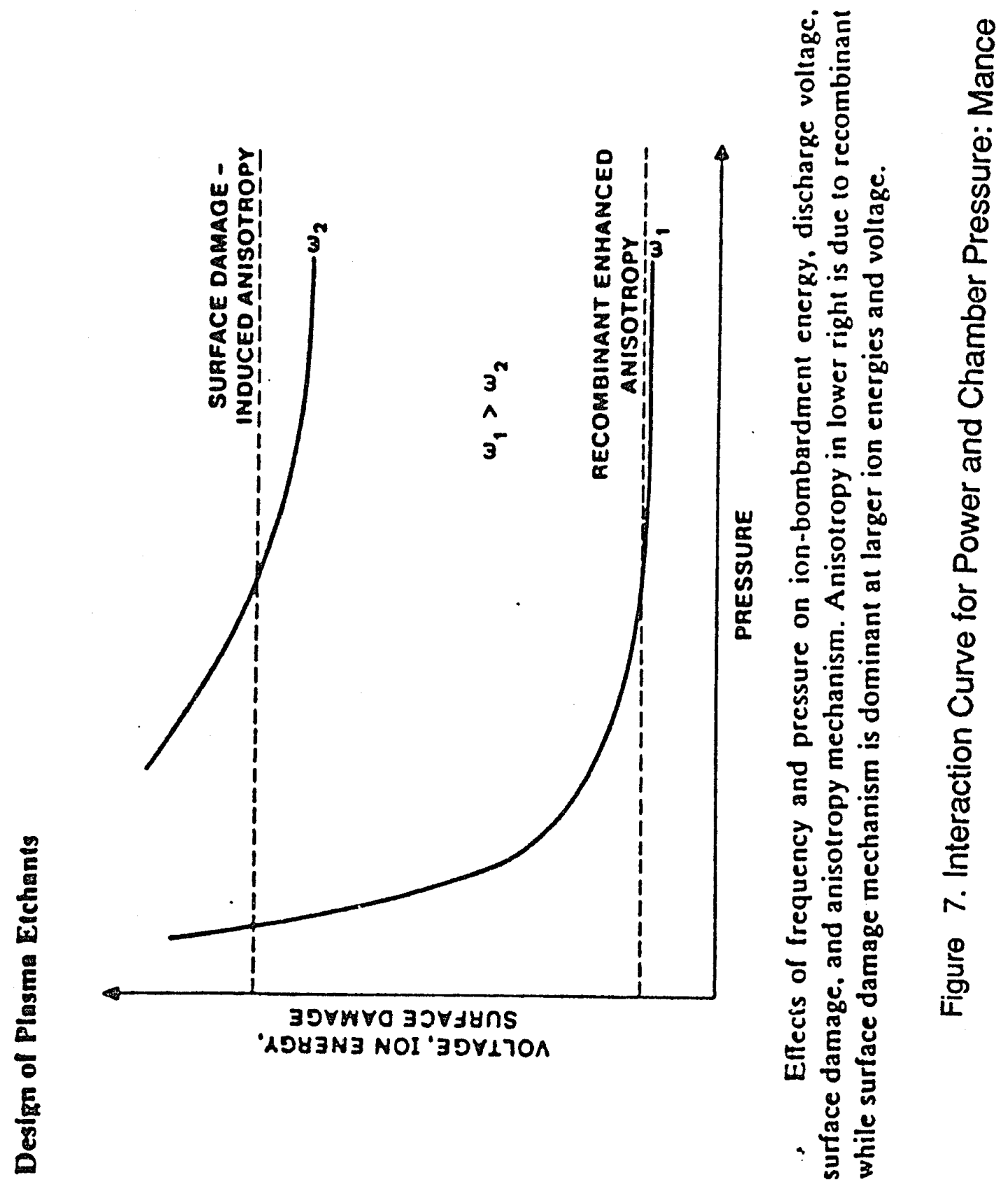




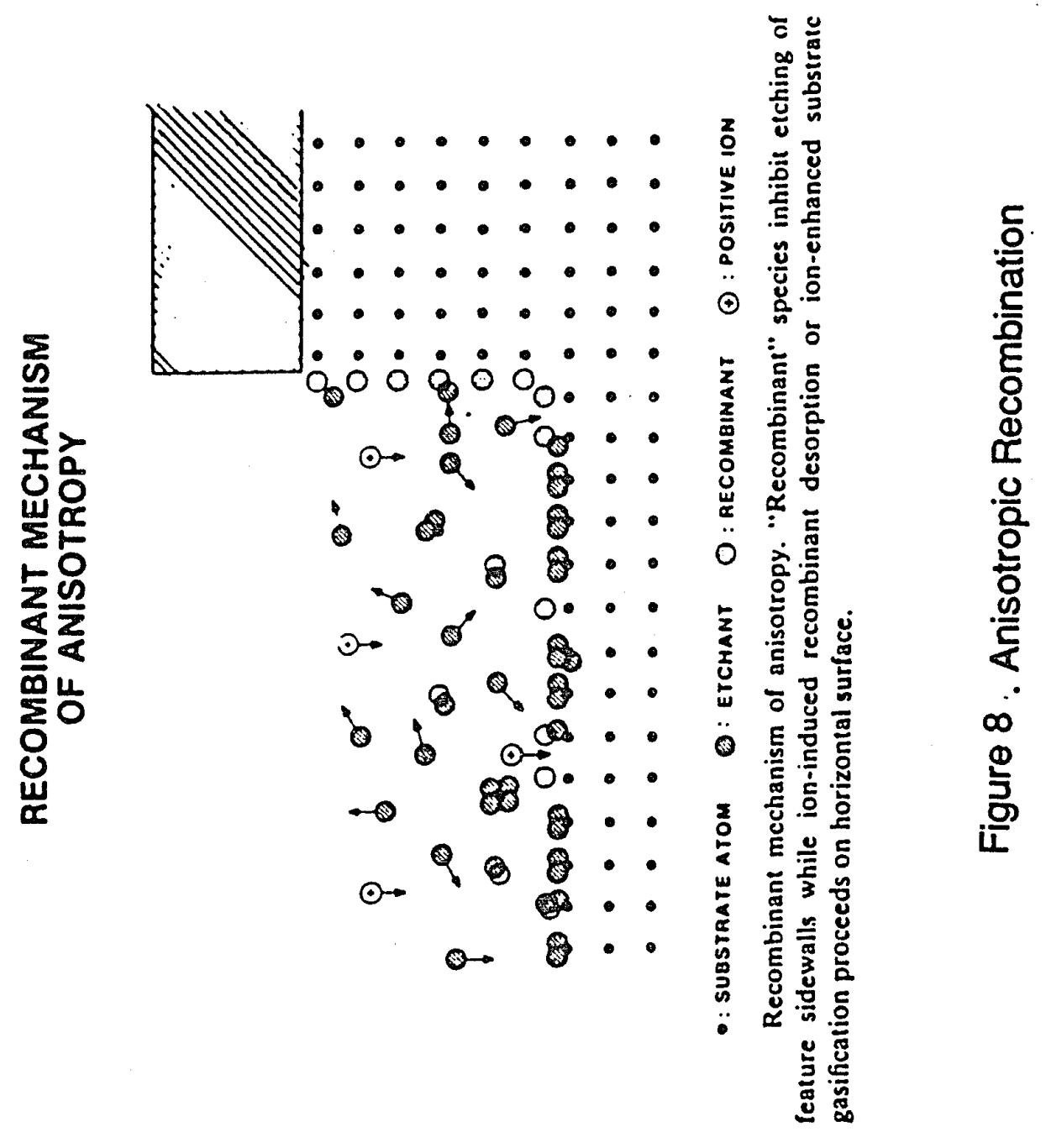


This recombinant mechanism can be used to help change the number and shape of pores generated by plasma etching.

As demonstrated in the past by Villamizar (1981) and others (Brockman, 1989), mechanical interlocking is considered the primary mechanism for adhesion. Although many factors can influence the breakdown of covalent, electrostatic, or encapsulation bonding, it is safe to say that the interlocking mechanism will remain intact. Therefore, mechanical interlocking should be maximized to insure durability of the plated part (Brockmann, 1989).

\subsection{Formation of Chemical Bonds}

Research indicates an improvement from $0.4 \mathrm{lb}$./in. to $5 \mathrm{lb}$./in. on comparable peel tests was obtained when chemical bonding is effective. Elaborate testing methods were developed by Ho (1989), called stretch-deformation testing, to determine the role of chemical bonding in this improvement. This effect has been explained by $\mathrm{Ho}$ (1989) as adhesion can be quantitatively correlated to the chemical reactivity of the interface. Kaplan (1990) hypothesized that enhanced surface reactivity is characterized by water wetability. These and other ideas will be outlined below.

Adhesion improvements attributed to chemical bonds have been demonstrated in both etch systems. In the acid etch system, both the chromic acid and the sulfuric acid species themselves have been attributed to increased 
adhesion. The role of these two species in adhesion will be outlined further. In the chromic acid bath, Krulik (1978) reports that large amounts of $\mathrm{Cr}^{4+}$ and $\mathrm{Cr}^{5+}$ absorb into the etched surface layers (monolayers in thickness). Ghorashi (1977) performed radioisotope experiments relating directly to the chrome species role in plating. Although Ghorashi (1977) did not verify the oxidation state, he did verify that chrome assists adhesion in the first 48 hours after plating. Ghorashi (1977) writes that long extraction times necessary to remove chrome from a chromic acid etched plastic surface with hydrochloric acid indicates strong chemical interactions between chrome and ABS. Krulik (1978) speculated that chrome was bound chemically in the form of complex esters. The rationale here was due to the oxidation state of the chrome. There was also speculation, within Ghorashi's experiment, that chrome was preferential to $C=N$ in the acrylonitrile group. What mechanism or even how long this increase in adhesion lasts has not yet been determined. Villamizer (1981) writes that sulfuric acid plays a role in increasing wetability by the introduction of sulfonic groups into unsaturated sites along the base polymer chain. He goes on to say that the polybutadiene is thus oxidized, and thus more reactive. These sites are believed to be where copper substitutes with sulfonyl and thus starts to agglomerate and grow the plating. This theory is somewhat substantiated by Brockmann (1989). Brockman did studies wherein differing concentrations of sulfuric acid were used after etching to study the effect of sulfuric chemical species on the electroless mechanism.

Introduction of polar groups onto the surface has been shown to increase the adhesion of metal to adhesives (Hall, 1972; Ghorashi, 1977). The best 
known systems involved the use of $\mathrm{NH}_{3}$. These compounds were chosen due to the common use of epoxies for metal and plastic bonding. Ho (1989) investigated and developed methods to measure chemical bonding strength by subtracting out the mechanical tensile strength. He has also found that the transfer of electrical charge and the sharing of electrons is the most important method of increased adhesion. This fact means that the increase in covalent bonding, measured indirectly by wetability, can lead to increased adhesion strength. Plasma etching can be used to increase wetability of plastic surfaces. Hall et al. (1972) reported that chemically induced bonding could be due to polar group addition, unsaturated group exposure, radical formation or electron ejection. Since plasma is rich in UV light that is known to propagate polymerization through radical formation. These radicals could thus lead to increased adhesive strength.

\subsection{Surface Effects}

Other mechanical reasons for successful adhesion have been proposed which can be described in terms of durability or surface boundary layer effects. These mechanisms are proposed to explain the fact that most failures of plating and adhesives are observed to be cohesive in the substrate in practice (Brockmann, 1989). Cohesive failures mean that the area near the bondline between the plastic and metal breaks within the plastic itself. In other words, the plastic is torn apart near the metal-to-plastic interface. Adhesive failures are failures at the bondline, where in the plating parts from the substrate without removing any of the substrate's surface. The Weak Boundary Layer (WBL), is 
one theory proposed to explain adhesive failure, since failure seems to occur at the boundary. According to this theory molecules inhibiting bonding are weakly attached to the surface. Other issues attributed to the WBL can be those of durability. Specifically the metalized film's resistance to moisture intrusion and thermal cycling. Bickermann has shown that the morphology of plating can be changed upon heat annealing completed parts ( $\mathrm{Ho}, 1989)$. Diffusion of low molecular weight compounds to the surface can occur during this heat annealing and thus be removed prior to plating.

Some surface effects which have been proposed to result from plasma etching include crosslinking of the substrate and elimination of low molecular weight fractions, such as unreacted monomer from the surface layer. Although this possibility of a weakened surface has been observed in plasma, the effect can be minimized with the proper selection of etch conditions. 


\subsection{RESEARCH HYPOTHESIS AND OBJECTIVE}

\subsection{Hypothesls}

Electroless copper plating can be accomplished on an ABS substrate after $\mathrm{O}_{2}$ plasma etching. The resultant effect on adhesion, as measured by peel strength, is a function of chamber pressure and flowrate within the plasma equipment.

\subsection{Justification}

Diffusion of activated species, from the primary plasma to the substrate, is very dependent on pressure; the higher the pressure, the shorter the mean free path. The mean free path is the distance active species will most likely travel before undergoing collisions that deactivate radicals or neutralize ions. With low pressure operations, microscopic roughening of the surface has been attributed to more energetic bombardment (Flamm et al., 1980). Low pressure and frequency increase the energy of ions bombarding a substrate. In general, the flow rate of $\mathrm{O}_{2}$ was the control for chamber pressure.

\subsection{Objective}

One objective of this study was to characterize an electroless plating system used in industry. This work was done in order to determine bath times leading to acceptable peel strengths. 
The main objective of this study was to obtain a relationship between peel strength of $\mathrm{O}_{2}$ plasma etched/copper plated ABS to varied plasma etch conditions. A further objective was to determine the magnitude of size, size meaning diameter, and shapes of pores under varying etch conditions. These topography characteristics were obtained by Scanning Electron Microscopy (SEM). The SEM allows inspection at a microscopic scale, in this case approximately $10^{-6}$ meters. Topographical features and the determination of pore size and the number of pores on the surface can be obtained from SEM analysis. 


\subsection{RESEARCH DESIGN AND PROCEDURES}

\subsection{Taguchl Methods}

In the initial design of an experiment, an established design method must be decided upon. In this study, Taguchi experimental design was used. This methodology was deemed appropriate since the starting parameters for the experiment were not defined. By the use of Taguchi design, the extremes of the plasma etch machine could be tested and areas for additional investigation could be determined.

Taguchi methods can be divided into two major elements: (1) Design Optimization, which involves the use of orthogonal arrays, linear graphs and Signal-to-Noise Ratio ( $\mathrm{S} / \mathrm{N}$ ) in the design of experiments (DOE); and (2) Evaluation of Quality, that involves the Loss Function and Signal-to-Noise Ratio. This study used the first element. The basic tools used to obtain relatively large amounts of information from small scale experiments are Orthogonal Arrays and Linear Graphs.

In the preliminary design of a Taguchi experiment, a standard fishbone diagram, called a cause and effect diagram, is the most useful manner in which to generate a listing of the factors to test. Parameters within the engineered system over which engineers have design control are referred to as control factors, or factors for short. The cause and effect diagram generated for the 
investigation is shown in Appendix C. It was determined to test four factors: 1) flowrate of oxygen, 2) time, 3) power setting, and 4) chamber pressure. The frequency of the RF generator on the machine used was fixed and was therefore not a control factor. A measurable output characteristic that adequately describes the process must be decided upon at this time. This output characteristic is called a quality characteristic. The quality characteristic in this study was peel strength.

Since important deviations from ideal performance are caused by factors not under the engineers control, some representation of those factors must be included within the Taguchi analysis. These deviations are called noise. In this study, the noise factor considered was that of the position of the sample in the plasma chamber, there are many other sources of noise but these were not studied. It was said in Section 2.0 that there are two types of plasma within the chamber; primary and secondary. These plasma types are dependent upon position relative to the electrodes within the chamber. Samples, called coupons, were placed in the center of the chamber as well as the edge to include the effect of this noise upon adhesion results.

Orthogonal arrays are chosen and a Taguchi experiment is developed after determination of factors for investigation. The convention for naming arrays is $L_{a}\left(b^{C}\right)$ where:

$$
\begin{aligned}
& a=\text { number of experimental runs } \\
& b=\text { number of levels of each factor } \\
& c=\text { number of columns in the array }
\end{aligned}
$$


Arrays can have factors with many levels, although two and three level factors are most commonly used, as they were in this study. Levels here refer to the conditions at which a factor, for example power, is run. For example, in this study the power setting was run at two levels: (1) 200 Watts and (2) 50 Watts.

Experiments are typically designed with emphasis on main effects. Main effects are those factors which most influence the quality characteristic one is trying to control, in this case peel strength. These main effects aren't used to fine tune a process, but to influence the process dramatically.

There are situations in which it is desired to analyze interactions between factors; Taguchi has provisions for these analyses. Interactions are checked through the use of specific triangular tables. Table II shows an $L_{8}$ array and its corresponding triangular tables. These tables allow factors and interactions to be assigned in a non-arbitrary method. The method for using triangular tables is as follows, using the array in Table II and the triangular table on the lower right as an example. When assigning an interaction between two factors, designated $A$ and $B$, factor $A$ is assigned to column 1 of the array, and factor $B$ to column 2. Their interaction effect is assigned to column 3. Note the triangular table. Column 3 appears on the top side of the line intersecting points 1 and 2. This interaction is called $A \times B$, since these are the control factor's array assignments. The other interactions are assigned accordingly. The triangle at the lower left is an alternate method of assigning interactions to the array. Both triangular tables were used in this experiment. 
Table II: Taguchi L8 Orthogonal Array

$$
L_{8}(27)
$$

\begin{tabular}{|c|ccccccc|}
\hline No. & 1 & 2 & 3 & 4 & 3 & 6 & 7 \\
\hline 1 & 1 & 1 & 1 & 1 & 1 & 1 & 1 \\
2 & 1 & 1 & 1 & 2 & 2 & 2 & 2 \\
3 & 1 & 2 & 2 & 1 & 1 & 2 & 2 \\
4 & 1 & 2 & 2 & 2 & 2 & 1 & 1 \\
5 & 2 & 1 & 2 & 1 & 2 & 1 & 2 \\
6 & 2 & 1 & 2 & 2 & 1 & 2 & 1 \\
7 & 2 & 2 & 1 & 1 & 2 & 2 & 1 \\
8 & 2 & 2 & 1 & 2 & 1 & 1 & 2 \\
& 4 & 1 & 1 & & & & 1 \\
& & & & & & & \\
\hline Group & 1 & 2 & & & 3 & &
\end{tabular}
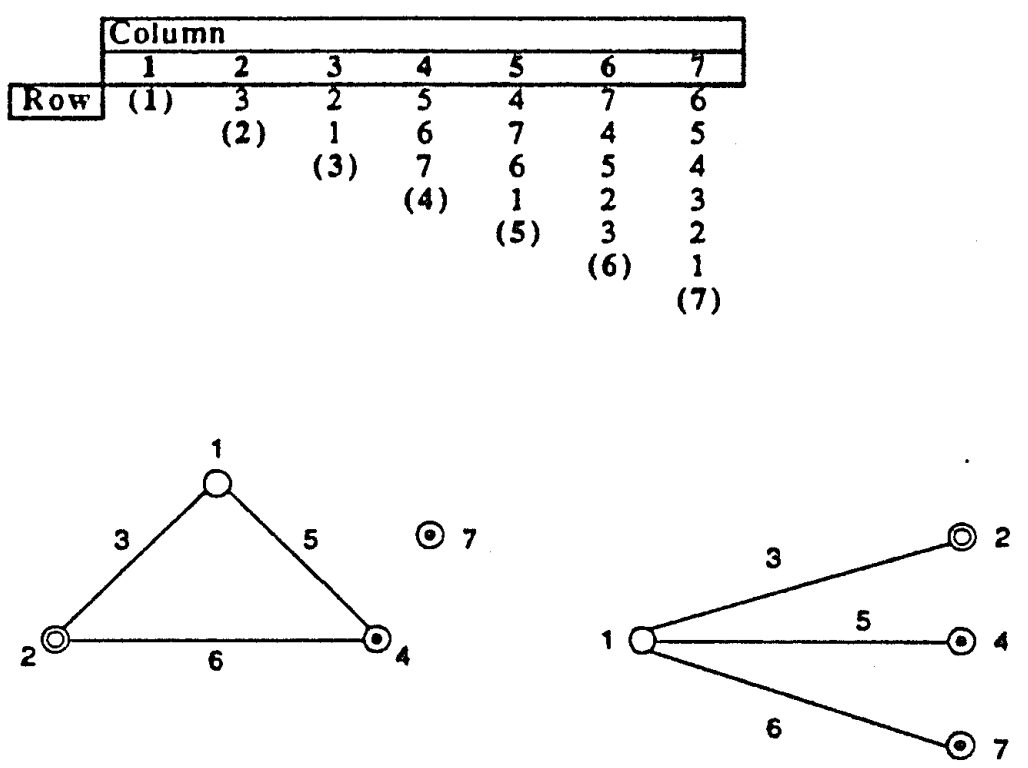

- 1889. American Supptier tratiaute, Inc. 
One of the main aspects used with these orthogonal arrays is the Linear Graph. These graphs are pictorial equivalents of the above described triangular tables that represent the assignment of interactions between all elements in the orthogonal array. A Linear Graph is used as follows:

- Factors are assigned to points of the graph.

- An interaction between two factors is assigned to the line segments connecting the two (or three) points.

- The strongest effects are those lines with the steepest slopes.

- On interaction graphs, intersecting lines represent strong interactions, conversely, truly independent reactions are represented by parallel lines. One important aspect of Linear Graphs is the need to find main effects. Main effects are important since engineers are looking for control factors. A good control factor will have a predictable and strong influence on the measured quality characteristic.

A statistical measure of performance called the $S / N$ ratio is used in evaluating the quality of the product. In this $\mathrm{S} / \mathrm{N}$ method, quality of the product means the characteristics one can measure which affect the performance of the product. For example, in this study the quality characteristic was peel strength. The $S / N$ ratio measures the effect of noise factors on performance. As mentioned, the noise factor in the plasma experiments was the position of the coupon in the etching chamber.

The $\mathrm{S} / \mathrm{N}$ ratio is an evaluation of the stability of performance of an output characteristic. Higher performance as measured by a high $\mathrm{S} / \mathrm{N}$ ratio implies a 
smaller loss. Loss means obtaining unacceptable results. In this case, loss means peel values under $3.0 \mathrm{Kg} / \mathrm{cm}$. There are three standard types of $S / \mathrm{N}$ ratio. Two methods were used: (1) Larger-the-Better, and (2) Nominal the-Best. Larger-the-Better means the highest quality characteristic value, in this case in peel strength, the better. Nominal-the-Best means that the least amount of variation in the quality characteristic, in this case in peel strength, is the best result.

The $S / N$ ratio is an objective measure of quality that takes both the mean and variation into account. The following is true about $S / N$ as a measure of performance:

- $S / N$ increases as the mean peel strength decreases.

- $S / N$ increases as the peel strength variability decreases.

- For each $\mathrm{S} / \mathrm{N}$ increase of $3 \mathrm{~dB}$, the loss, i.e., obtaining peel strengths below 3.0, decreases by half.

A confirmatory experiment is made after the experiment in the orthogonal array is completed and the corresponding Linear Graphs have been analyzed. First, an optimal quality characteristic value (peel value in this study) is predicted. Then, a confirmatory experiment is performed with the factors set at the levels predicted to give the optimum quality characteristic value. The setting of each level in this confirmatory experiment is obtained from the analysis of the Linear Graphs. The actual value of the quality characteristic obtained from the confirmatory experiment is then compared to the predicted value. Confirmation results near the predicted results indicates that the experiment has good 
reproducibility. Better than predicted results mean that there might be interactions working to produce better results than anticipated. Worst than predicted results means either poor reproducibility or that the results of the experiment cannot be accepted. If the confirmation run does not confirm the experiment one of the following conditions exist: (1) poor additivity due to strong impinging interactions, (2) not enough control factors were selected to assure reproducibility, (3) a significant control factor might have been missed, or (4) factor levels may have been set too narrow to detect effects of changes in factor levels.

\subsection{Experimental Procedures and Apparatus}

The research objective was obtained by the following experiment:

A) An existing acid etch system and subsequent electroless/electrolytic plating line at SJSU was characterized. This line was set-up as laboratory scale but otherwise typical to plating lines used in industry. A Taguchi parameter design

experiment $\left[\mathrm{L}_{9}\left(3^{4}\right)\right]$, was used to obtain results to characterize the system. Table III presents the Lg orthogonal array used to study chromic acid etching and the rest of the plating system. The factors under investigation were: (1) acid etch time, (2) catalyst time, (3) accelerator time, and (4) electroless time. The results of the 4 tests, mean peel strength, and the variance are also presented. Note that this is a 4 factor, 3 level test. The purposes of these tests were two fold: (1) to study the effect of chromic acid etch time on adhesion, and (2) to 


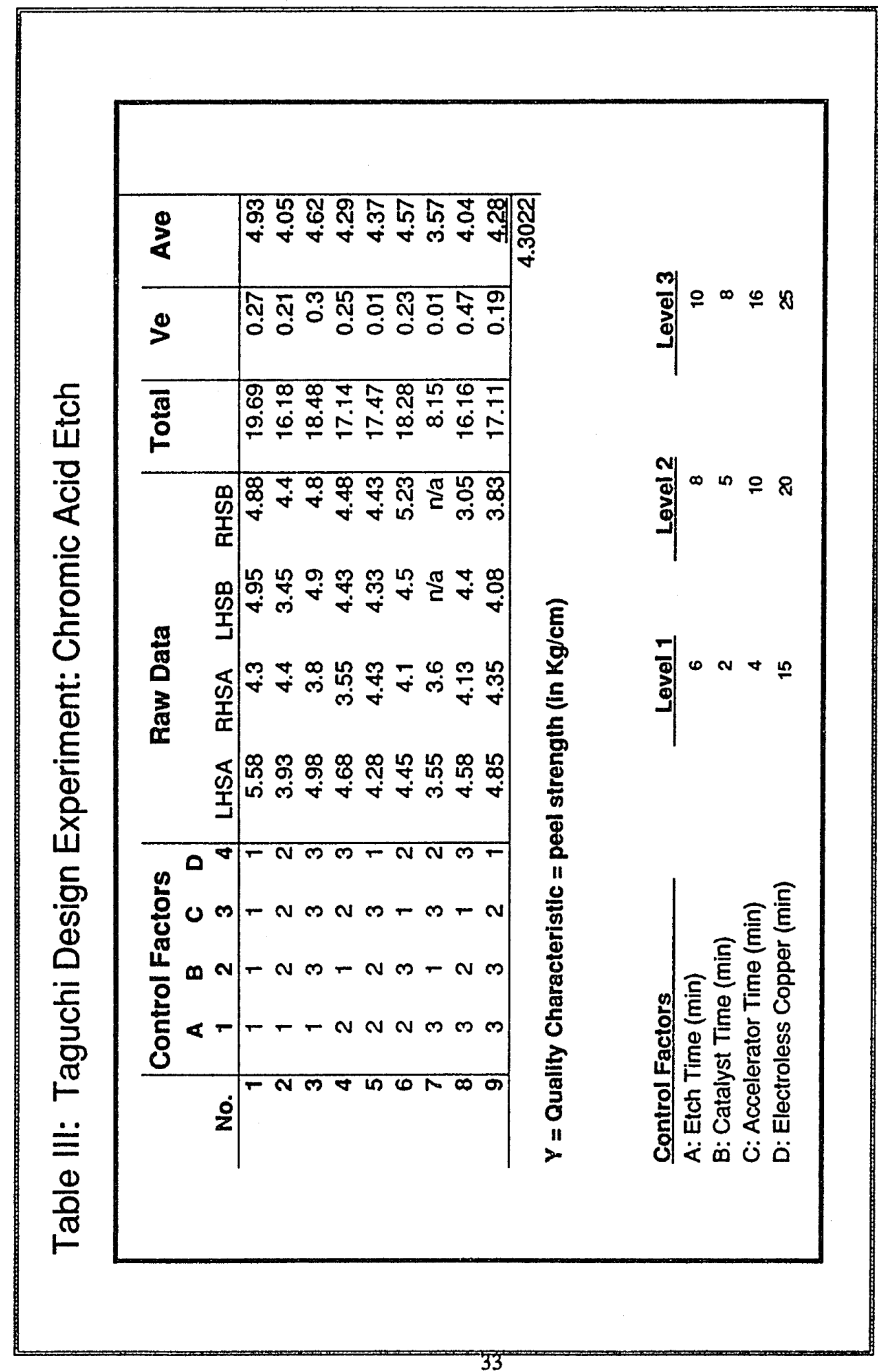


standardize the plating line. The purpose of this standardization was to determine operational lengths of bath times which would result in good adhesion for chromic acid etched samples. Once these bath times were set a chromic acid etched sample would be run though the plating line with each set of plasma etched samples as a check on the stability of the plating baths. Samples, called coupons, were obtained from GE plastics. The coupons were made of ABS resin and had dimensions of $76.5 \mathrm{~mm} \times 101.6 \mathrm{~mm} \times 3.17 \mathrm{~mm}$. Coupons were washed in a high phosphate soap, brand name Alconex, containing no animal fat. These coupons were then etched and plated within eight hours using the conditions described by the Taguchi orthogonal array, shown in Table III.

Repeatability studies for the peel test equipment were performed. Tests were conducted on standard coupons prepared and etched by chromic acid, as described above, to determine the variance of the peel test equipment used. Ten samples were prepared using the same wash method described above and then acid etched and neutralized for eight minutes in each bath. These coupons were then plated per the standard plating conditions determined from the characterization study described earlier. These coupons were then peel tested as described below.

B) $90^{\circ}$ peel tests were performed on the above mentioned plated parts using a Sebastian 5 Multipurpose Tester per ASTM B-532. See Appendix A for description of the Multitester and the ASTM test. The ASTM procedure was followed with the exception of temperature conditioning prior to peel testing. This conditioning was recommended but was not a required step. All coupons 
were allowed to remain at ambient conditions for a minimum of 48 hours prior to pe日l testing as prescribed by Ghorashi (1976).

C) The acid etch topography was characterized by SEM using a Hitachi $S 520$ SEM per standard procedures. Samples for SEM evaluation were prepared using the same washing procedure and were etched and neutralized at the same time as those prepared for subsequent plating.

D) Plasma etching was obtained with $\mathrm{O}_{2}$ plasma using a March CS-1701 plasma etcher. See Appendix A for the plasma instrument description. This system allowed for varying each of the following control parameters: (1) gas flow, (2) time, (3) chamber pressure, and (4) RF power setting. The power setting can be varied between 1 and 600 watts by a RF generator. A control point for the plasma treatment was developed by the use of a Taguchi parameter design array $\left[L_{8}\left(2^{7}\right)\right]$. See Table II for a description of this array. The purpose of the Taguchi experiment was to determine the roles of the four parameters and their effect on adhesion as measured by peel strength. Included in this analysis were evaluations of interactions of flowrate with each of the other three parameters. The triangular table on the lower right of Table II shows the design used for this analysis. Standard test coupons were washed with Alconex high phosphate soap and then were etched within eight hours. These plasma etched samples were then plated within 48 hours using the standard plating conditions determined from Taguchi analysis described in A) above for chromic acid etching. It is important to note that there was no attempt to optimize the plating steps 2-7 shown in Figure 2 for plasma etched coupons. Rather, the standard 
conditions for plating from the acid etch experiment as described above was considered sufficient since relative peel strengths of plasma etched coupons etched under varying etch condition were to be compared. This study did not attempt a comparison of chromic acid etch to plasma etched coupons since good adhesion was expected for both methods. An acid etched coupon was plated with each set of plasma etched coupons to act as a control to ensure that the plating baths were operational. If the actual peel strength of the chromic acid etched sample matched the expected value within experimental error limitations then the baths were assumed to be operational.

E) The effect of the plasma parameter conditions on topography was photographed by SEM. Here again, as in C), the coupons used for SEM evaluation were processed with the coupons etched for subsequent plating.

F) Coupons were $\mathrm{O}_{2}$ plasma etched at 50 Watts for 10 minutes at flowrates of 20 and $80 \mathrm{ml} / \mathrm{min}$. Coupons were etched at chamber pressures varied at approximately 50 millitorr increments. For example, one coupon at a time, two coupons total, were etched at 380 millitorr and $80 \mathrm{ml} / \mathrm{min}$. and then another two coupons etched at $430 \mathrm{millitorr}$ and $80 \mathrm{ml} / \mathrm{min}$. flowrate of oxygen, and so on. In addition, coupons with flowrates of $20,40,60,80,100$ at 380 millitorr and 50 Watts were etched for 10 minutes. All coupons were later plated and tested as described in $\mathrm{B}$ ).

G) Scanning Electron Microscope (SEM) micrographs were taken for coupons etched for 10 minutes, at 50 Watts with an $\mathrm{O}_{2}$ flowrate of $20 \mathrm{ml} / \mathrm{min}$. and 
chamber pressures of 170,270 , and 480 millitorr. SEM micrographs were also taken of coupons etched for 10 minutes, at 50 Watts and chamber pressure at 380 millitorr pressure for flowrates of $20,40,60,80$ and $100 \mathrm{ml} / \mathrm{min}$. flowrates. These micrographs were used to evaluate the effect of these parameters on topography.

H) A curve of peel strengths versus flowrate, at constant chamber pressure was developed. A curve of peel strengths versus chamber pressure was developed for the two flowrates described above, namely 20 and $80 \mathrm{ml} / \mathrm{min}$.

I) Film thickness measurements were made using a digital readout, outside diameter micrometer. These thickness measurements were used to determine the film thickness variance. These measurements were necessary since the tensile strength of the film itself can influence peel strength as reported by Heymann (1970). Attribute conditions such as cohesive versus adhesive failure and plating appearance were observed and recorded. 


\subsection{RESULTS}

\subsection{Introduction}

The following section will present results of the experiments outlined in section 4.0. This study can be divided into three distinct elements: (1) characterization of steps $(1 a-c),(4),(5)$ and $(6)$ of the electroless plating system shown in Figure 2; (2) effect of the four plasma etching parameters, oxygen flowrate, time RF power and chamber pressure on adhesion; and (3) one variable testing of the effect of each flowrate and chamber pressure on adhesion. Each of the three elements' output was measured by peel strength and SEM photographs.

\subsection{Acid Etch Experiment}

The mean peel strength resulting from the variation of times in the plating baths are shown in Table III. Figures 9 through 12 are the linear graphs associated with the response graphs from the Taguchi array. Each data point represents the average of twelve peel tests run at the conditions indicated in the Orthogonal Array. The following conclusion can be stated based on the data shown in the linear graphs. Time in the accelerator and the acid baths are the main effects. The times, called levels, selected for these baths were based on 


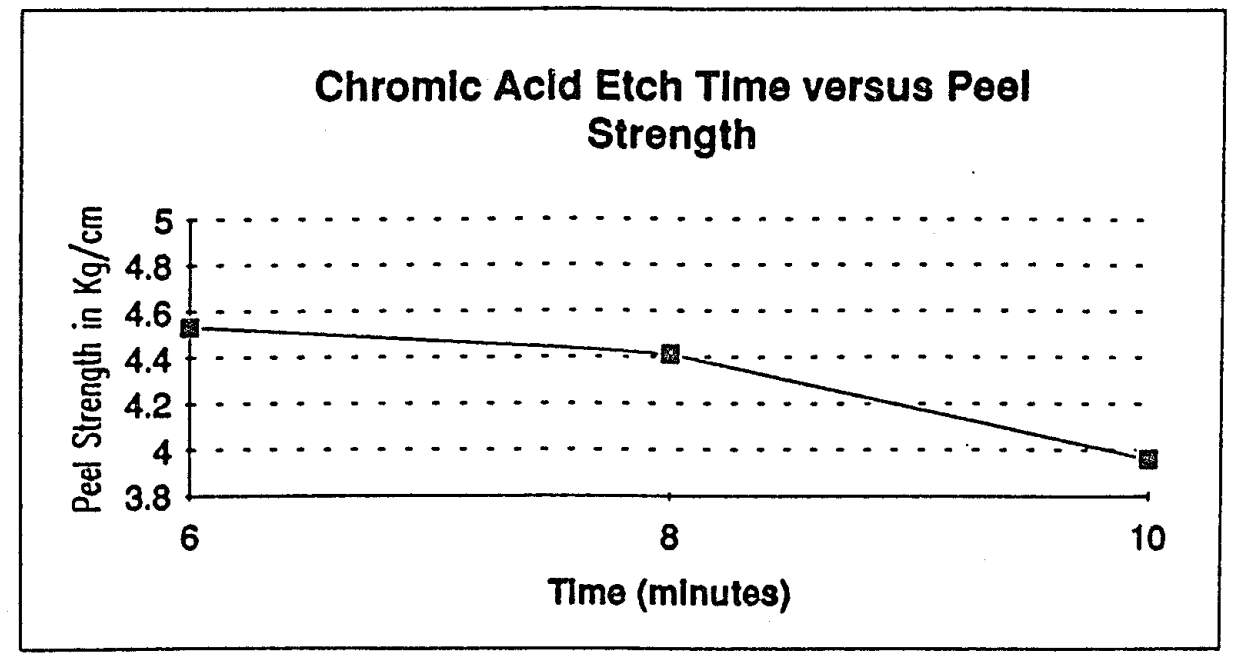

Figure 9. Linear Graph Chromic Acid: Acid Etch Time

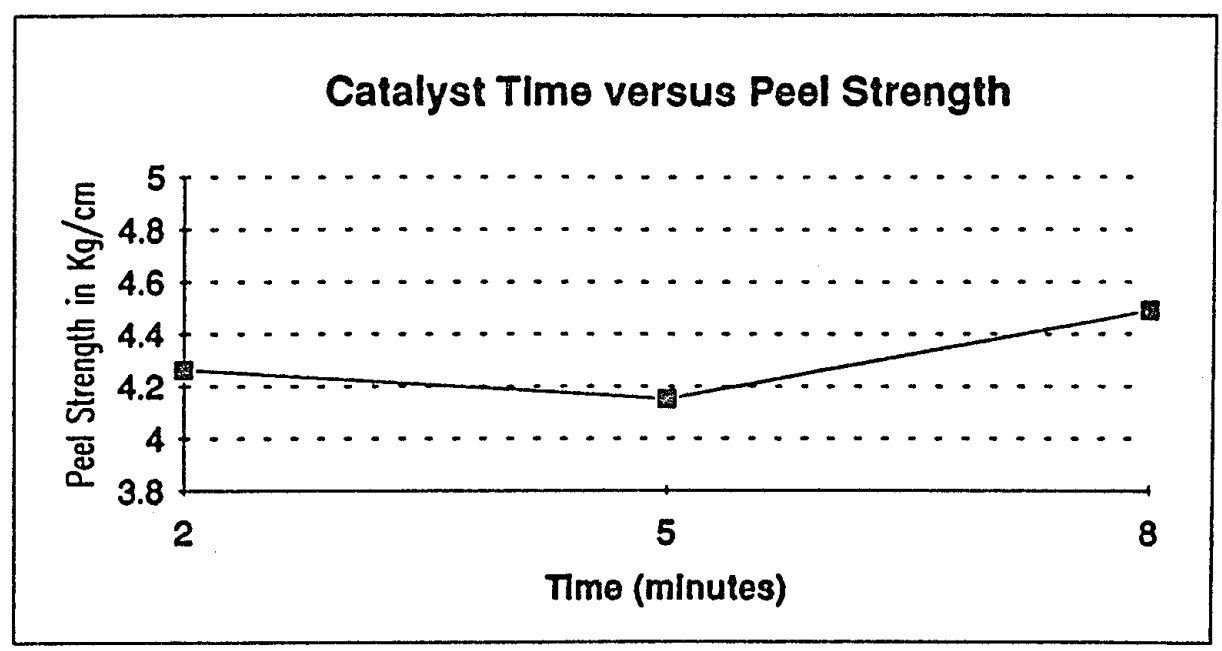

Figure 10. Linear Graph Chromic Acid: Catalyst Time 


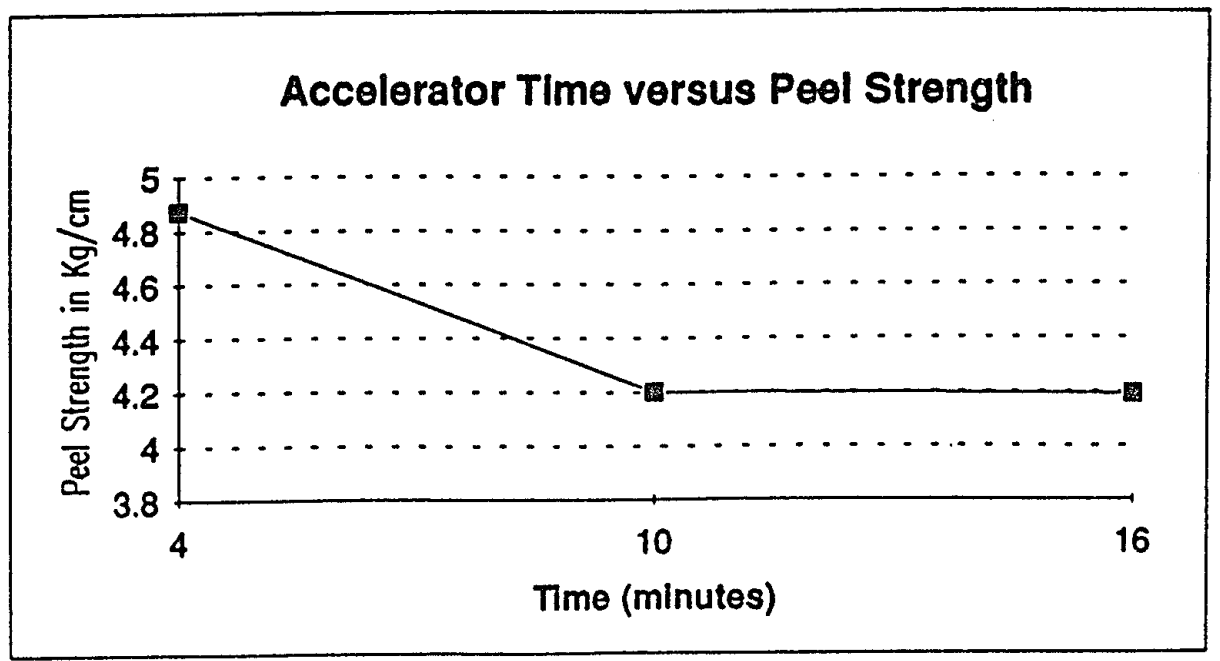

Figure 11. Linear Graph Chromic Acid: Accelerator Time

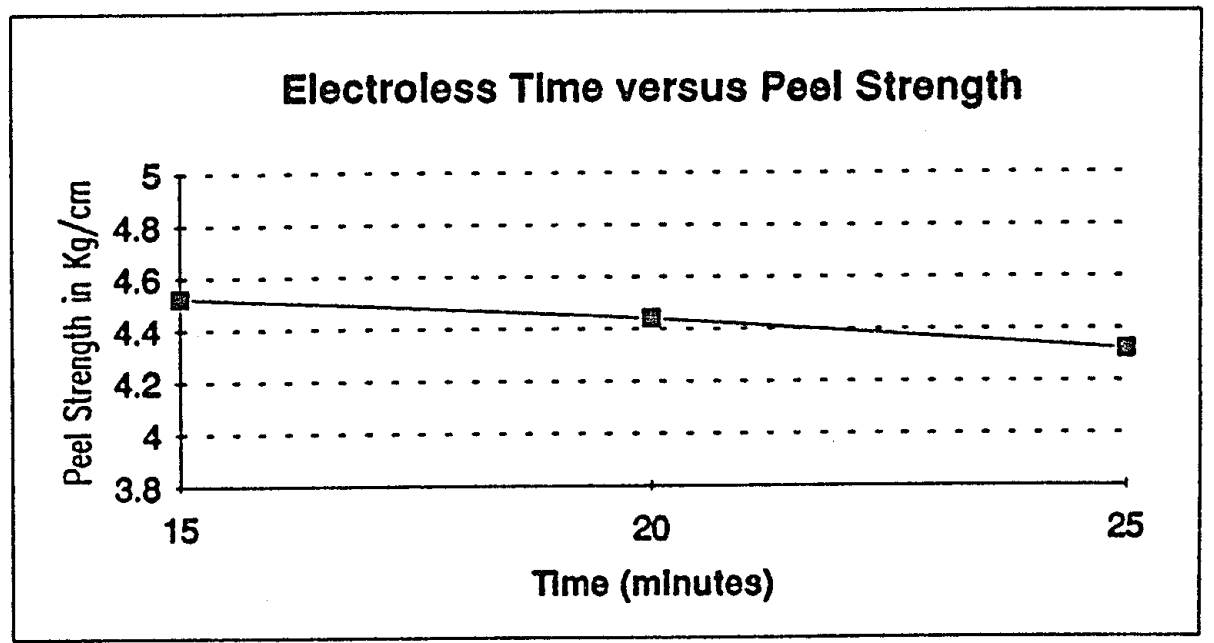

Figure 12. Linear Graph Chromic Acid: Electroless Time 
standard plating times used in industry. See Appendix B for the calculations associated with these graphs.

\subsection{Acid Etch "Standard" Topography}

Photographs 2 through 4 present the topography results of chromic acid etched coupons at 6,8 , and 10 minute etch times. Photograph 1 is a coupon with no etching, called a blank. Table IV catalogues the pore size and number of pores per unit area ( 100 square micrometers). Photographs 5 through 8 show topography generated under chromic acid etch times of $2,5,10$, and 20 minutes. These photos show substantial surface pitting as etch time is extended. 


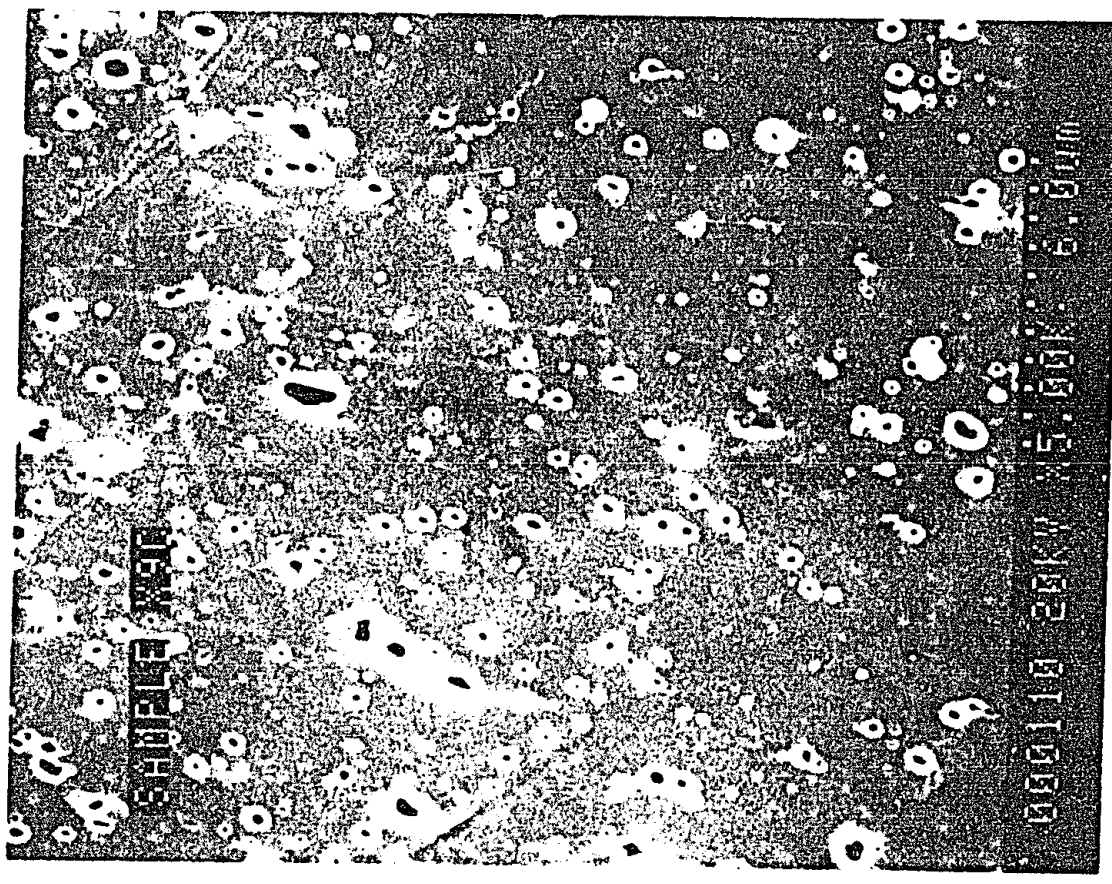

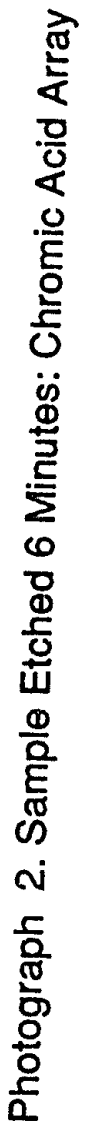

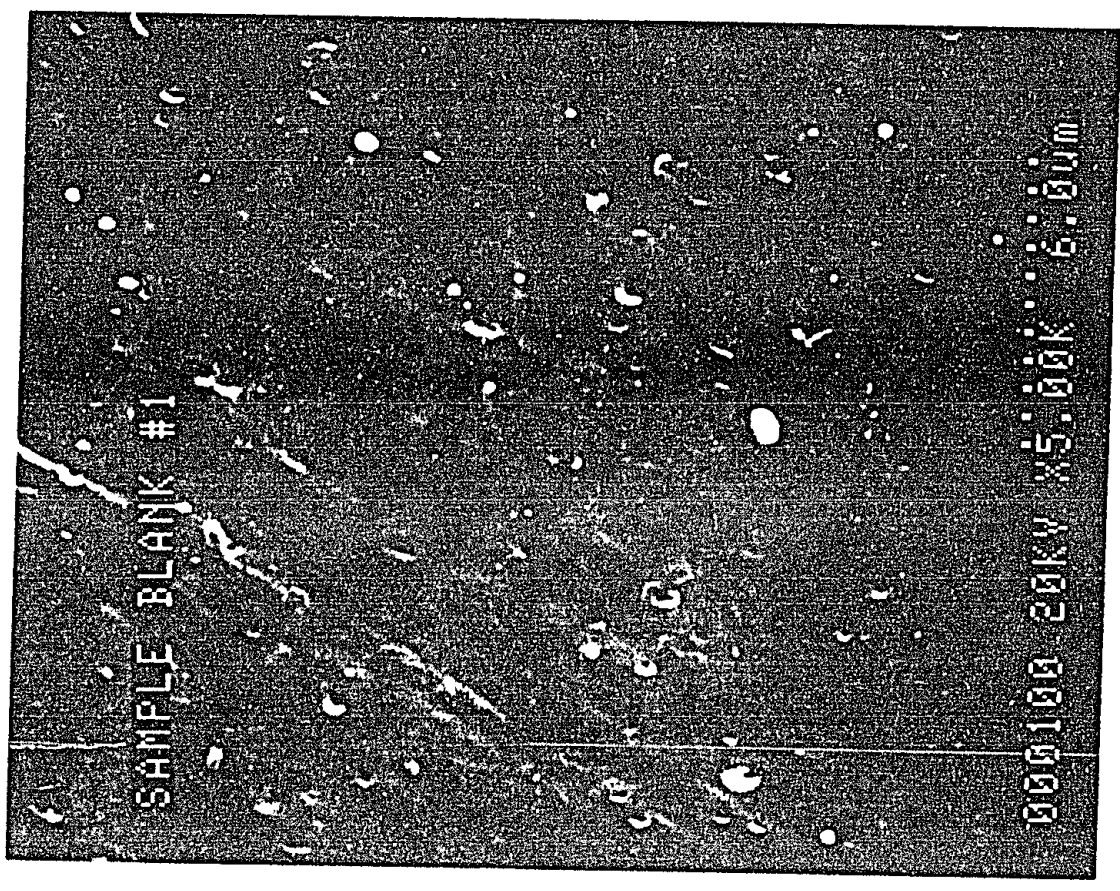

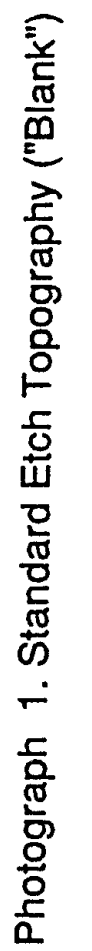



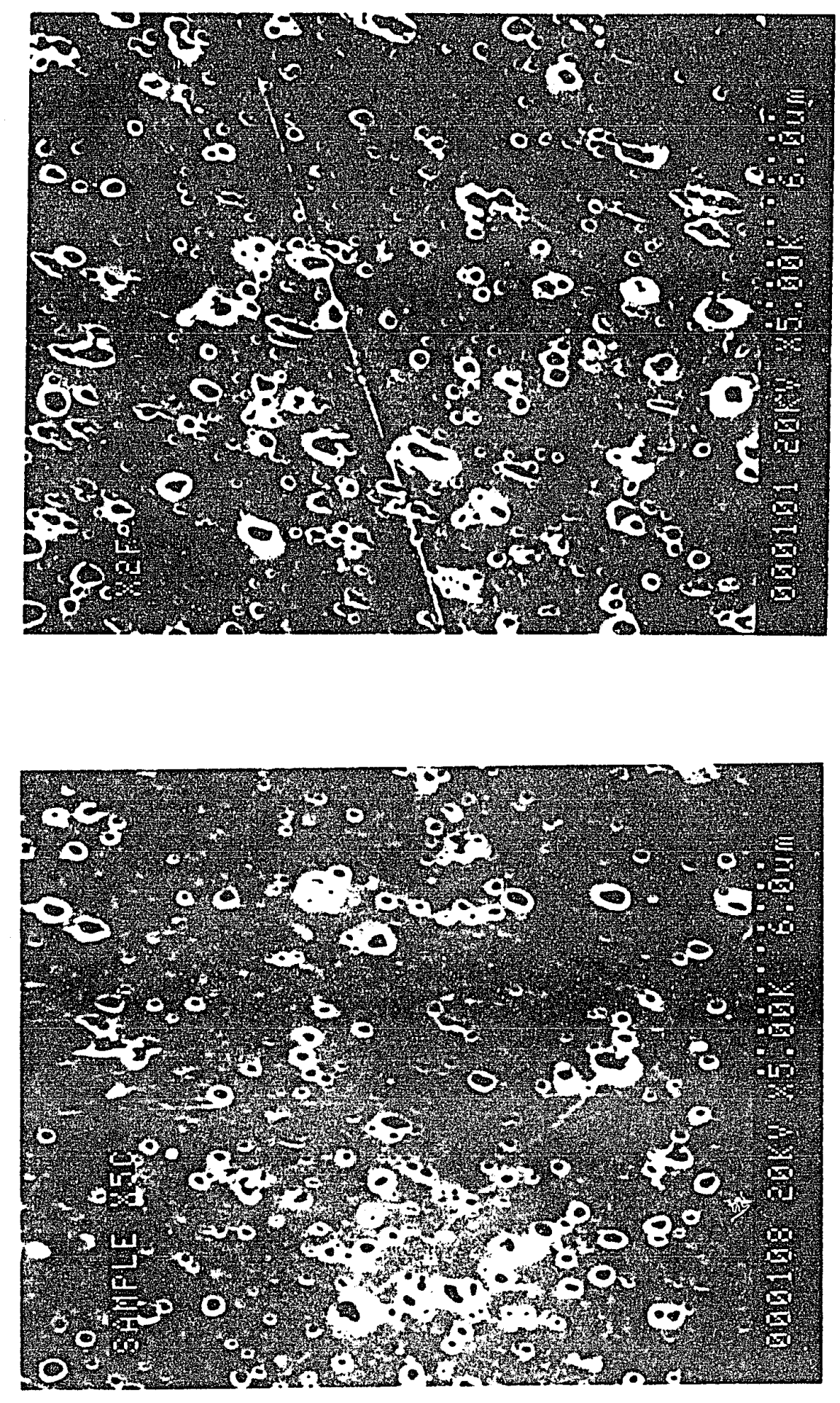

준

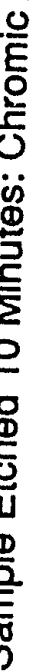

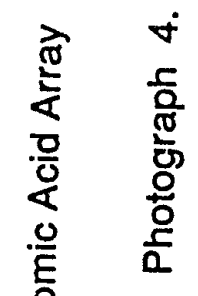


Table IV: Effect of Etching Period on Topography; Gurley

\begin{tabular}{|c|c|c|c|c|}
\hline \multirow[b]{2}{*}{ Sample No. } & \multirow[b]{2}{*}{ Etchlng Portod } & \multicolumn{2}{|c|}{$\begin{array}{c}\text { Porosity } \\
\text { Aroa } 10 \times 10 \text { umeters }\end{array}$} & \multirow[b]{2}{*}{$\begin{array}{c}\text { Pool Strongth } \\
(\mathrm{Kg} / \mathrm{cm})\end{array}$} \\
\hline & & $\begin{array}{c}\text { Number of } \\
\text { Pores }\end{array}$ & $\begin{array}{r}\begin{array}{r}\text { Pore Redlus } \\
\text { (umoters) }\end{array} \\
\end{array}$ & \\
\hline \multicolumn{5}{|c|}{ Chromle Acld } \\
\hline \multicolumn{5}{|l|}{ Taguchl } \\
\hline Xoc & 6 minutes & 55 & 0.25 & 4.53 \\
\hline C5C & 8 minutes & 110 & 0.2 & 4.41 \\
\hline$\times 2 C$ & 10 minutes & 80 & 0.14 & 3.06 \\
\hline \multicolumn{5}{|c|}{ SEM Samples } \\
\hline $\mathrm{C} 2-2$ & 2 minutes & 33 & 0.4 & NA \\
\hline C5-1 & 5 minutes & 36 & 0.7 & NA \\
\hline C10.1 & 10 minutes & 17 & 2.7 & N/A \\
\hline $\mathrm{C}_{2} \mathrm{O}-1$ & 20 minutes & 33 & 1.2 & NA \\
\hline \multicolumn{5}{|l|}{ Plasma Etch } \\
\hline \multicolumn{5}{|l|}{ Tagueh! } \\
\hline Sample 1 & 10 minutes & 18 & 0.6 & 3.52 \\
\hline Sample 2 & 10 minutes & 14 & 0.3 & 3.92 \\
\hline Sample 3 & 10 minutos & 18 & 0.1 & 3.93 \\
\hline Samplo 4 & 10 minutes & 20 & 1.2 & 4.35 \\
\hline Sample 5 & 5 minutes & 5 & 0.06 & 4.42 \\
\hline Samplo 6 & 5 minutes & 18 & 0.9 & 4.24 \\
\hline Samplo 7 & 5 minutes & 16 & 0.3 & 4.71 \\
\hline Samplo 8 & 5 minutes & 3 & 0.06 & 3.24 \\
\hline \multicolumn{5}{|c|}{ Varlod Flowrato } \\
\hline Sample 34 & 10 minutes & 20 & 0.7 & 4.08 \\
\hline Sample 7 & 10 minutes & 16 & 0.3 & 4.37 \\
\hline Sample 33 & 10 minutes & 29 & 0.5 & 4.74 \\
\hline Sample 32 & 10 minutes & 20 & 0.3 & 4.97 \\
\hline Sample 31 & 10 minutes & 30 & 0.6 & 5.14 \\
\hline
\end{tabular}




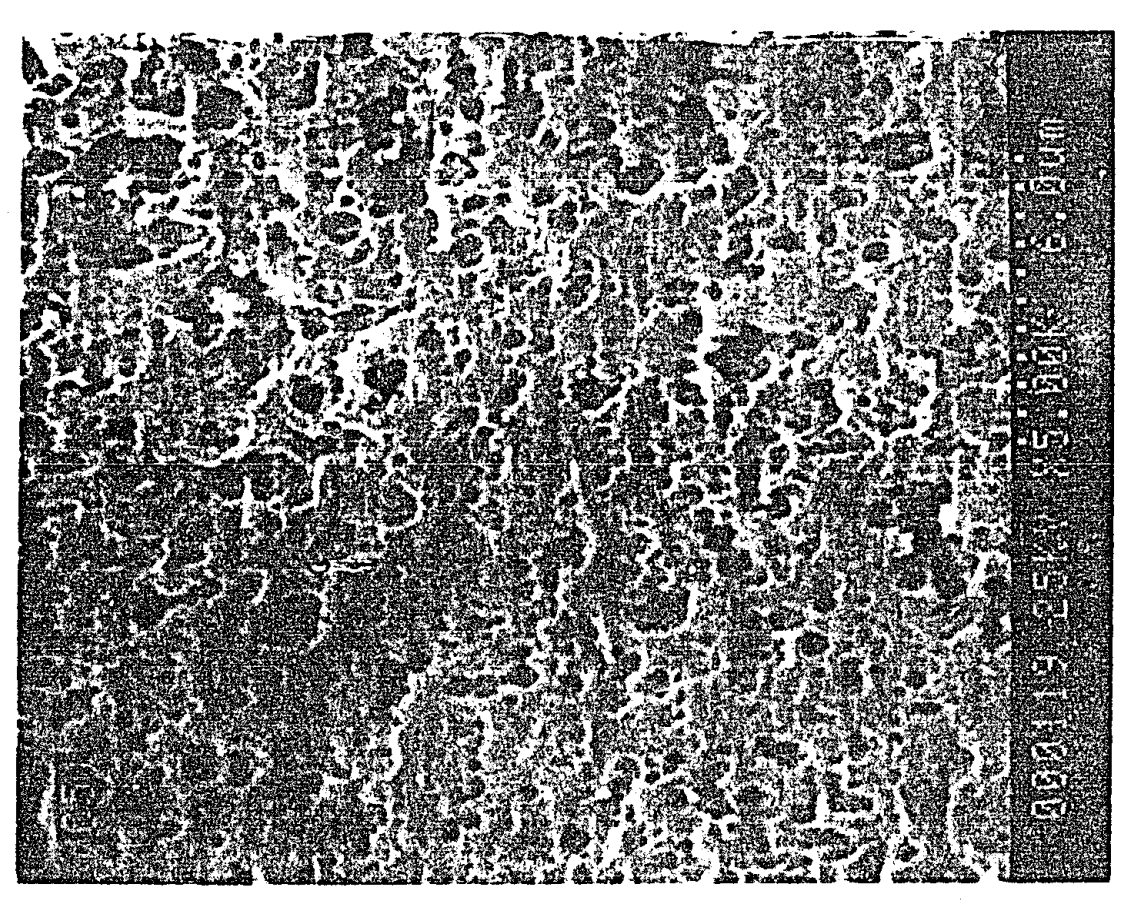

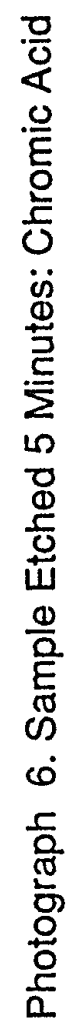

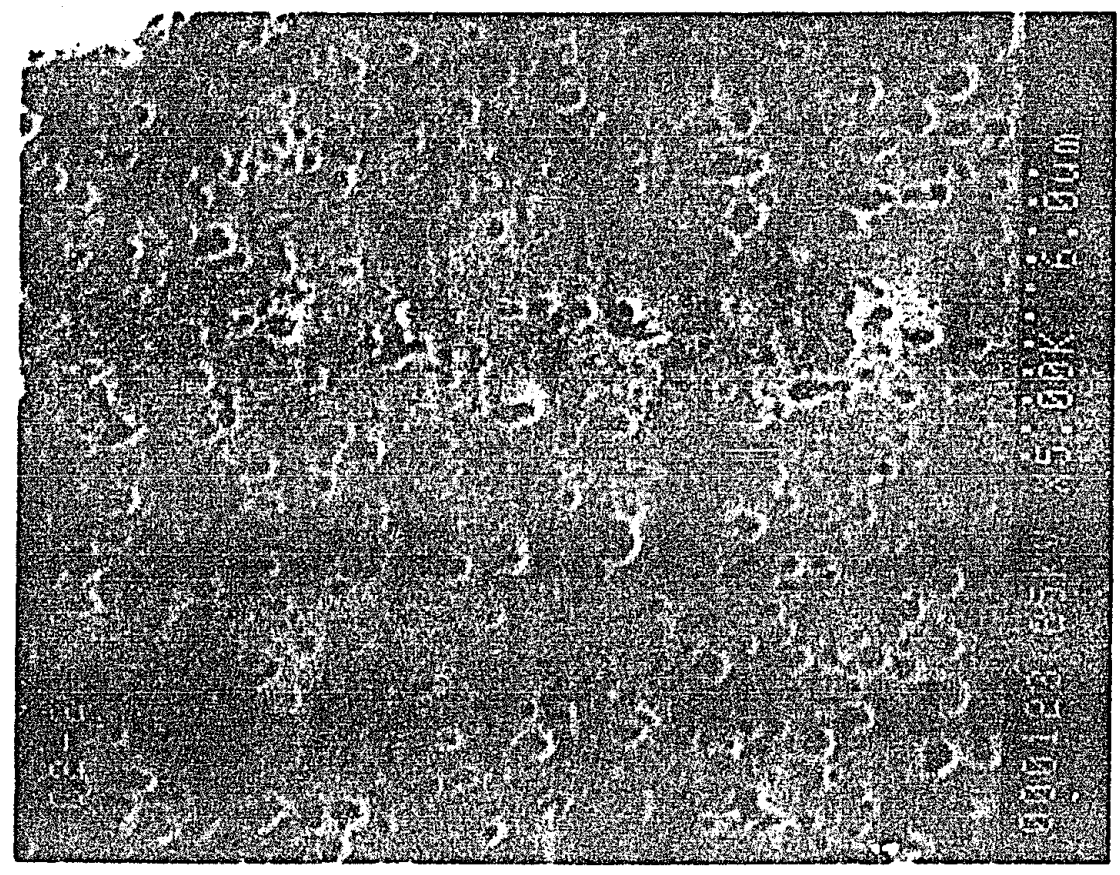

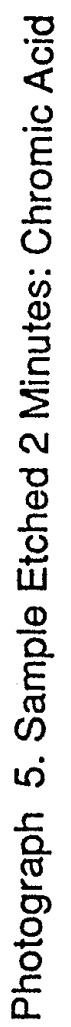




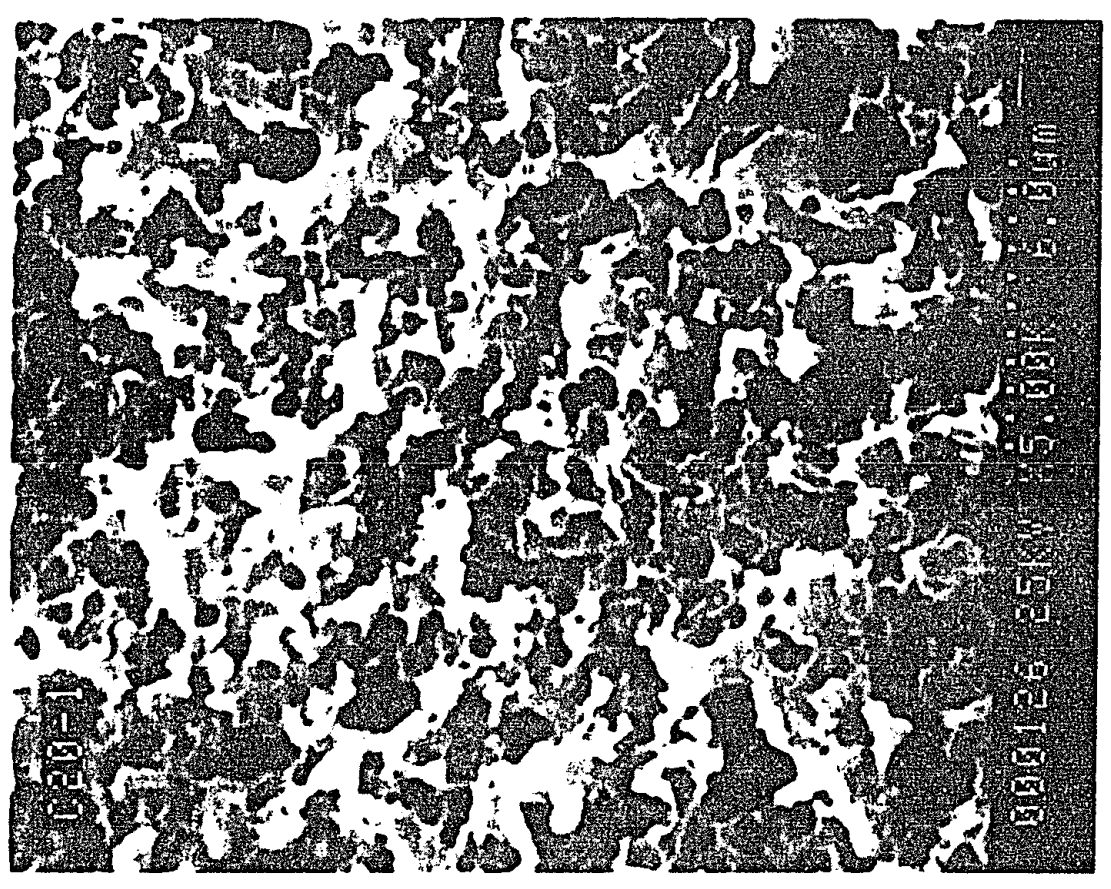

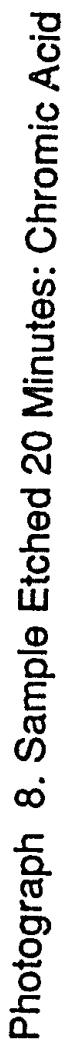

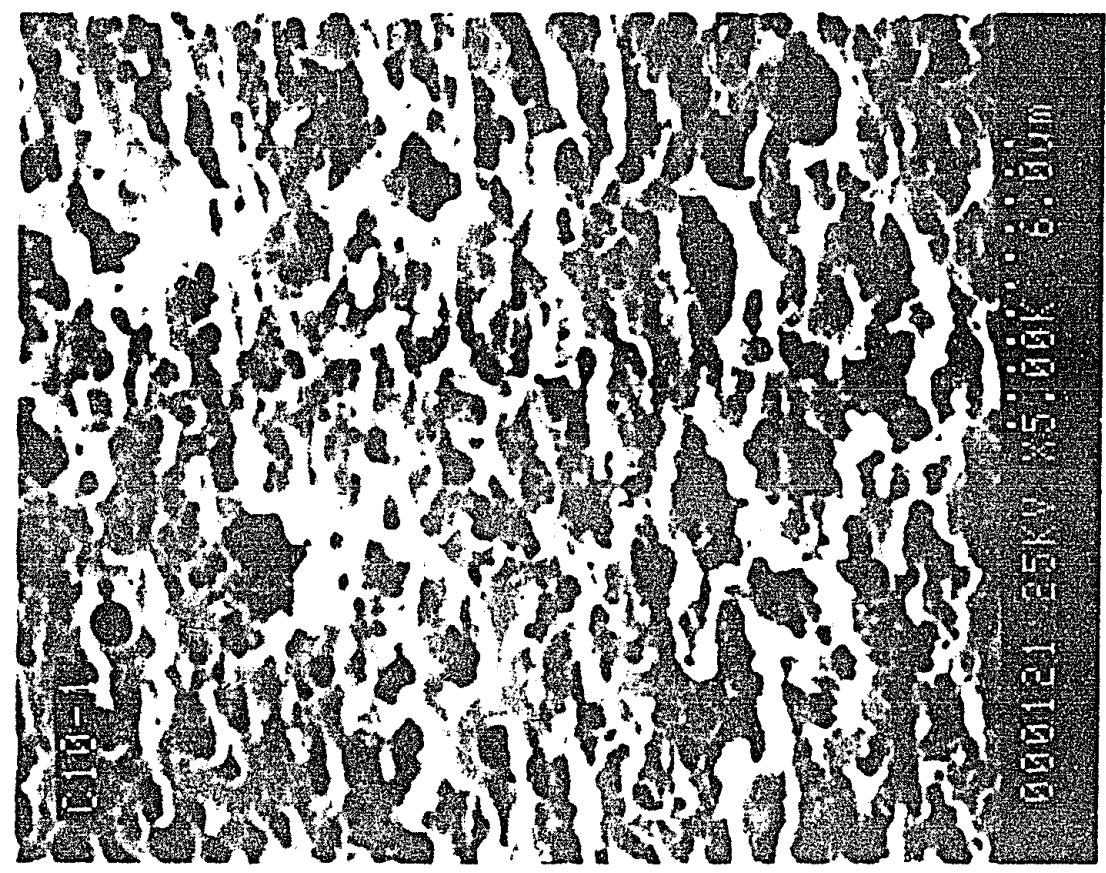

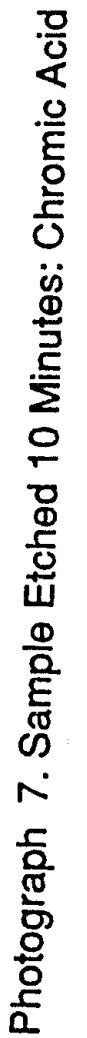




\subsection{Plasma Etch Experiment}

Table $V$ presents the $L_{8}$ orthogonal array used to study the effects of varied plasma etch conditions on adhesion. The results of the 4 factors, flowrate, time, power, and chamber pressure, are indicated. The mean peel strength results, sensitivity, variance, and $\mathrm{S} / \mathrm{N}$ ratio(s) for Nominal-the-Best and Larger-the-Better analysis are presented. Response graphs, Figures 13 through 16, show the relative magnitude of the effect of each factor, flowrate, time, power, and chamber pressure on peel strength. Here each data point represents the average of sixteen peel tests. These linear graphs are pictorial representations of each factor's effect on adhesion. For explanation of these and other calculations refer to Appendix C. Examination of the Linear Graphs show that flowrate and chamber pressure are the factors most affecting peel strength. Figures 17 through 20 show the results of the response graphs associated with three analysis methods used involving mean peel strength and the signal-tonoise ratio. The three analysis methods being mean peel strength results shown on the top graph, Larger-the-Better analysis shown in the middle graph, and Nominal-the-Best shown on the bottom graph. Note that each method of analysis has different $Y$ value scales; this is due to nature of the Taguchi analysis. However, the same scale was kept for the response graphs in a single analysis method. One must compare graphs from the same analysis type in order to reach meaningful conclusions. It was interesting that power had a varying effect on adhesion as determined by the two signal-to-noise analysis techniques. Power showed little effect on the Larger-the-Better $S / N$ ratio, but showed a significant effect using the Nominal-the-Best analysis. 


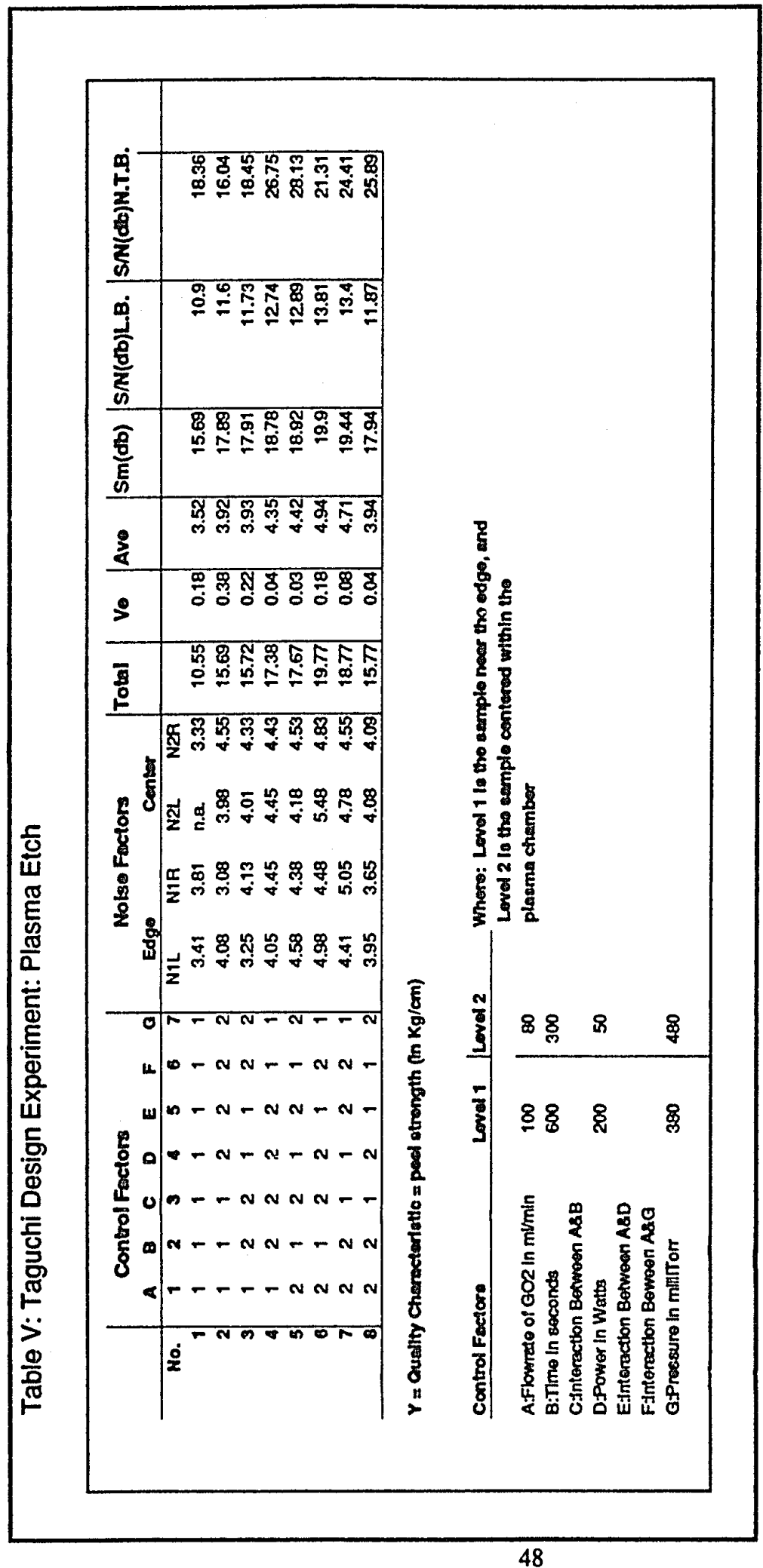




\section{Response Graph of Mean Peel Strengths}

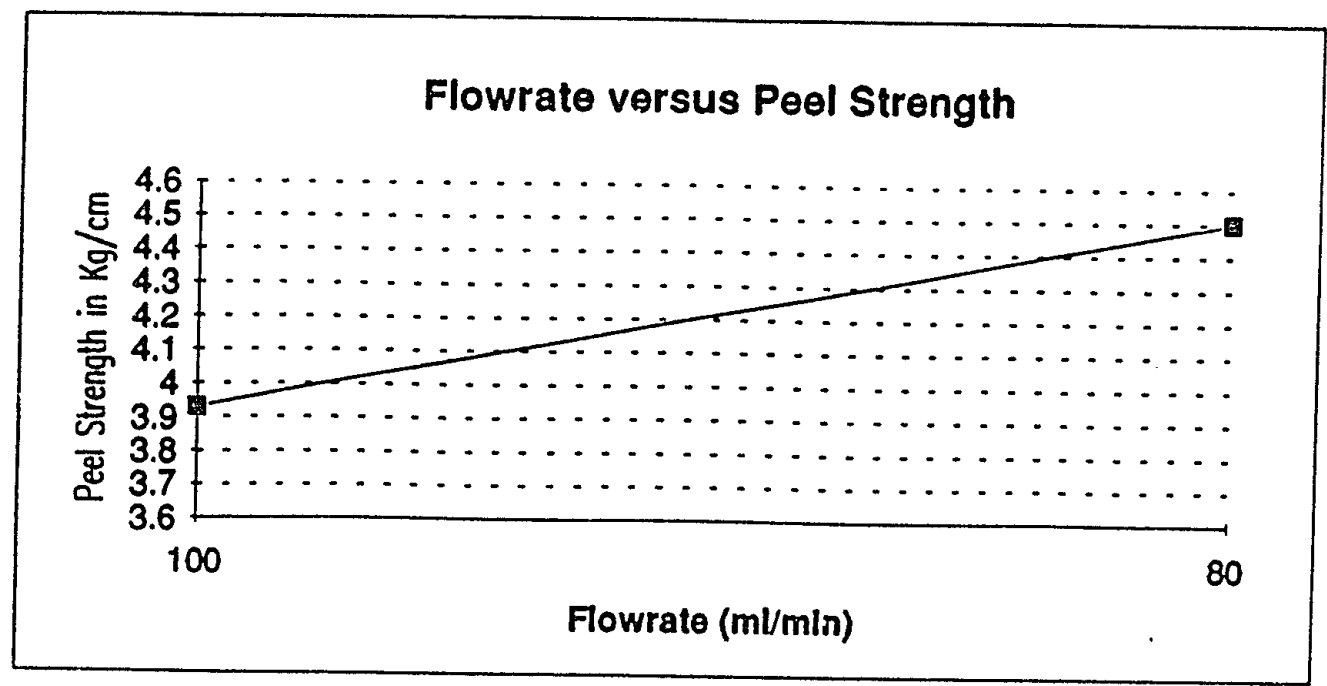

Figure 13. Linear Graph Plasma Etch: Flowrate

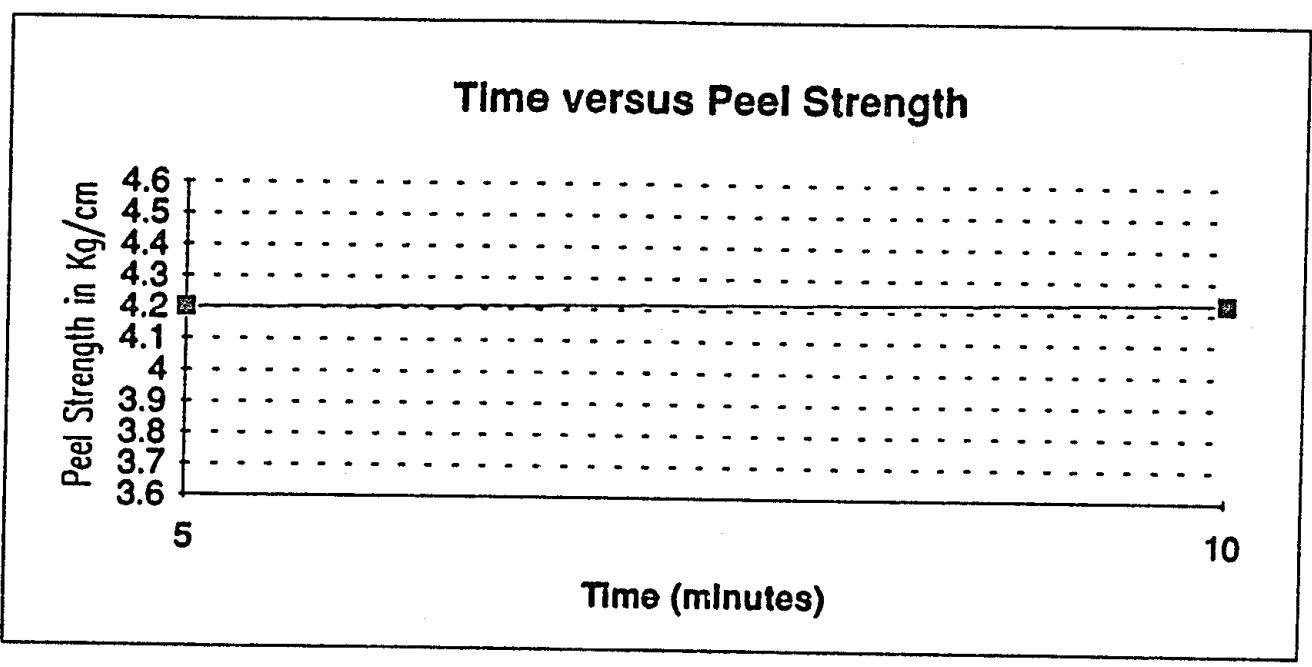

Figure 14. Linear Graph Plasma Etch: Time 


\section{Response Graph of Mean Peel Strengths}

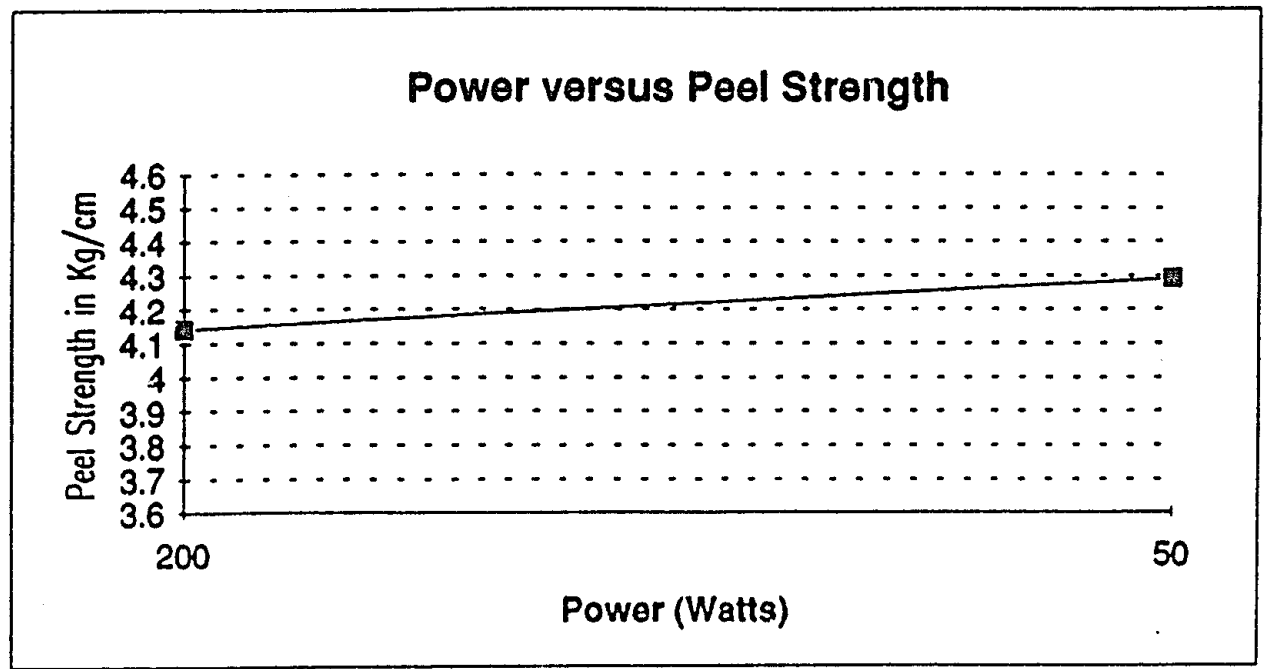

Figure 15. Linear Graph Plasma Etch: Power

\section{Chamber Pressure versus Peel Strength}

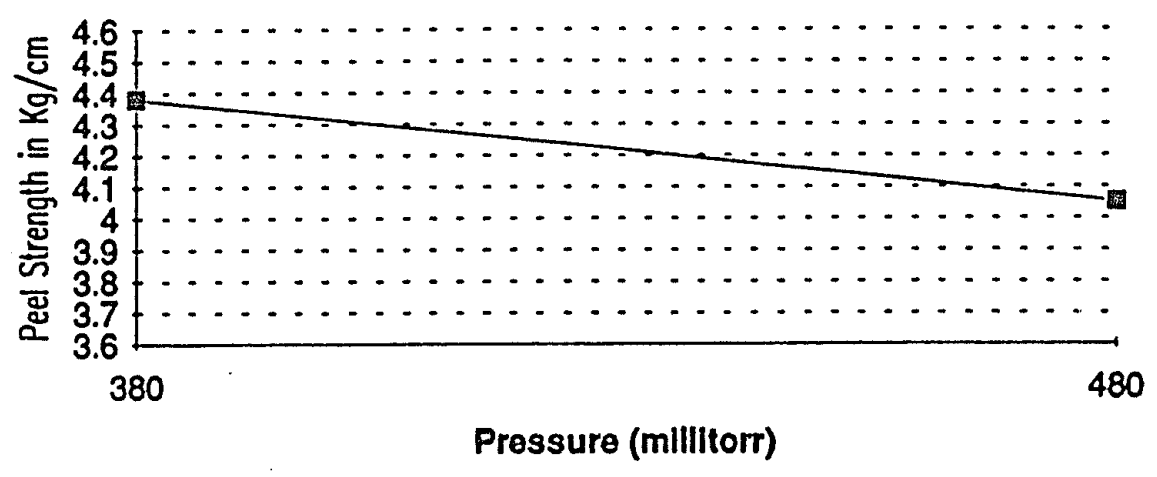

Figure 16. Linear Graph Plasma Etch: Chamber Pressure 
Flowrate versus Peel Strength

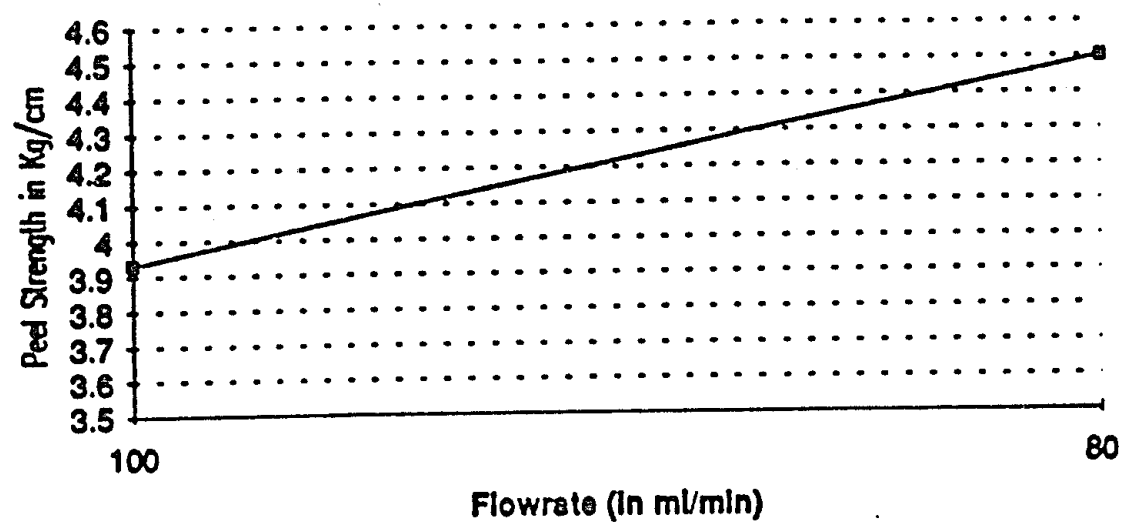

Signal to Noise Ratlo for Flowrate (Larger the Botter)

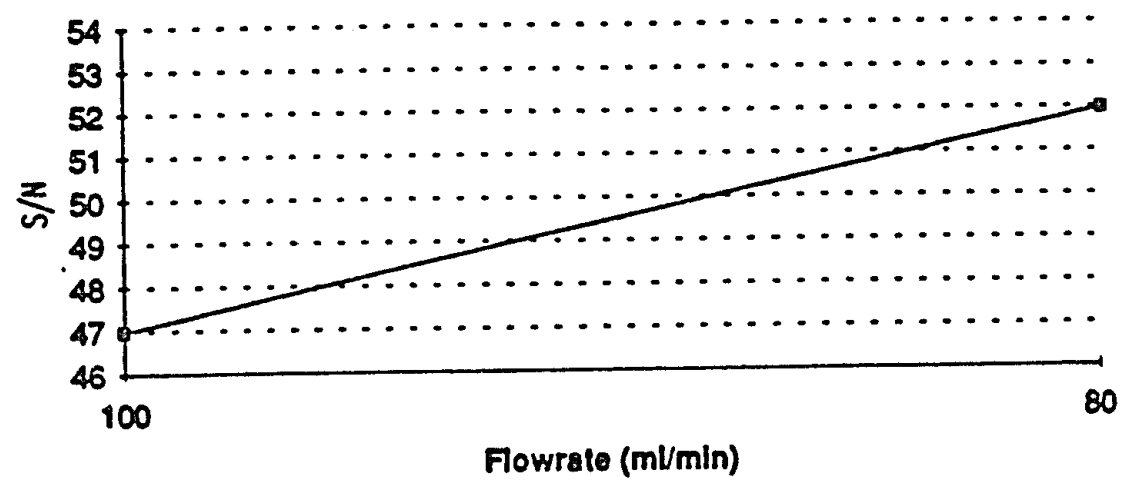

Slgnal to Nolse Ratio for Flowrate (Nomlnal the Best)

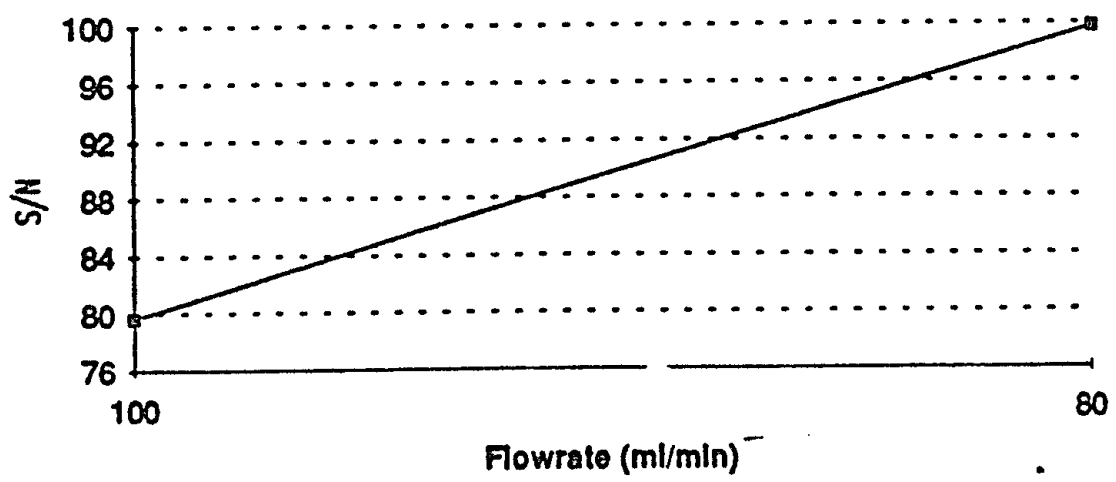

Figure 17. S/N Response Graphs and Mean Peel Strength: Flowrate 


\section{Power Level versus Peel Strength}

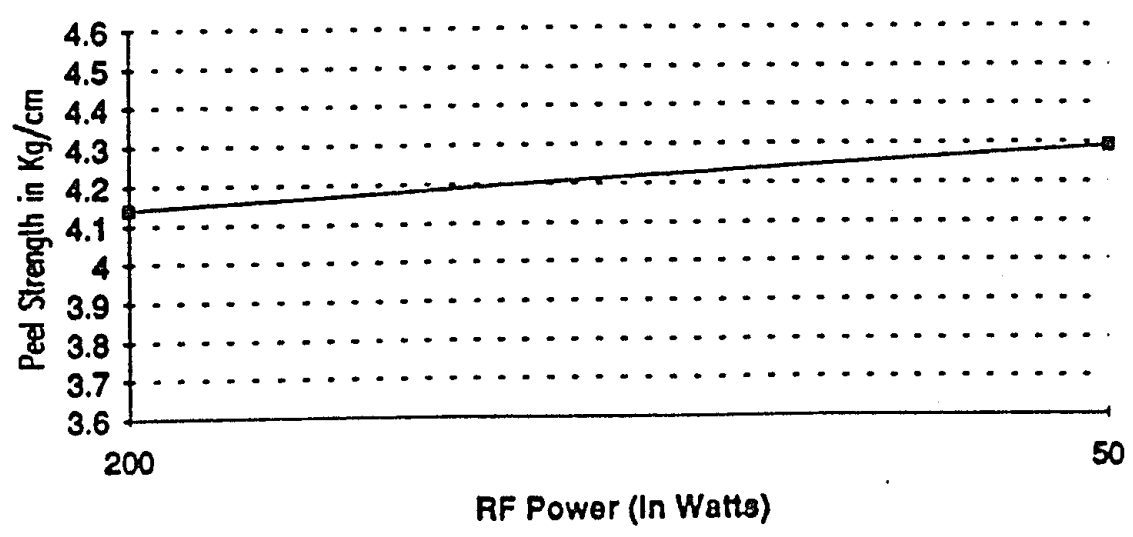

Signal to Nolse Ratlo for Power (Larger the Better)

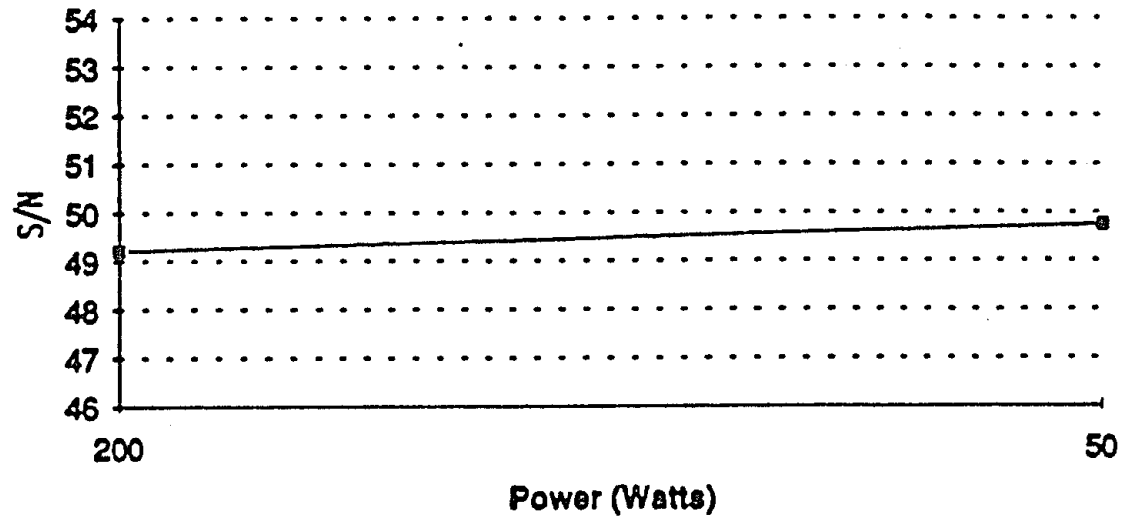

Signal to Nolse Ratlo for Power (Nominal the Best)

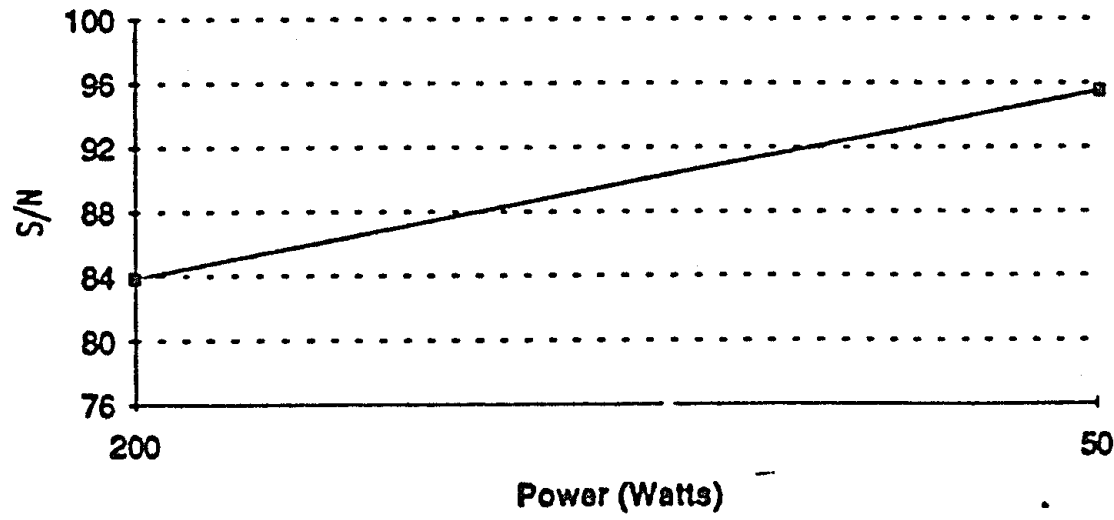

Figure 18. S/N Response Graphs and Mean Peel Strength: Time 
Time under RF Power versus Peel Strength

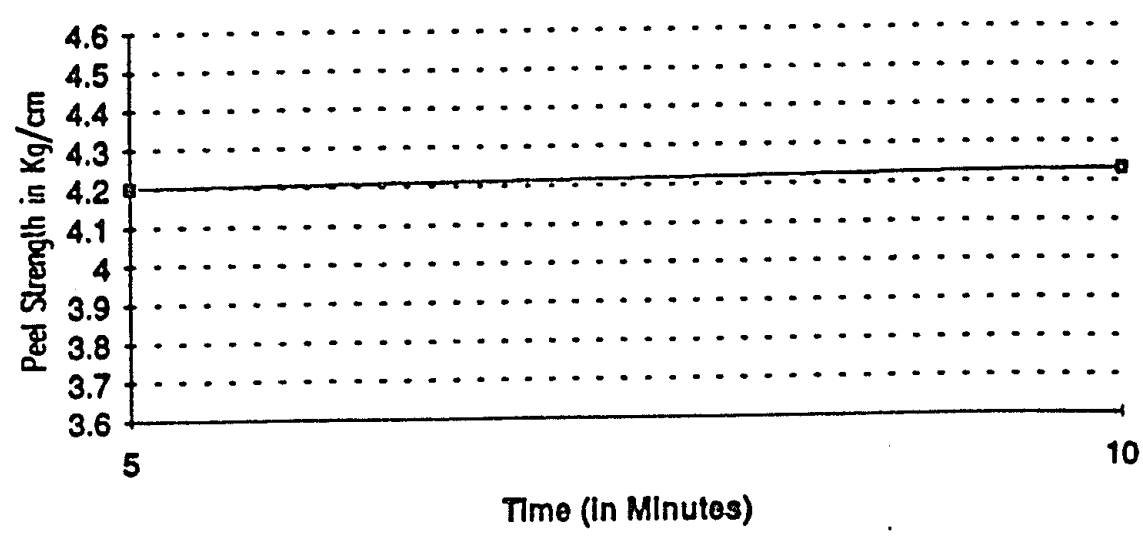

Signal to Nolse Ratio for Time (Larger the Better)

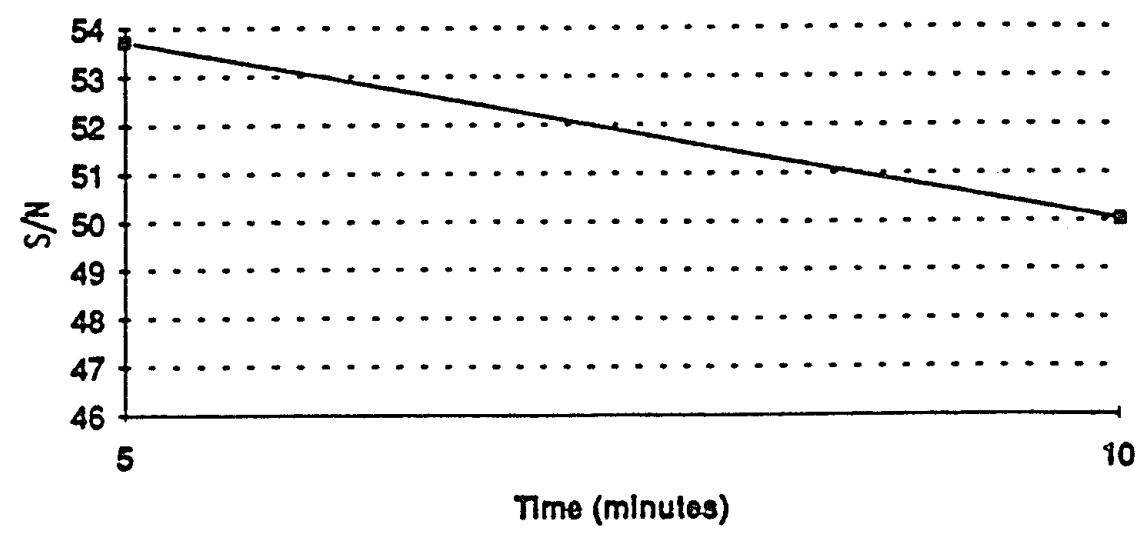

Signal to Noise Ratio for Time (Nominal the Best)

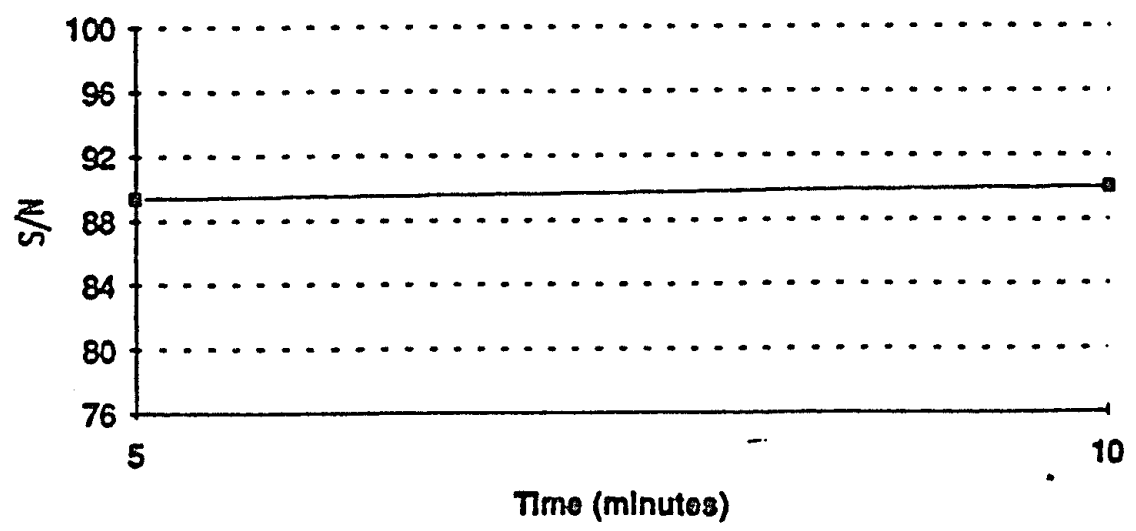

Figure 19. S/N Response Graphs and Mean Peel Strength: Power 
Chamber Pressure versus Peel Strength

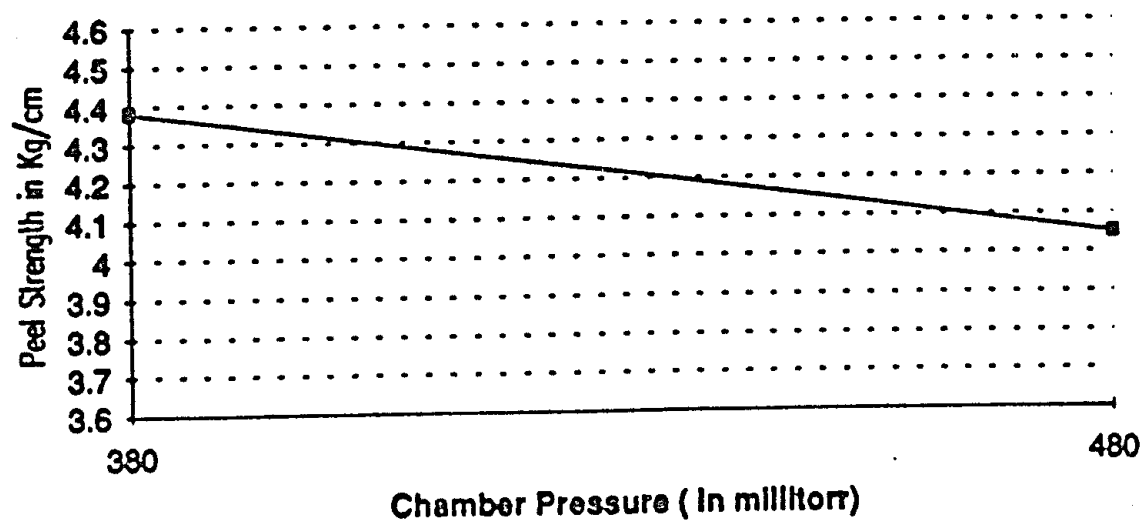

Signal to Nolse Ratio for Pressure (Larger the Bottor)

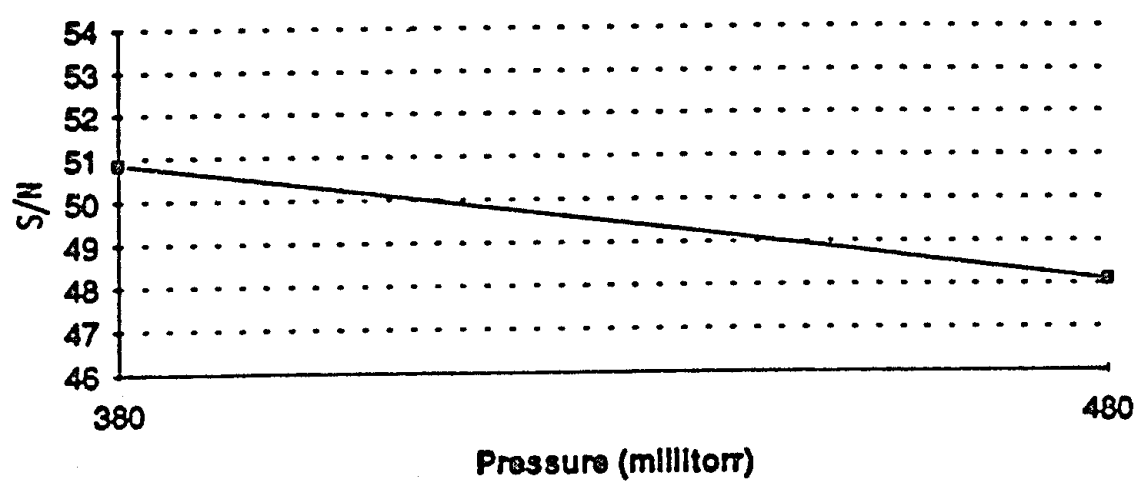

Signal to Nolse Ratio for Pressuro (Nominal the Best)

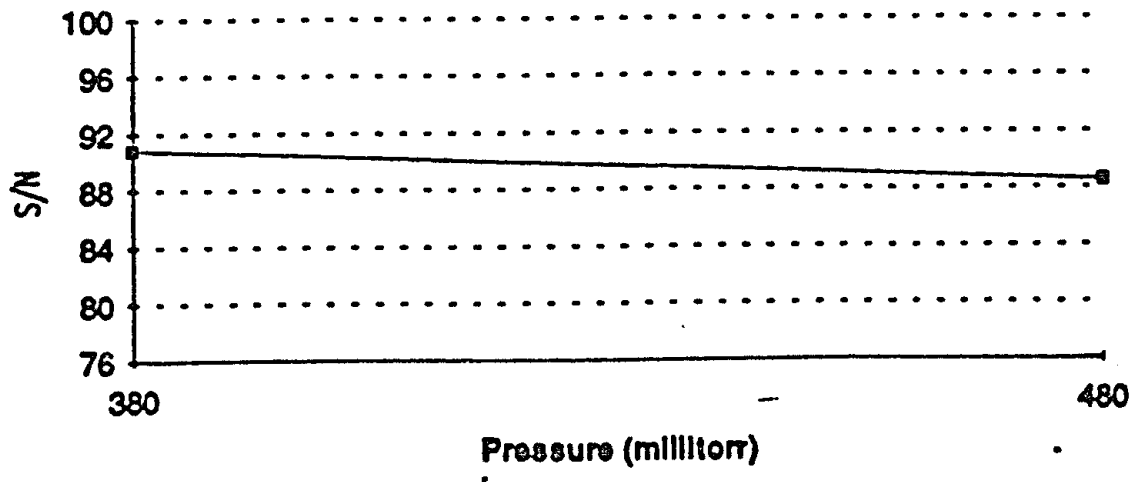

Figure 20. S/N Response Graphs and Mean Peel Strength: Chamber Pressure 54 
Figure 21 shows the interaction response graphs associated with this experiment. Note that the main interaction was that of flowrate and time.

\subsection{Plasma Etch Topography}

Photographs 9 through 16 present results of the plasma etch conditions on topography. Note those coupons etched at 380 millitorr, numbers $9,12,14$, and 15, have a much smoother appearance than those at 480 millitorr. Table IV, presented in Section 5.3, catalogues the pore size and number of pores per unit area here, 100 square micrometers. The data indicates samples etched under conditions which resulted in excellent adhesion had pore size outside of the critical pore size regime reported in section 3.1. Researchers postulated that a critical pore size was necessary to achieve good mechanical bonding. However, results indicate either that mechanical interlocking is not necessarily the only factor for superior adhesion or the critical pore size is over a greater range than previously believed. The results shown in the photographs also suggest that power can be an important factor in determining the type of surface etching. Photographs 9 through 12 show a topography that is much more coarse than the other samples. The major differences in these sample sets were the power settings. It was also interesting that photographs 13 and 14 had comparable, if not equivalent, peel strength, but completely different topography. 
Interactlon Response Graphs
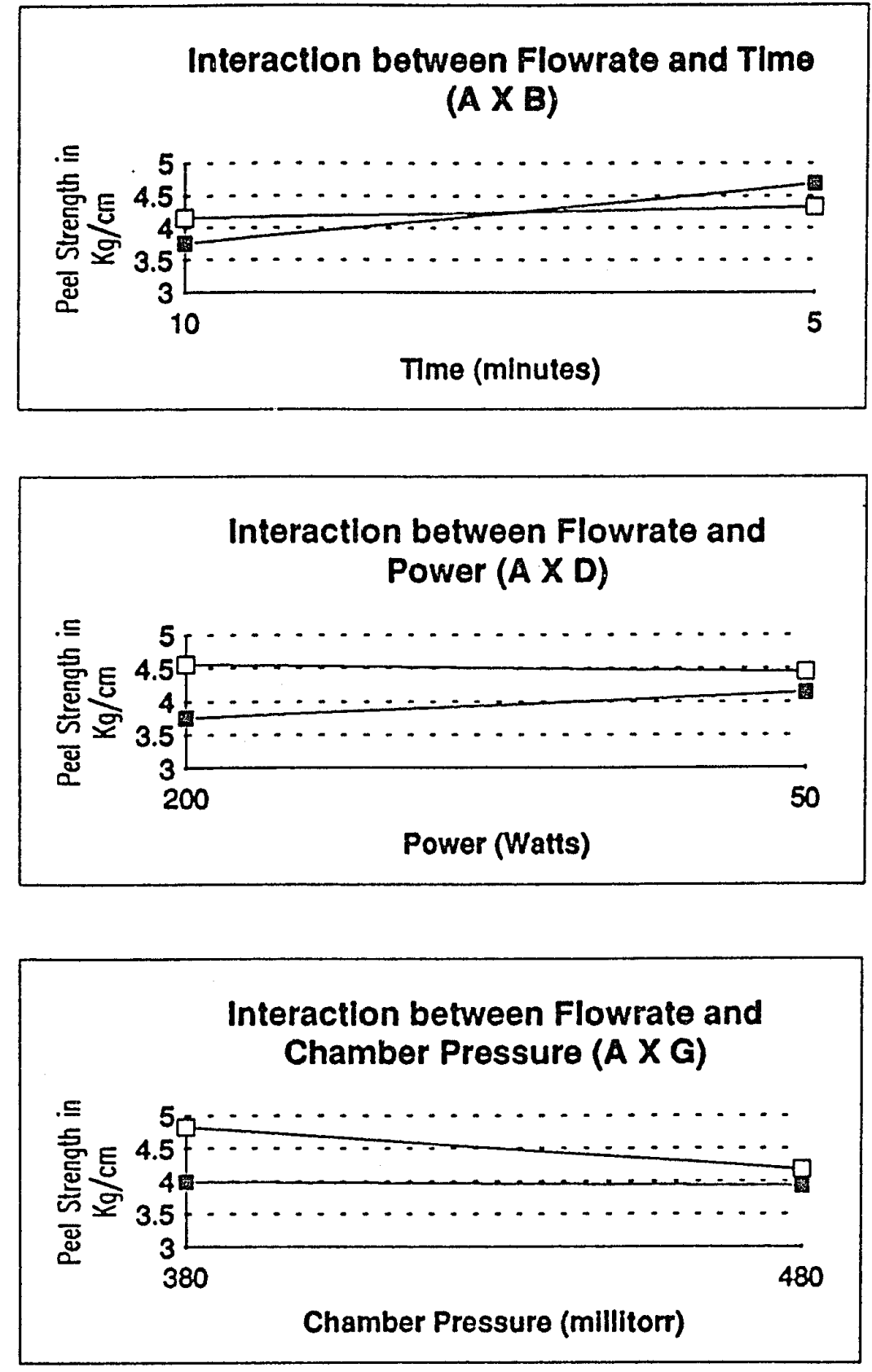

Figure 21. Interaction Response Craphs 


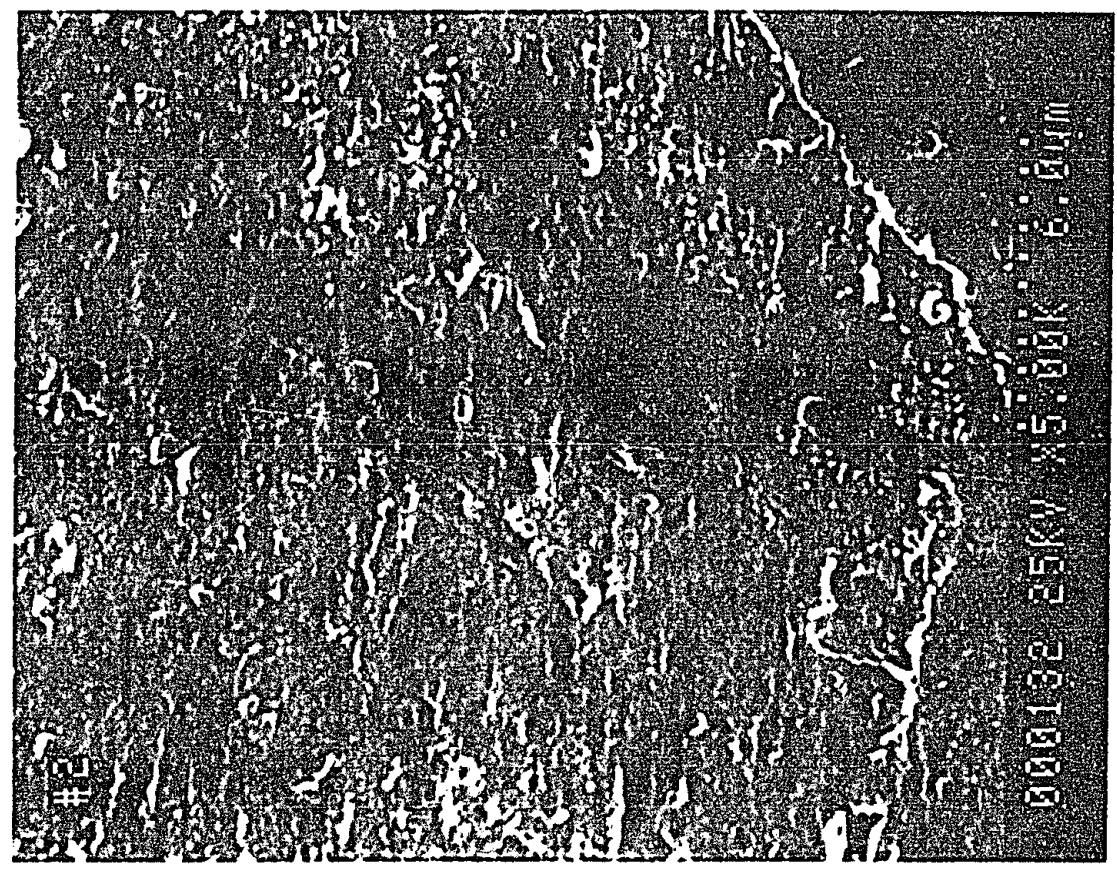

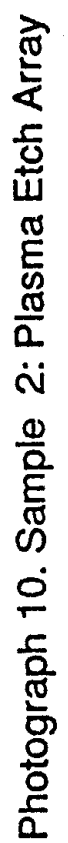

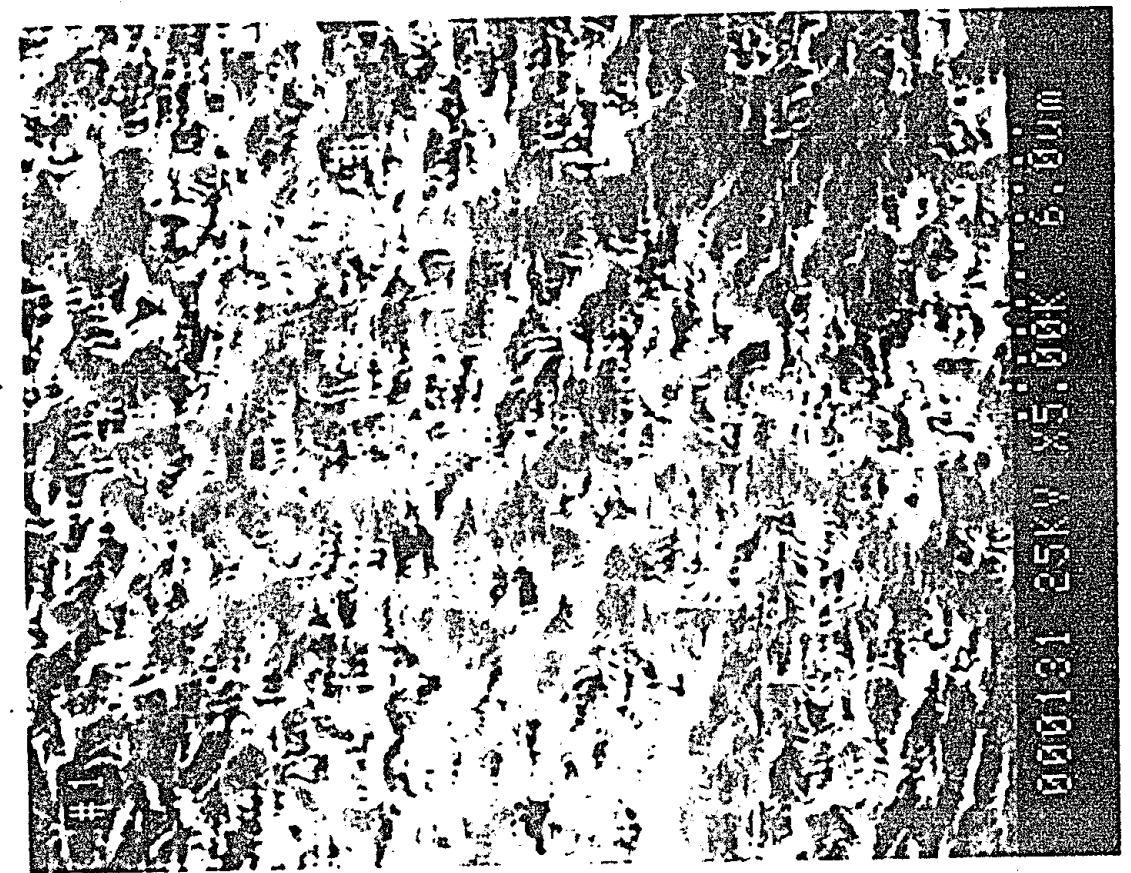

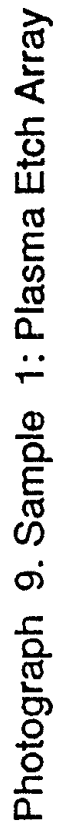




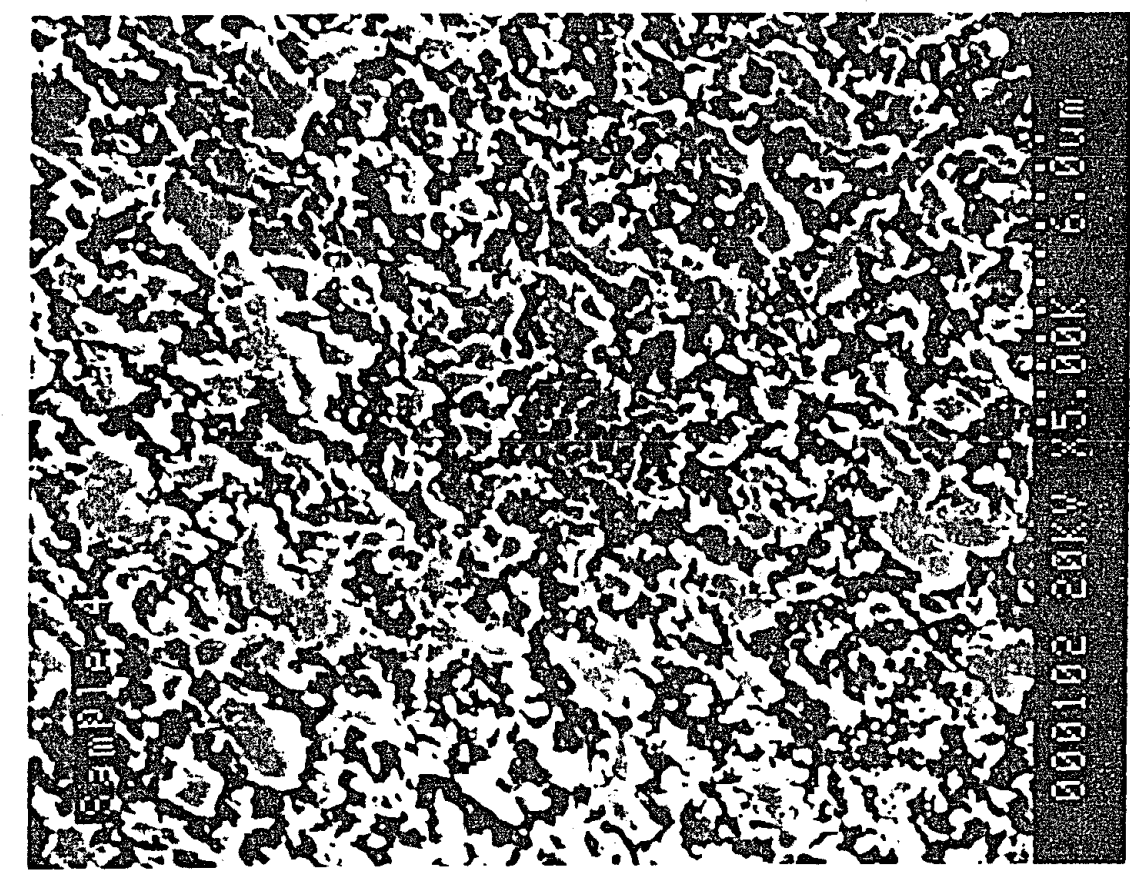

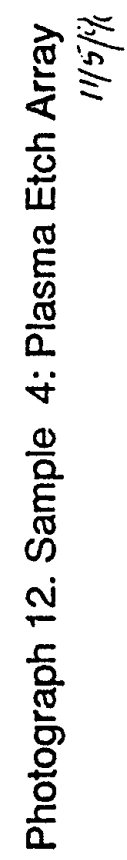

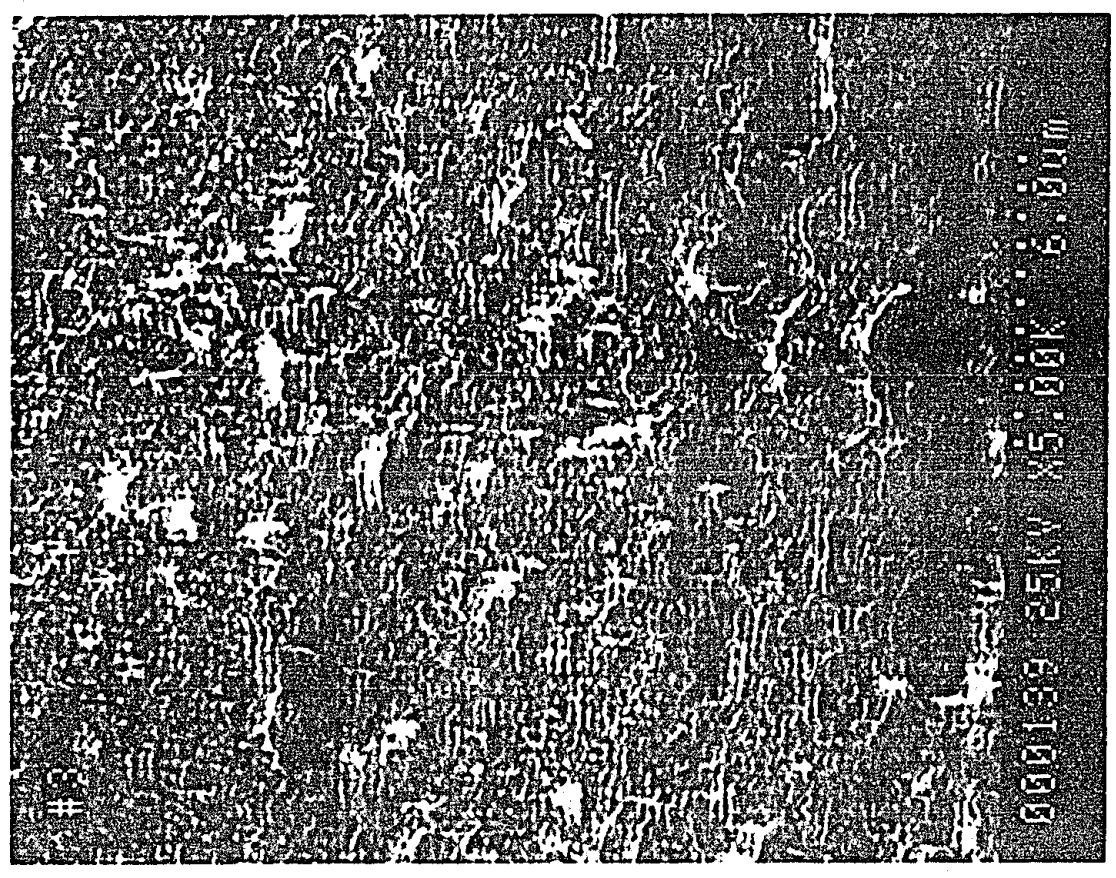

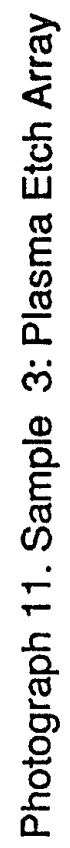




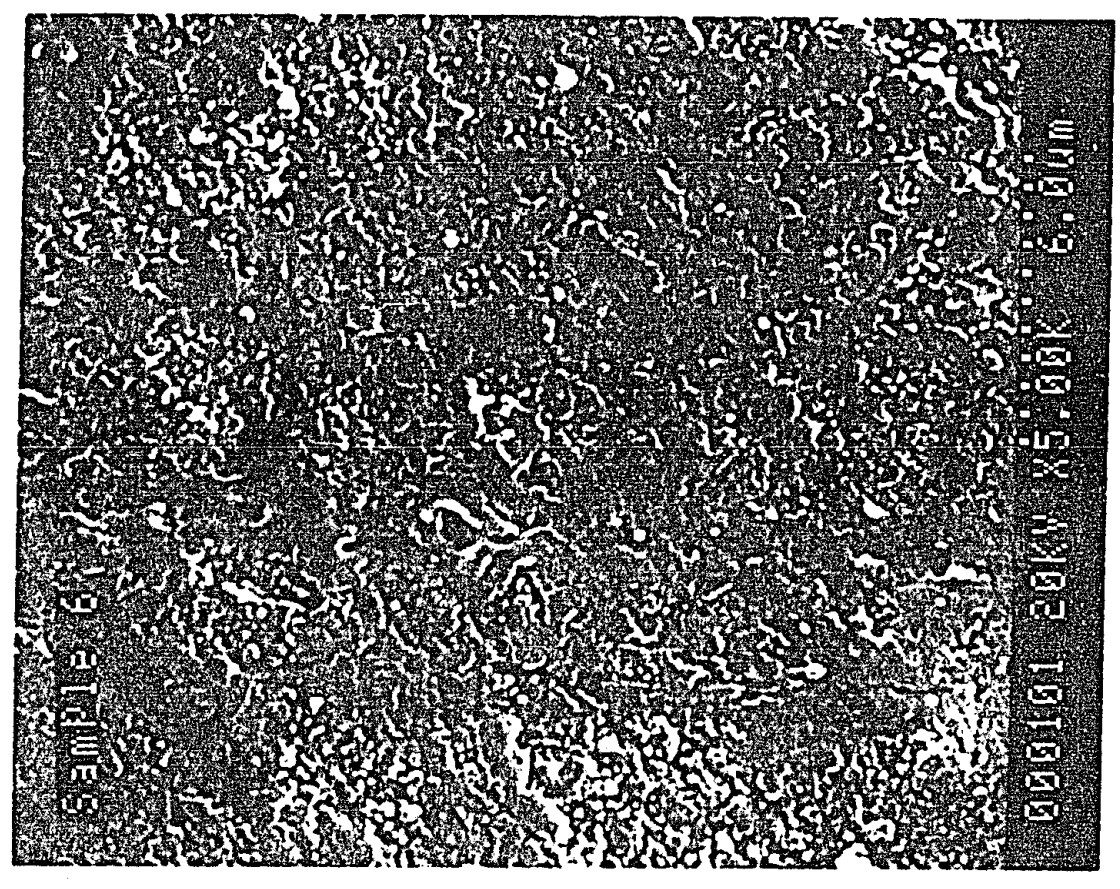

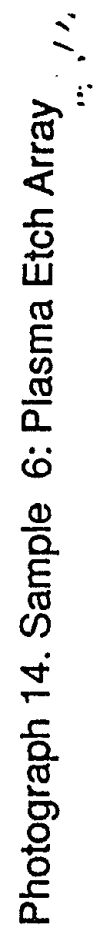

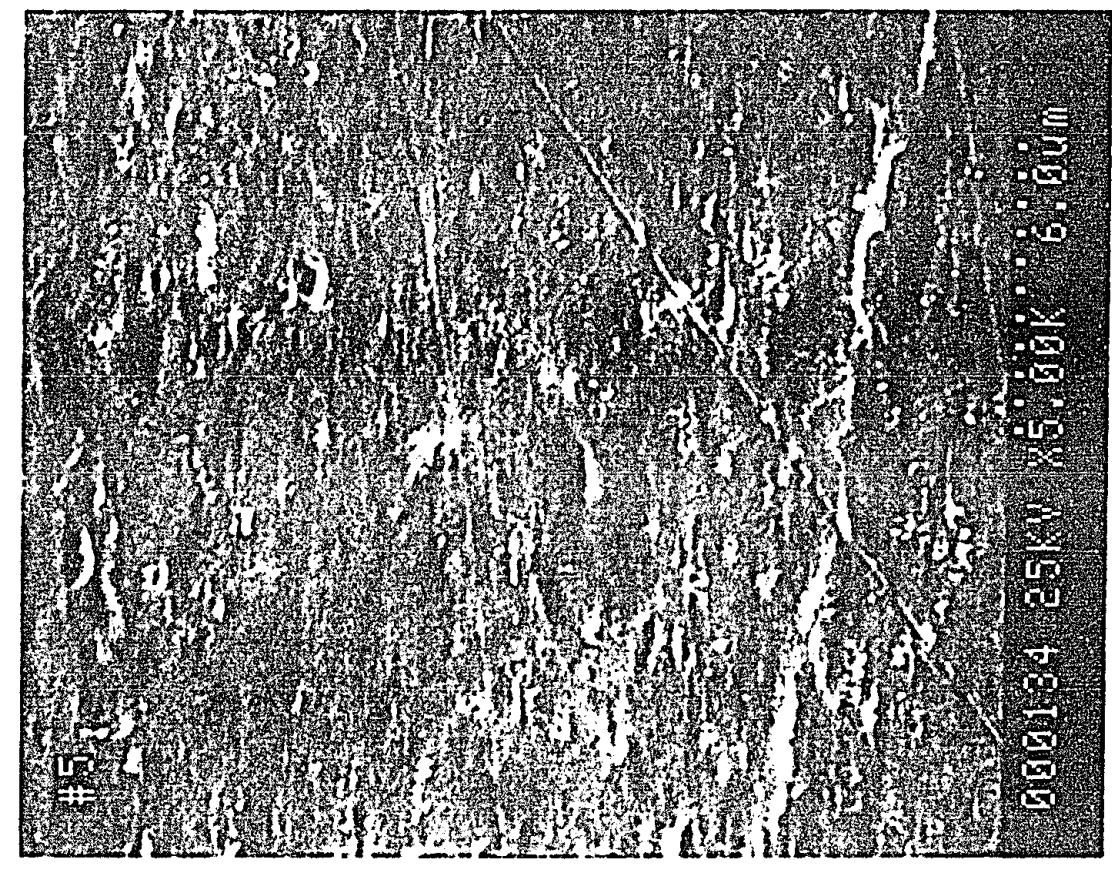

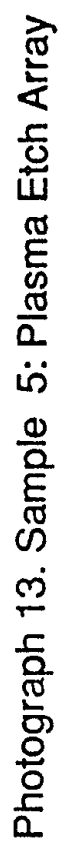




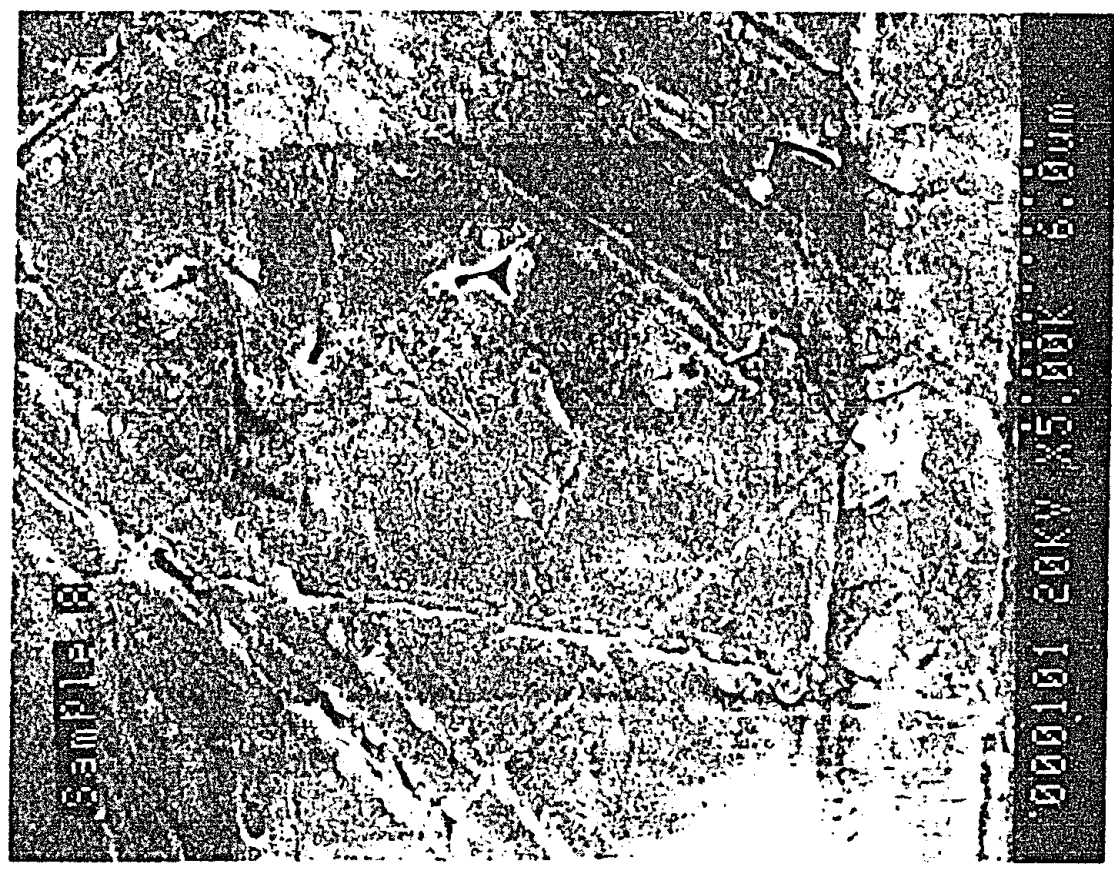

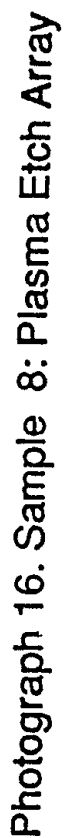

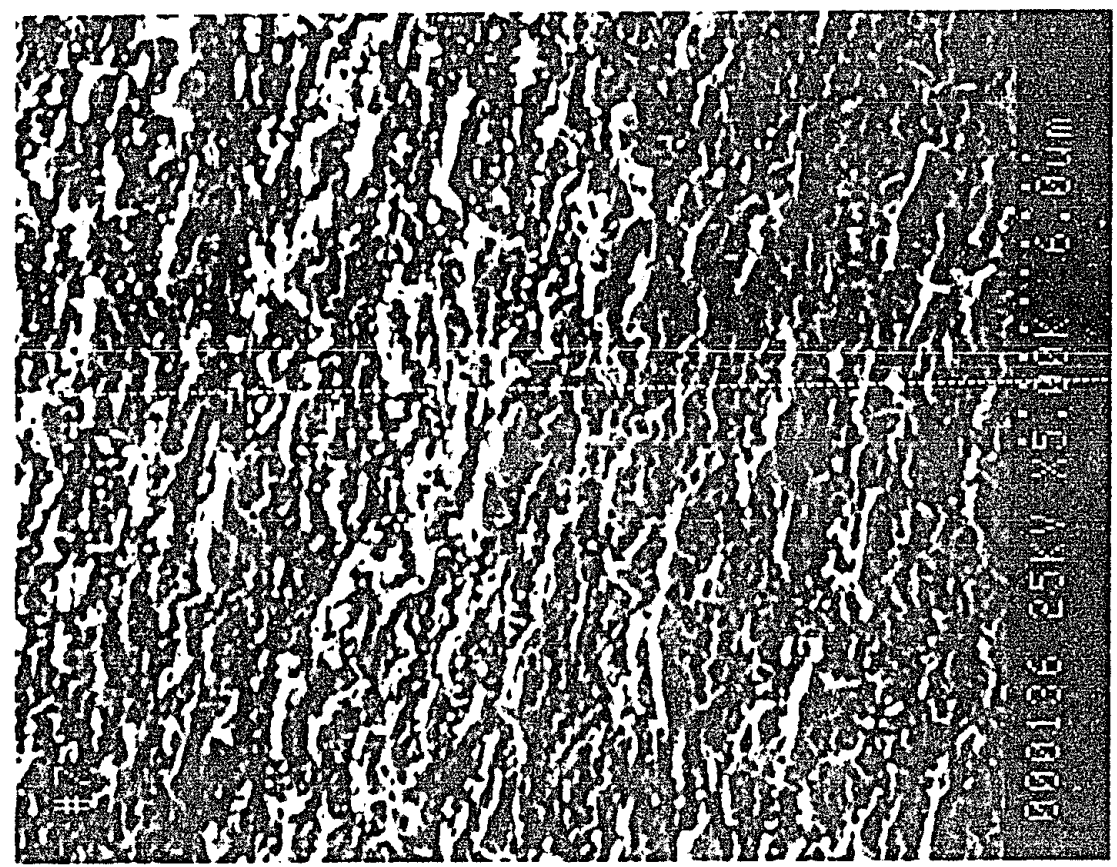

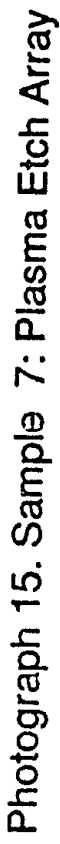




\subsection{One Varlable Testing}

Figure 22 is a graphical representation of mean peel strength results for 2 separate plasma etch runs. These coupons were etched at a constant 380 millitorr chamber pressure at 50 Watts, for 10 minute etch rimes. Two coupons were etched at a flowrate of $20 \mathrm{ml} / \mathrm{min}$., two more coupons at $40 \mathrm{ml} / \mathrm{min}$., two more coupons at $60 \mathrm{ml} / \mathrm{min}$., two coupons at $80 \mathrm{ml} / \mathrm{min}$., and two more coupons at $100 \mathrm{ml} / \mathrm{min}$. Included in the graph are the $y$ intercept and linear correlation coefficients (R squared) for each of the 4 experiments, and the average of the experiments. The y intercept and correlation coefficients for the total experiment, i.e., 20 data points, are also presented. This analysis indicates a strong linear relationship exists, with a linear correlation coefficient of over 0.90 existing between flowrate and adhesion. SEM photographs for these same conditions are shown in photographs 17 , through 21 . Note that the pore size essentially remained constant, while the number of pores increased as the flowrate was decreased.

Figure 23 shows mean peel strength results of varied chamber pressure at a constant $80 \mathrm{ml} / \mathrm{min}$. flowrate, at 50 Watts and 10 minute etch times. Two coupons, with two peel tests each, one called left hand side (LHS) and one called right hand side (RHS), are reported for each pressure investigated. Included in this graph are the $y$ intercept and linear correlation coefficients $(R$ squared) for each of the 4 experiments, and the average of the experiments. The $y$ intercept and correlation coefficients for the total experiment, i.e., 20 data points, are also presented. This analysis indicates a linear relationship exists for 


\section{Effect of Flowrate on Peel Strength @ Constant Chamber Pressure of $\mathbf{3 8 0}$ millitorr}

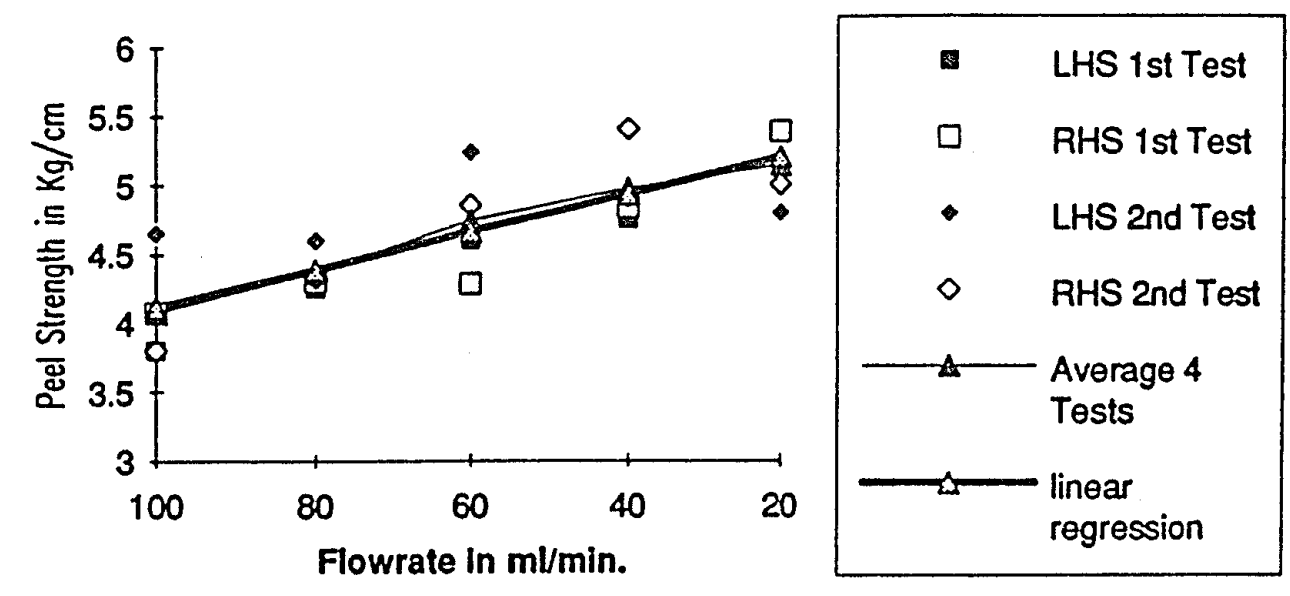

Figure 22. One Variable Testing: Varied Flowrate 


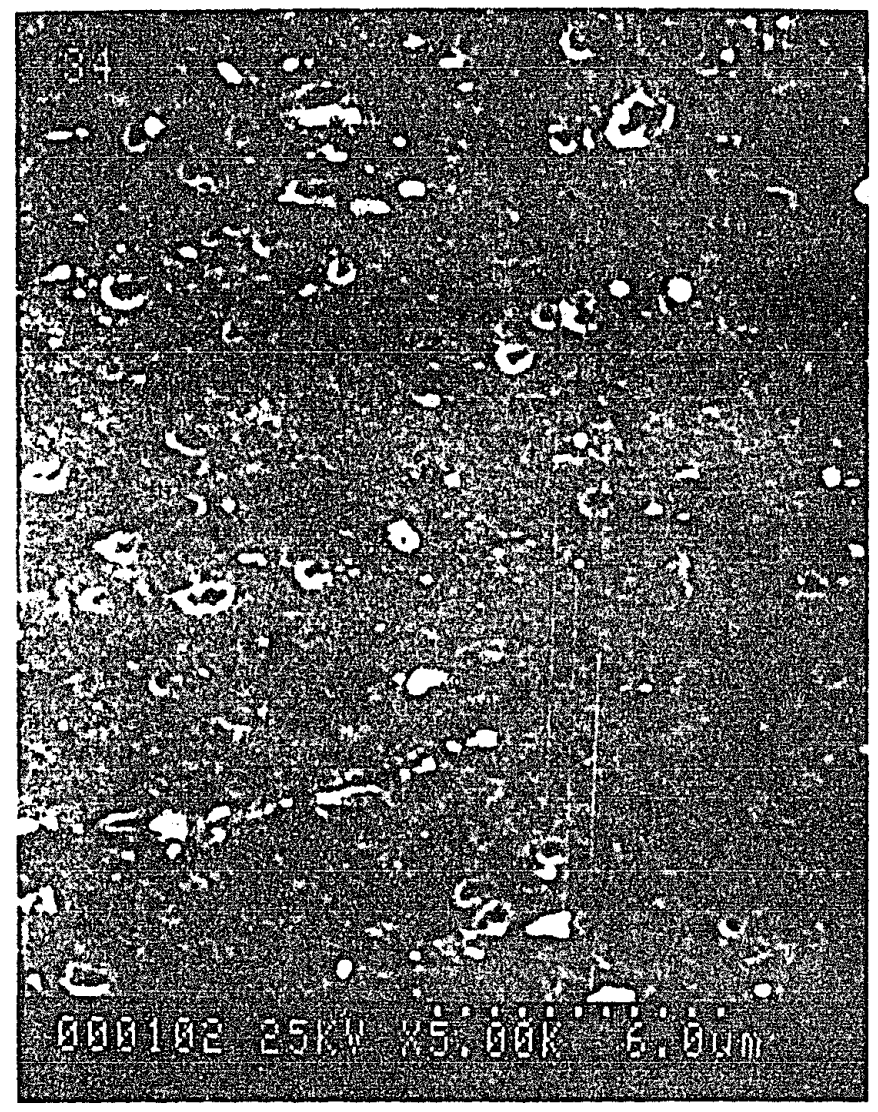

Photograph 17. Flowrate $100 \mathrm{ml} / \mathrm{min}$. @ 380 milltorr, 50 Watts for 10 minutes 


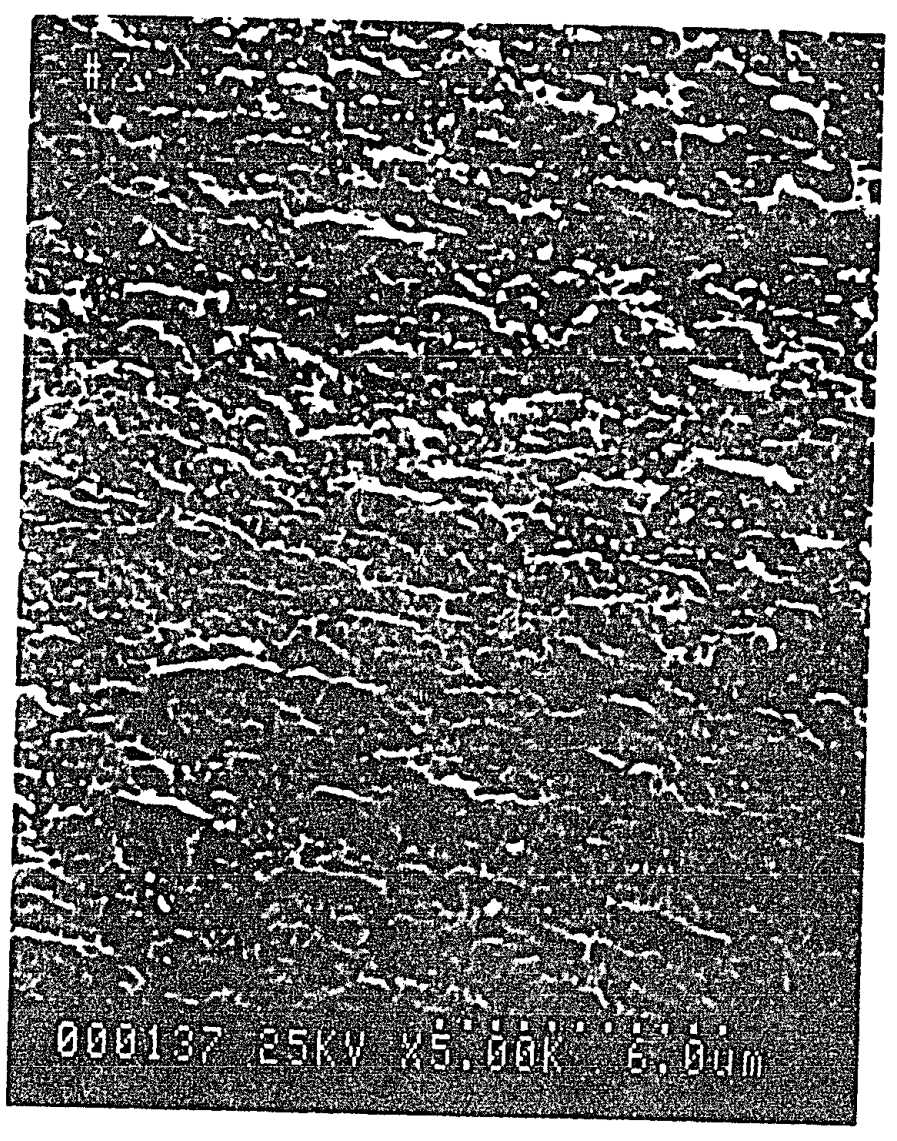

Photograph 18. Flowrate $80 \mathrm{ml} / \mathrm{min}$. @ 380 milltorr, 50 Watts for 10 minutes 


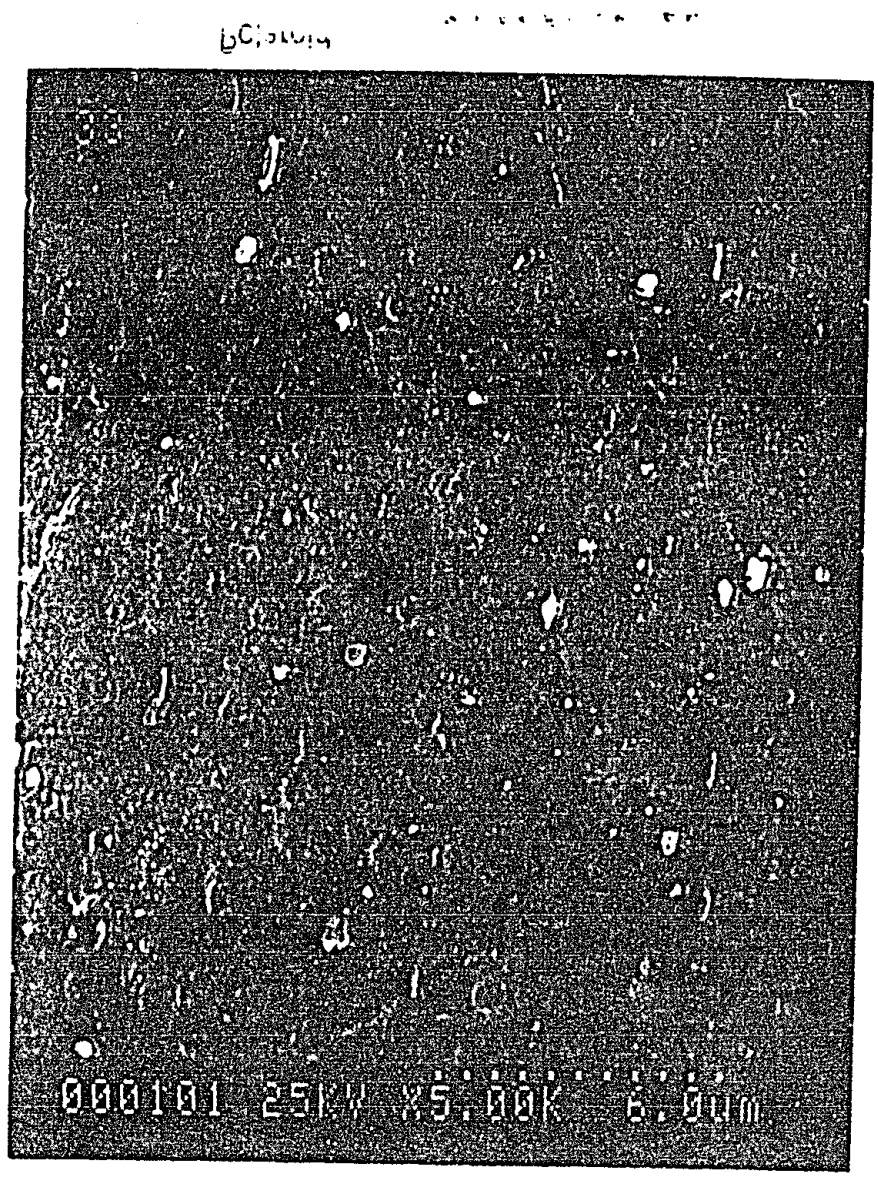

Photograph 19. Flowrate $60 \mathrm{ml} / \mathrm{min}$. @ 380 milltorr, 50 Watts for 10 minutes 


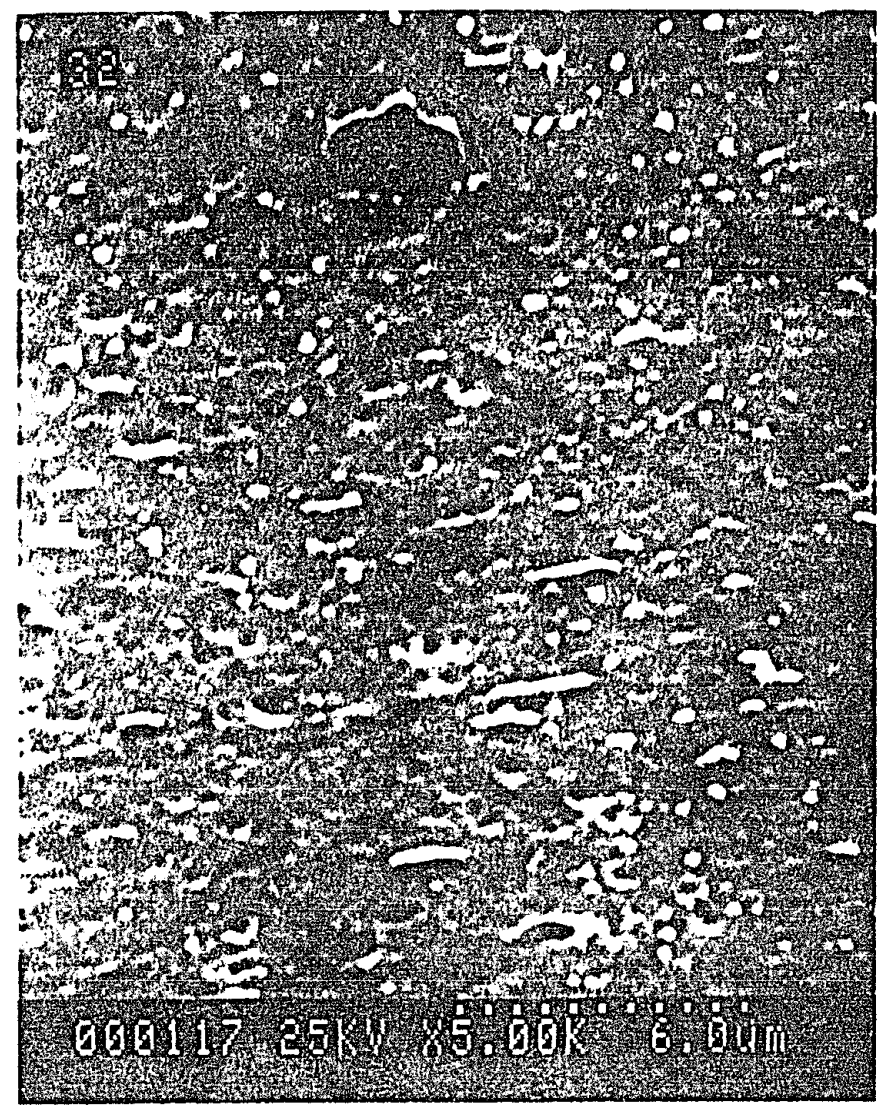

Photograph 20. Flowrate $40 \mathrm{ml} / \mathrm{min}$. @ 380 milltorr, 50 Watts for 10 minutes 


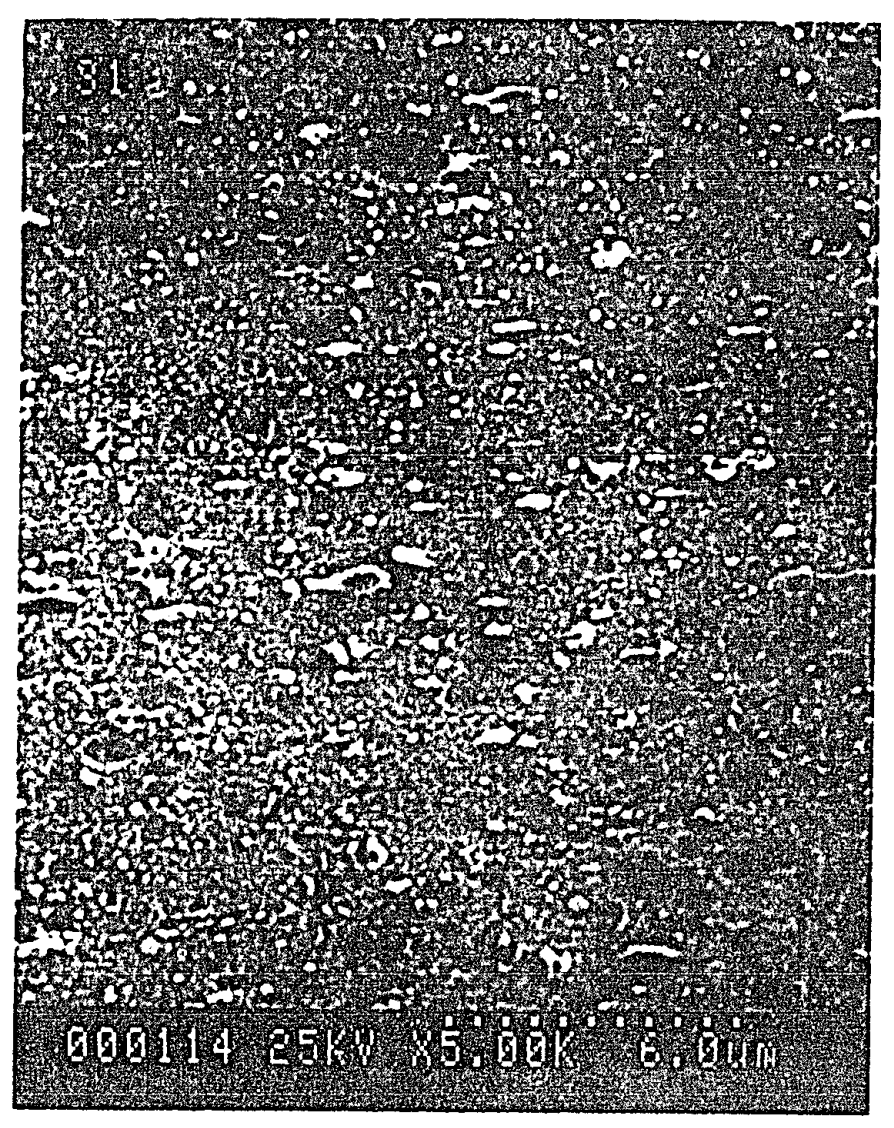

Photograph 21. Flowrate $20 \mathrm{ml} / \mathrm{min}$. @ 380 milltorr, 50 Watts for 10 minutes 


\section{Effect of Chamber Pressure on Peel Strength @ Constant Flowrate of $80 \mathrm{ml} / \mathrm{min}$.}

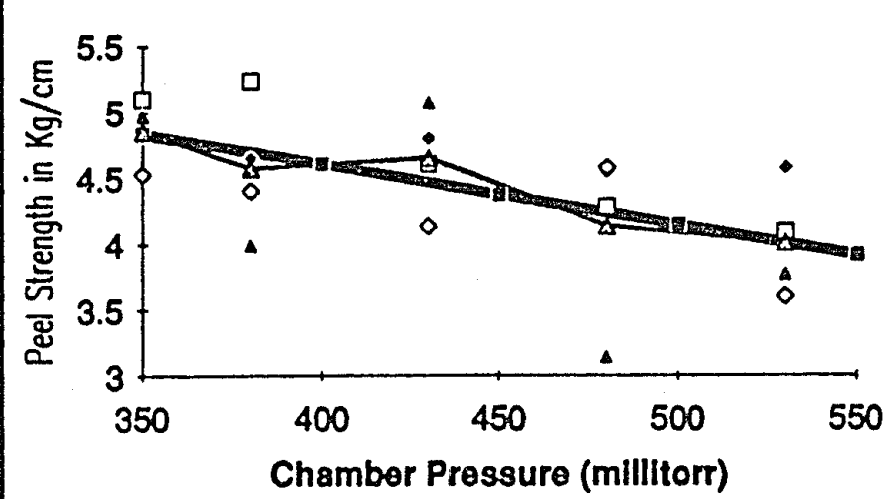

linear regression

口 1st Test LHS

- $\quad$ Ist Test RHS

- 2nd Test LHS

a 2nd Test RHS

$\longrightarrow$ Ave. 4 Tests

Figure 23. One Variable Testing: Varied Chamber Pressure, $80 \mathrm{ml} / \mathrm{min}$. 
this effect. This relationship is sufficient to characterize the effect of chamber pressure in this flow regime. This factor is a strong effect but not predictable. In other words chamber pressure could not be used to fine tune the process. However, the linearity of the factor suggests that this factor could be used to move the mean of the results in a predictable manner. In other words, this factor can influence the peel strength in a positive manner but could not be used to fine tune a process to a fixed peel strength number.

Figure 24 shows mean peel strength results of varied chamber pressure $(380,325,270,220$, and 170 millitorr) at a constant $20 \mathrm{ml} / \mathrm{min}$. flowrate, at 50 Watts and 10 minute etch times. Two coupons, with two peel tests each, RHS and LHS, are reported. Included are the y intercept and linear correlation coefficients ( $R$ squared) for each of the 4 experiments, and the average of the experiments. The $y$ intercept and correlation coefficients for the total experiment, 20 data points, are also presented. Linear, power and logarithmic functions are not adequate to describe these results. Correlation coefficients were under -0.65 for all the above mentioned functions. Linear correlation coefficients were near 0.30 , while power correlation coefficient was near 0.65 . Therefore, because there is a definite break in the data at 220 millitorr, these results suggest that some other mechanism, or more than one physical phenomenon, must be important in this flow regime. It is important to note that some of the highest peel values were noted while doing this experiment. What this important mechanism influencing adhesion might be is discussed below. 


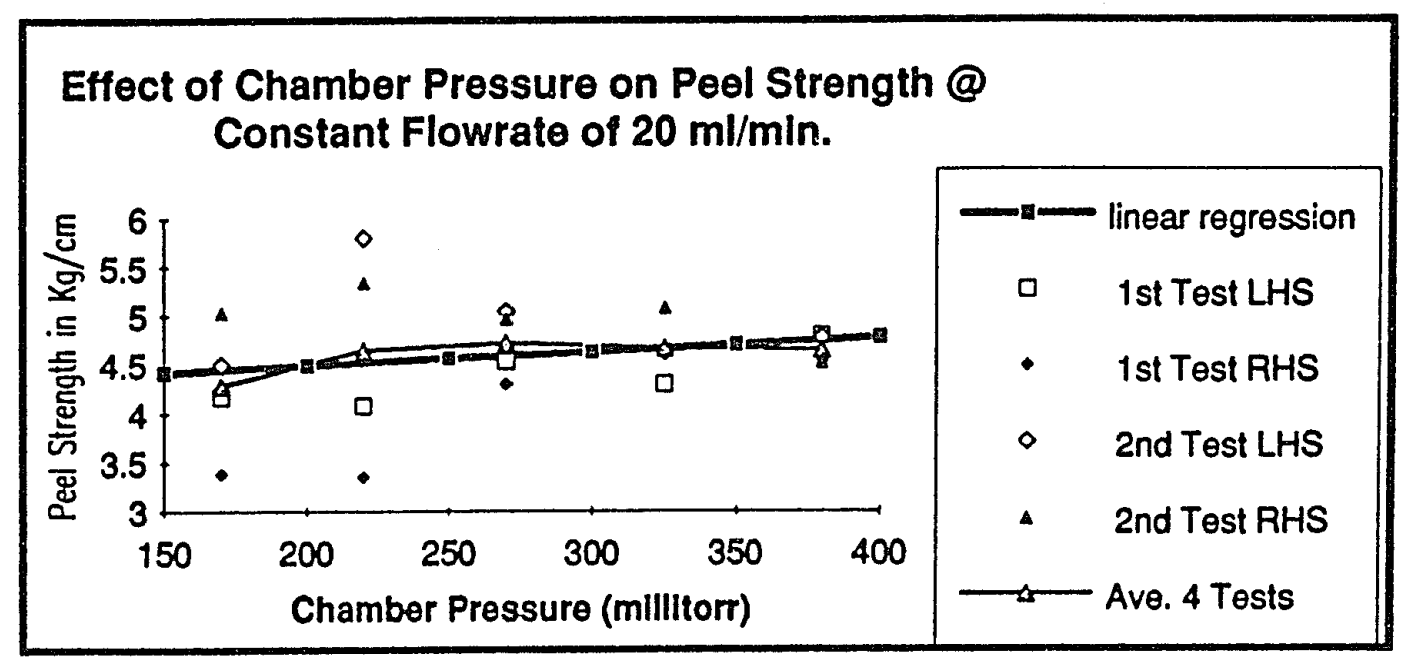

Figure 24. One Variable Testing: Varied Chamber Pressure, $20 \mathrm{ml} / \mathrm{min}$. 
SEM photographs 22,23 , and 24 show the topography for samples at 380 , 270 and 170 millitorr, respectively. This topography is dramatically different from those encountered in the plasma experiment at high flowrates. The photos indicate a "dirty" surface. This topography suggests the "deposition" of materials back onto the surface. It is hypothesized that this dirty surface could be the deposition of polymer(s) or fraction of polymers back onto the surface. This mechanism is called recombinant anisotropy and was described earlier in Section 2. It was noted that the highest peel values obtained during any experiments came from samples with this "dirty" condition. This fact should be investigated further.

\subsection{Attribute Data}

Attribute data was recorded. An important attribute was the film thickness. It was important to measure the thickness since Heymann (1970) noted a dependence of peel strength on the thickness of the copper film. Figure 25 is a graphical representation of the compilation of film thickness of thirty-five copper plated samples. Table IX in Appendix D contains the data for this graph. The mean of the data points and 2 sigma upper and lower control limits are also indicated. The fact that all experimental data points were within a 2 sigma band indicates that the differences in peel strength due to tensile strength of the copper film was not a major factor in the experiment, thus no peel strength correction was needed for film thickness. Since the film thickness was consistent, the thickness variances did not contribute significantly to differences in peel strengths. 


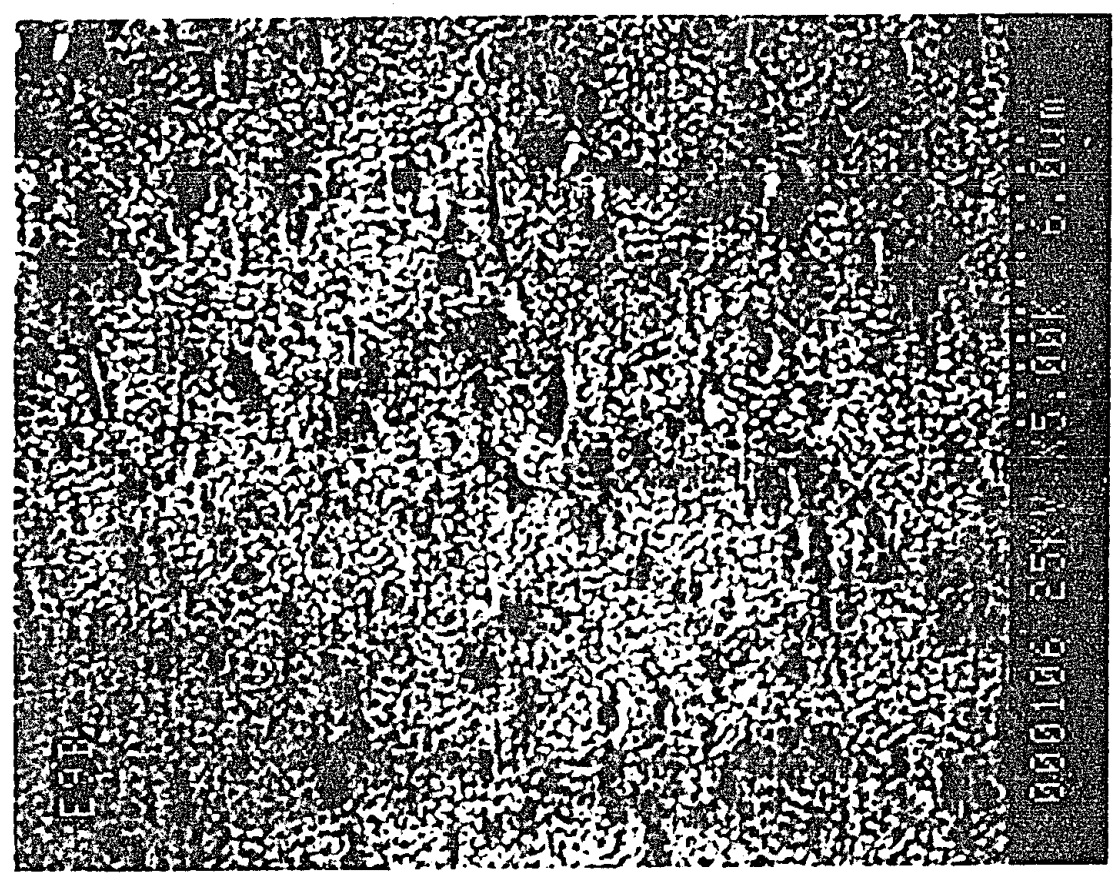

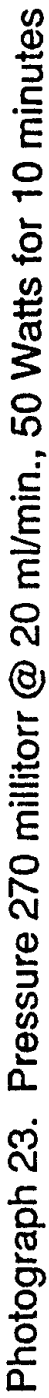

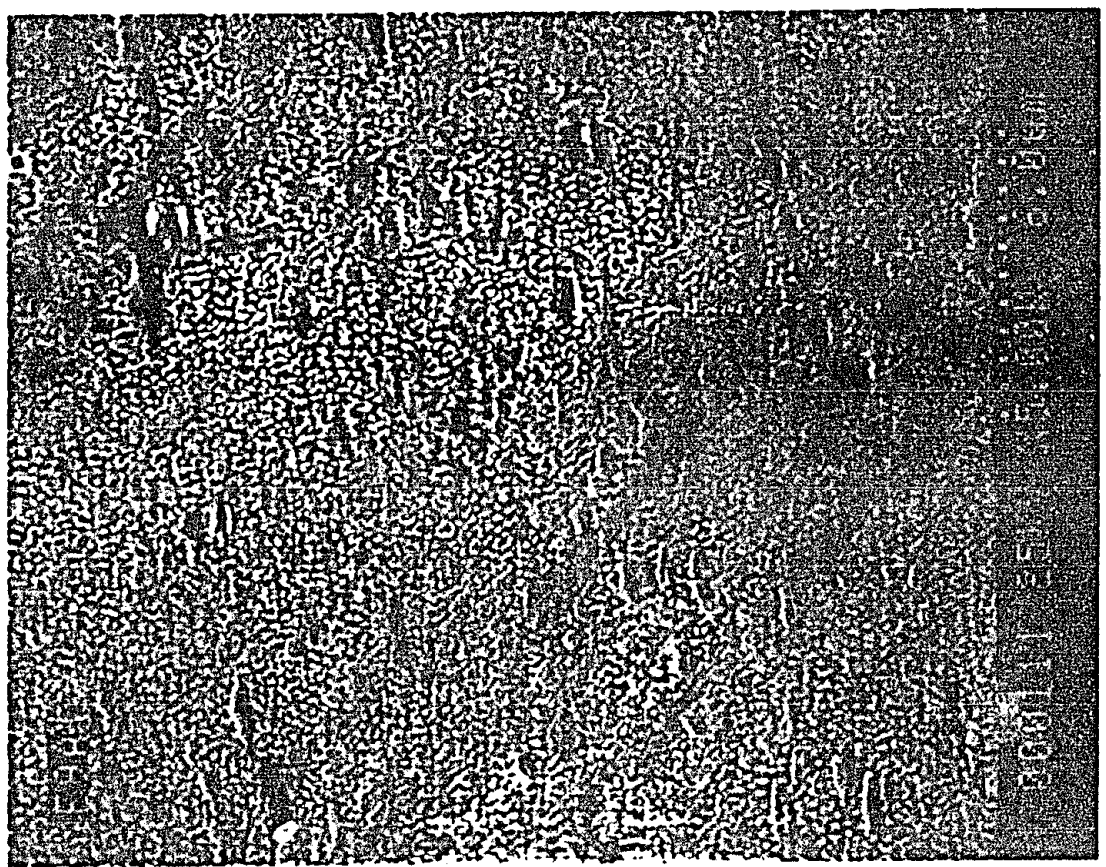




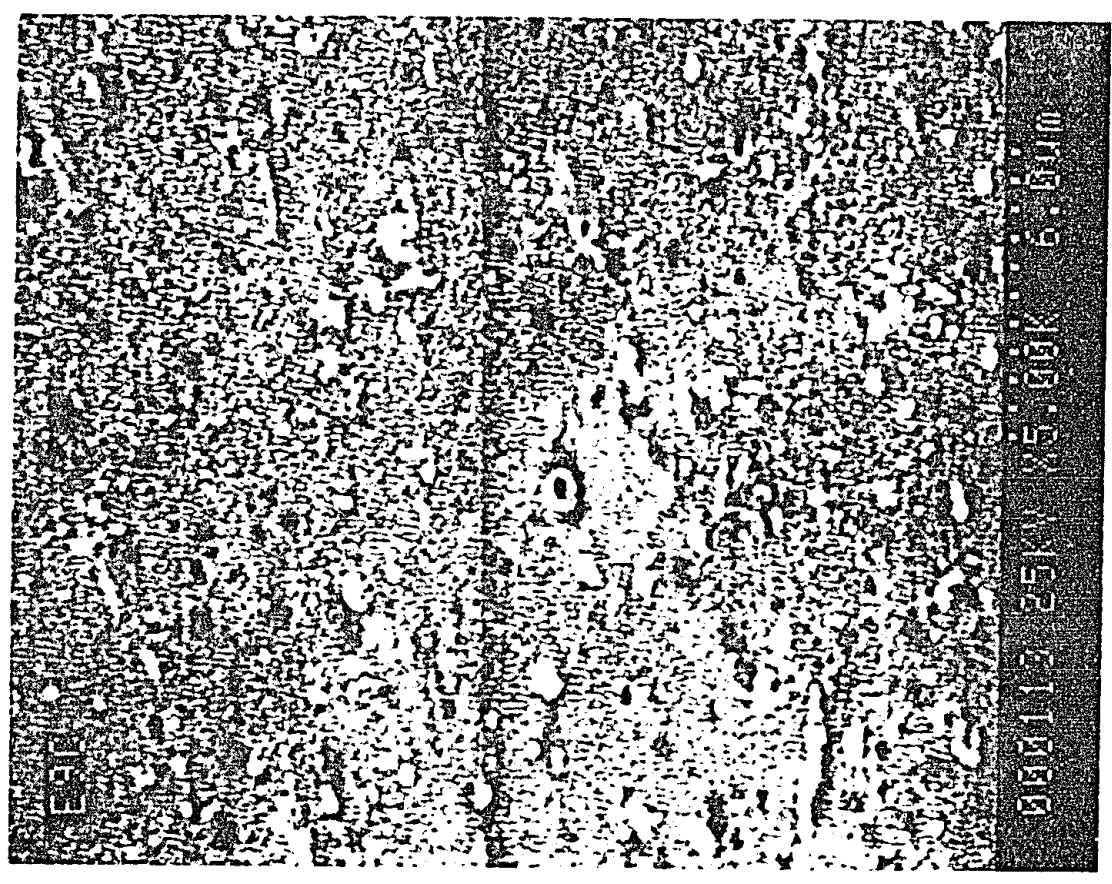

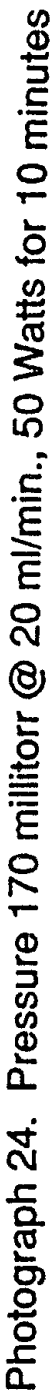




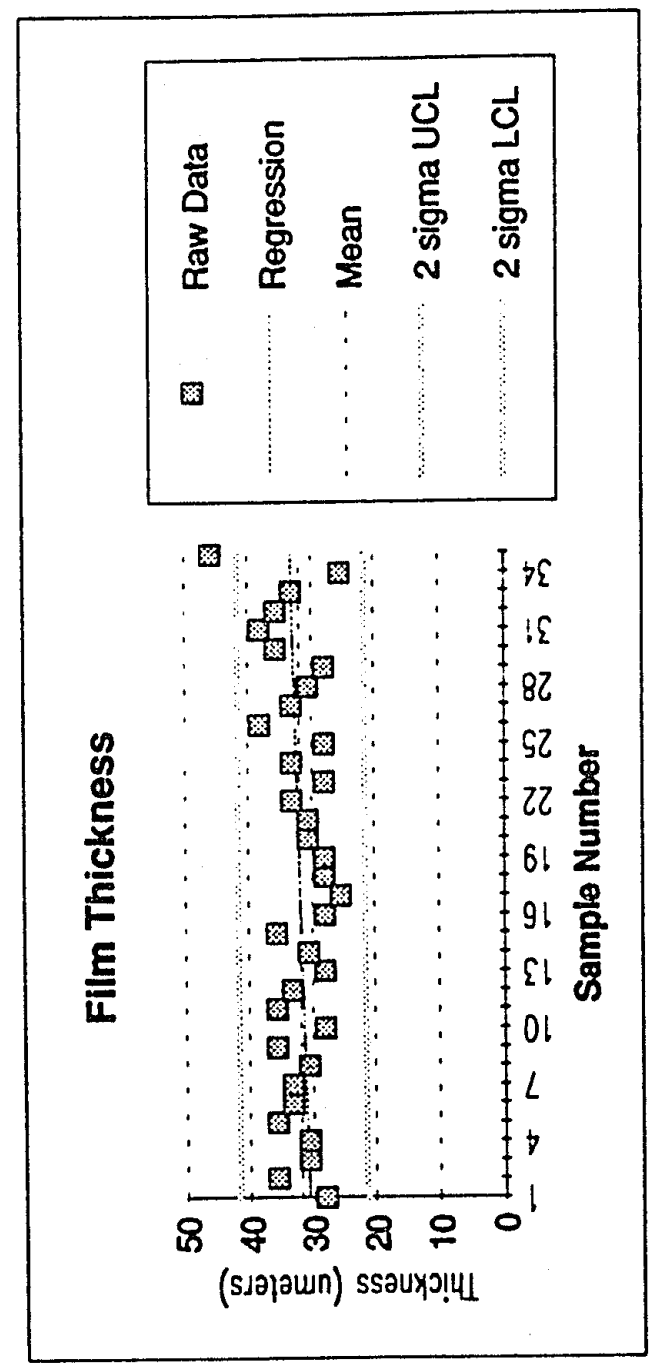

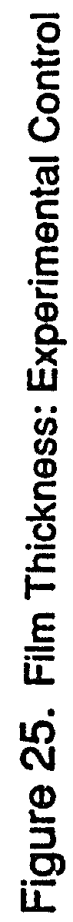


The SEM was used to evaluate the precision of the measurements taken on the film thicknesses as stated above. Photograph 25 is a cross section of the last data point on the before mentioned figure. This SEM photograph yields a 48 micrometer film thickness, which compares favorably with the 45 micrometer film thickness obtained using the outside diameter micrometer.

Another attribute worth noting is that of cohesive failures within the plastic. Peel tests on plasma etched coupons always resulted in cohesive failures within the plastic substrate. On the other hand, peel tests on chromic acid etched coupons typically resulted in incomplete cohesive failures or rather adhesive failures. Photographs 26 through 28 show this attribute. Note also that in photo 26 the edges of the coupon marked control showed partial cohesive failure. This occurred after a mistake was made when scribing peel tabs. On this specific coupon the entire peel test area was scribed just after plating per the ASTM test procedure when only the leading $15 \mathrm{~mm}$ tab should be scribed at this time. Scribing on the entire area is to be performed just prior to peel testing. See Appendix $\mathrm{A}$ for a description of scribing. The coupon was allowed to remain at ambient conditions for over $\mathbf{4 8}$ hours prior to peel testing. The photograph results show cohesive failure occurred only on the edges under the scribed area. This may suggest that oxygenation results in good adhesion, given that cohesive failures is a measure of good adhesion. 
Photograph 25. Cross Section: 45 micrometer Film Thickness
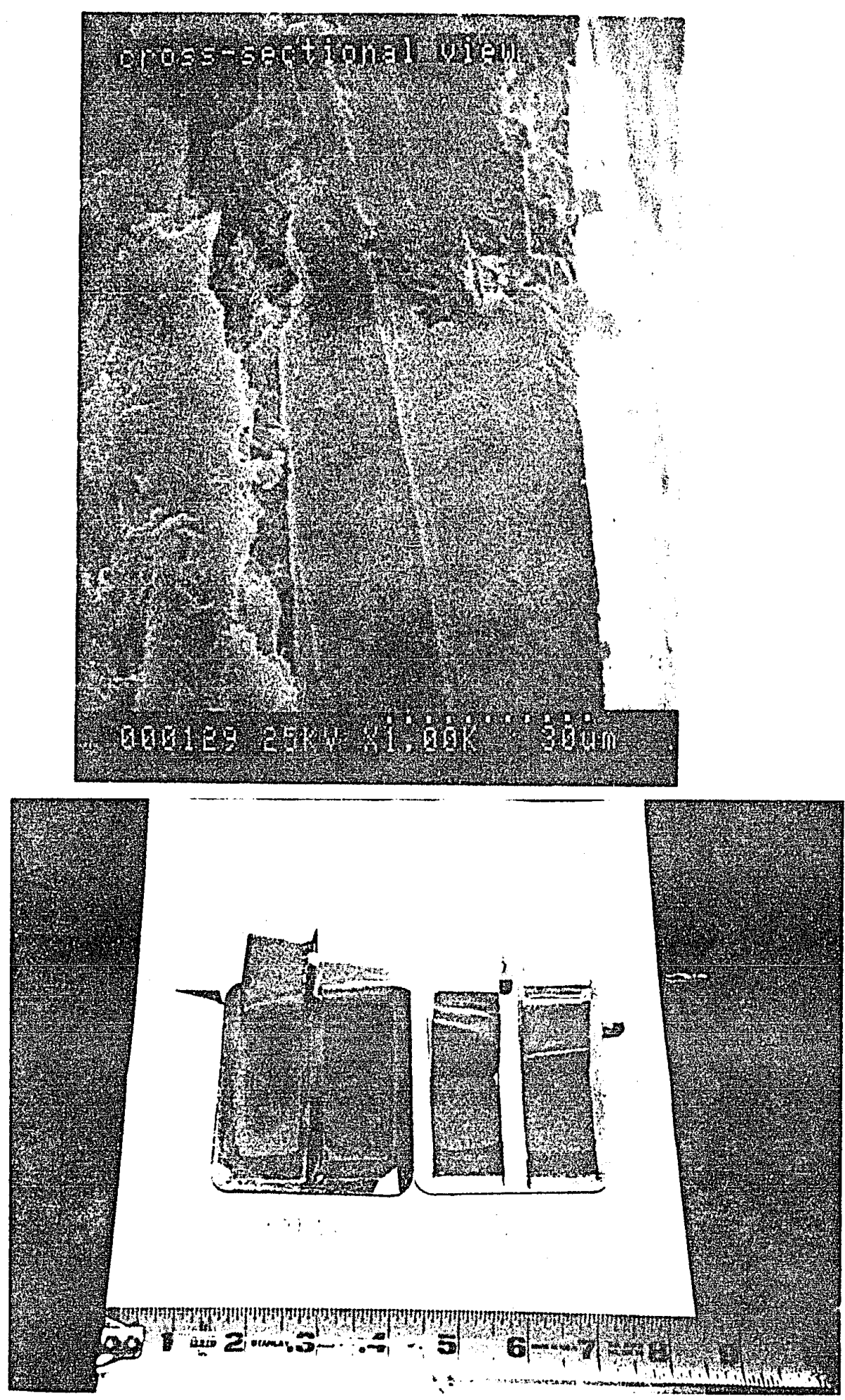

Photograph 26. Cohesive Failures: Left -- Chromic Acid; 


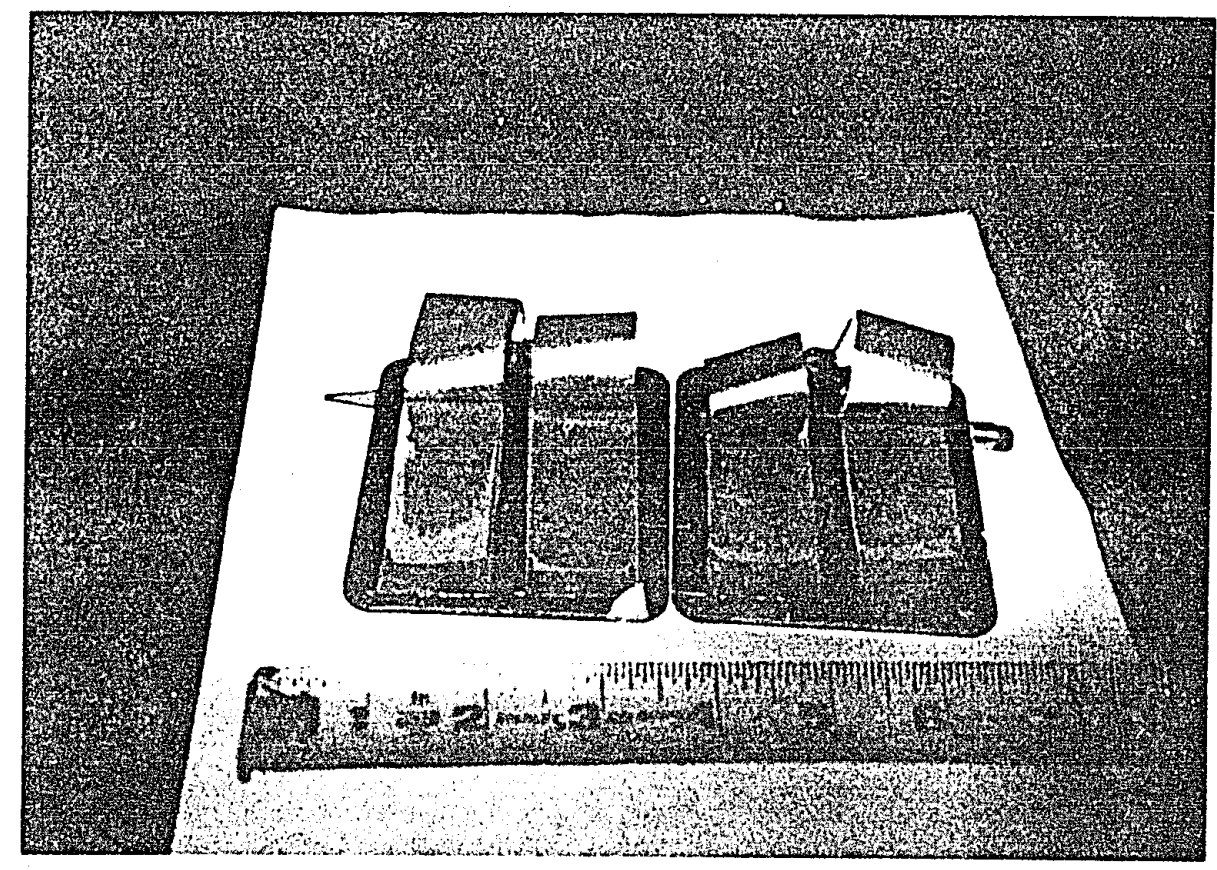

Photograph 27. Partial Cohesive Failures: Chromic Acid

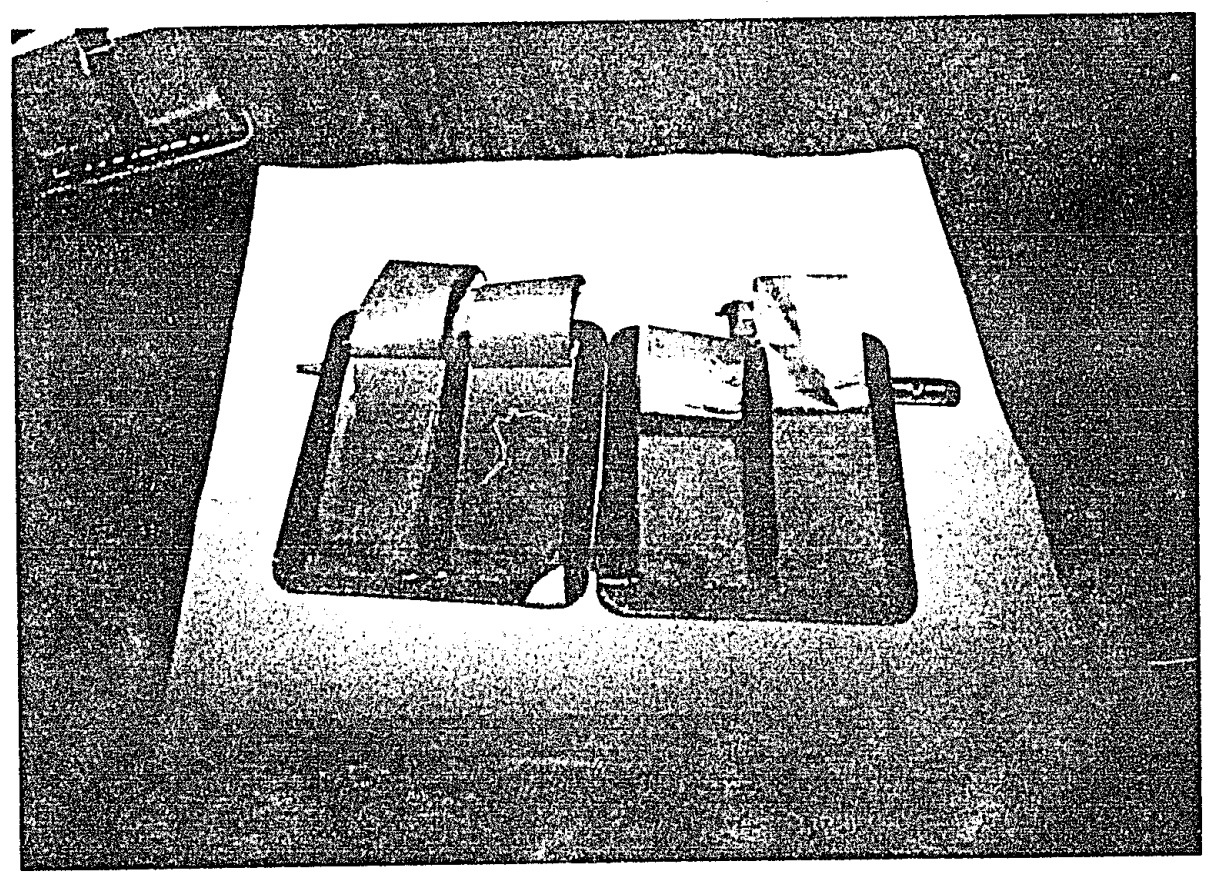

Photograph 28. Cohesive Failures: Left _- Chromic Acid; Right -- Plasma Etch 


\subsection{Repeatability and Reproducibility}

To make reasoned decisions using the peel test measurements as a basis, the degree of uncertainty of these experiments was quantified. This was done in terms of repeatability and reproducibility and standard error for the test.

Repeatability is taken to mean the random variation when all system parameters remain constant and equal for each coupon tested. Reproducibility means the systematic variation caused by differences between the plating baths, the plasma etcher, and the Sebastian $V$ peel tester.

Repeatability studies for the peel test equipment were performed. Ten coupons were prepared using the same wash method described earlier and then etched for eight minutes in the chromic acid bath, plated at 8 minutes in catalyst, 5 minutes in accelerator, 25 minutes in the electroless, and 36 minutes in the eletrolytic baths. These samples were then peel tested per ASTM B-533. This resulted in twenty tests in all as 2 peel tests, one on the right hand side and one on the left hand side, were tested. The results show that the percentage error in the testing equipment to be $3.3 \%$ of the measurement. The calculations for these results are presented in Appendix E, Table XI.

Reproducibility studies were also performed. These tests were performed on seven plasma etched coupons prepared and plated as described previously. These plasma etched samples were etched on different days and then plated on different days using new plating baths each time. See Appendix E, Table XI for these calculations. The standard error for these tests shows a sample standard 
deviation of 0.24 for peel values of $5.06 \mathrm{Kg} / \mathrm{cm}$. This represents $4.7 \%$ error of the reported peel strength. To check this result a statistical process control chart was developed from this data. The standard deviation attributed to the variation in the baths was considered to be 0.16 for peel values of $5.06 \mathrm{Kg} / \mathrm{cm}$. This represents a $3.2 \%$ error of the reported peel strength.

From the above studies, the relative error for the experiment is considered to under $5 \%$, since the largest error was $4.7 \%$ as described above. 


\subsection{DISCUSSION}

\subsection{Chromic Acid Main Effects}

The Response Graphs 9 through 12 presented in the results section show the relative magnitude of the effect of time in the acid, accelerator, catalyst and electroless plating baths on adhesion. The steeper the slope of the graph, the greater the effect of that factor. Time in the accelerator and the acid baths were the main effects. In each instance, peel strength was reduced by an increase in time in each of these baths. Ghorashi (1977) indicated that there is an interaction between catalyst and accelerator time. However, decreased time in the accelerator bath has not been reported in the literature to significantly improve adhesion. Figure 11 shows decreased time led to improved adhesion over the range investigated in this study. It is known that the accelerator removes excess tin from the sample surface which was deposited there from the catalyst bath. Excess tin must be removed to expose the Pd and thus, a predetermined time based on the ratio of catalyst to accelerator time is typically used (Krulik, 1987). Increased time in the catalyst bath appears to increase adhesion. More work would be necessary to confirm this last result. Literature suggests that there is a limit to how long samples can remain in the catalyst bath, after this optimum, extended times become detrimental to adhesion. Electroless time has a minor impact on adhesion. This last fact could be interpreted to mean that once the electroless has obtained a sufficient film thickness, additional electroless plating contributes no further value to adhesion 
The literature suggests this thickness to be somewhat greater than 2 micrometers.

As shown in SEM photographs, photographs 5-8, coupons after 2 minutes of chromic acid etching have dramatic destruction of the surface. This fact substantiates findings by Villamizer (1981). Additional etching most likely causes weakening of the substrate surface and thus leads to the lower measured peel strengths. This last fact could be verified by SEM and X-ray diffraction measurements of the backside of the peels of copper film. If the substrate was weakened then the backsides of peels etched for 8 minutes would most likely show thicker plastic layers attached than those etched for 2 minutes.

\subsection{Plasma Etch Main Effects}

An $L_{8}$ array, shown previously in Table II, was used as a design to study the effects of plasma etching on adhesion. Response Graphs, Figures 13 through 16, show the relative magnitude of the effect of each factor, flowrate, time, power, and chamber pressure, on adhesion. These graphs show that flowrate is the major factor affecting peel strength of plasma etched samples. Further, chamber pressure is considered a major contributor to adhesion, since the effect was nearly as significant as that of flowrate based on the slope of the Response Graphs. Each factor was analyzed by Larger-the-Better, and Nominal-the-Best linear graphing methods using peel strength as the response. Mixed results on time and power in the two methods of analysis, as shown in Figures 17 through 
20 , suggests that these two factors, although not independent factors, can affect peel strength through interactions. Note that each method of analysis has different scales. One must compare graphs from the same analysis method to be meaningful. On $\mathrm{S} / \mathrm{N}$ ratio response graphs changes in increments of $3 \mathrm{~dB}$ (decibels) are considered significant. Each $\mathrm{S} / \mathrm{N}$ graph has different scales since each analysis method accounts for the mean and variance differently. The meaningful results here are that power became significant in the Nominal-theBest analysis. This fact suggests that reduced variance in peel can be attained at lower power settings. This fact might also suggest that power could be an important factor in reliability or durability of the plating. The flatness on the Larger-the-Better analysis curve suggests that power is not the main effect for increasing adhesion. Refer to Section 2.4 for more information for interpreting these $\mathrm{S} / \mathrm{N}$ response graphs.

Figure 21 shows the response graphs for the interaction of flowrate with each of the other three factors, time, power, and chamber pressure, respectively. An interaction between flowrate and time was found as expected. Lower flowrates needed extended times to create the same effect. This fact means that oxidation of the surfaces could be occurring, wherein either molecular or atomic oxygen species are being used up. This fact could be verified by some additional experimentation such as X-ray Photo Spectroscopy (XPS) to determine the presence of oxygen within the substrate surface.

Factors of time and power had varying results dependent upon analysis technique used, for example Nominal-the-Best or Larger-the-Better. Time was 
important in the Larger-the-Better analysis, while power became important using the Nominal-the-Best strategy. The effect of power was described earlier. Time was important for the Larger-the-Better analysis. This suggests while time does not affect the variance of the peel strength, time was important to increasing the peel value. Here again this may be due to some chemical dependence of adhesion. These contradictory results for time and power suggests these factors are not independent. This interaction will be discussed further when discussing the confirmation run. Under traditional Taguchi analysis the larger $S / N$ values are thought to protect against noise resulting in a better product. Nominal-theBest analysis had values at least $30 \mathrm{~dB}$ higher than those determined under the Larger-the-Better analysis. This fact could be important to the durability of the plating. Reduced variance in peel strengths could arise from the mode of failure for these coupons being different. This fact should be investigated further, but is outside of this study.

The SEM photographs showed the effect of etching on substrate topography. The most noticeable effect on topography was due to chamber pressure. The low chamber pressure runs, i.e., 380 millitorr, made for a relatively smooth looking surface. This is documented by photographs $10,11,13$, and 16 . Conversely, the photographs of the high pressure runs, photographs $9,12,14$, and 15 , show a drastically modified surface. It is interesting to note that photographs 13 and 14 are dramatically different in appearance but had nearly identical peel results. In fact, these two samples resulted in two of the top three peel test results. The conditions under which these coupons where etched were the same for flowrate and time, $80 \mathrm{ml} / \mathrm{min}$. and 5 minutes, but different for power 
and chamber pressure. Photograph 13 was etched at 200 Watts and 480 millitorr while photograph 14 represents 50 Watts and 380 millitorr.

\subsection{The Confirmation Run}

If each factor were selected for the best signal-to-noise ratio, what would the effect be on ultimate peel strength? This question can be answered by Taguchi methods using a simple formula for prediction of ultimate peel strength based on experimental results. The predicted result is compared to the appropriate experimental result in what is termed a confirmation run. The Factor Setting used during the confirmation experiment are chosen as those expected to give the highest response, here peel strength. The Factor Settings are based on the results of the various analysis methods used to interpret the experimental data. For these calculations, the assumption is made that each factor is independent. Factors that are not independent will change the confirmation experimental response from the predicted value in a positive or negative way. Table $X$ shows the predicted results and actual results of confirmation run(s) performed under both the Nominal-the-Best and Larger-the-Better techniques. Both methods resulted in experimental peel strengths of approximately $5.10 \mathrm{Kg} / \mathrm{cm}$. Peel strength is reported in $\mathrm{Kg} / \mathrm{cm}$, where $\mathrm{Kg}$ is a force element. This result was greater than the $4.70 \mathrm{Kg} / \mathrm{cm}$ predicted. Better than predicted results are not uncommon in Taguchi experiments since factors often are not independent. Since these confirmation experiments had results higher than predicted, it can be said that the main effects of flowrate and chamber pressure 


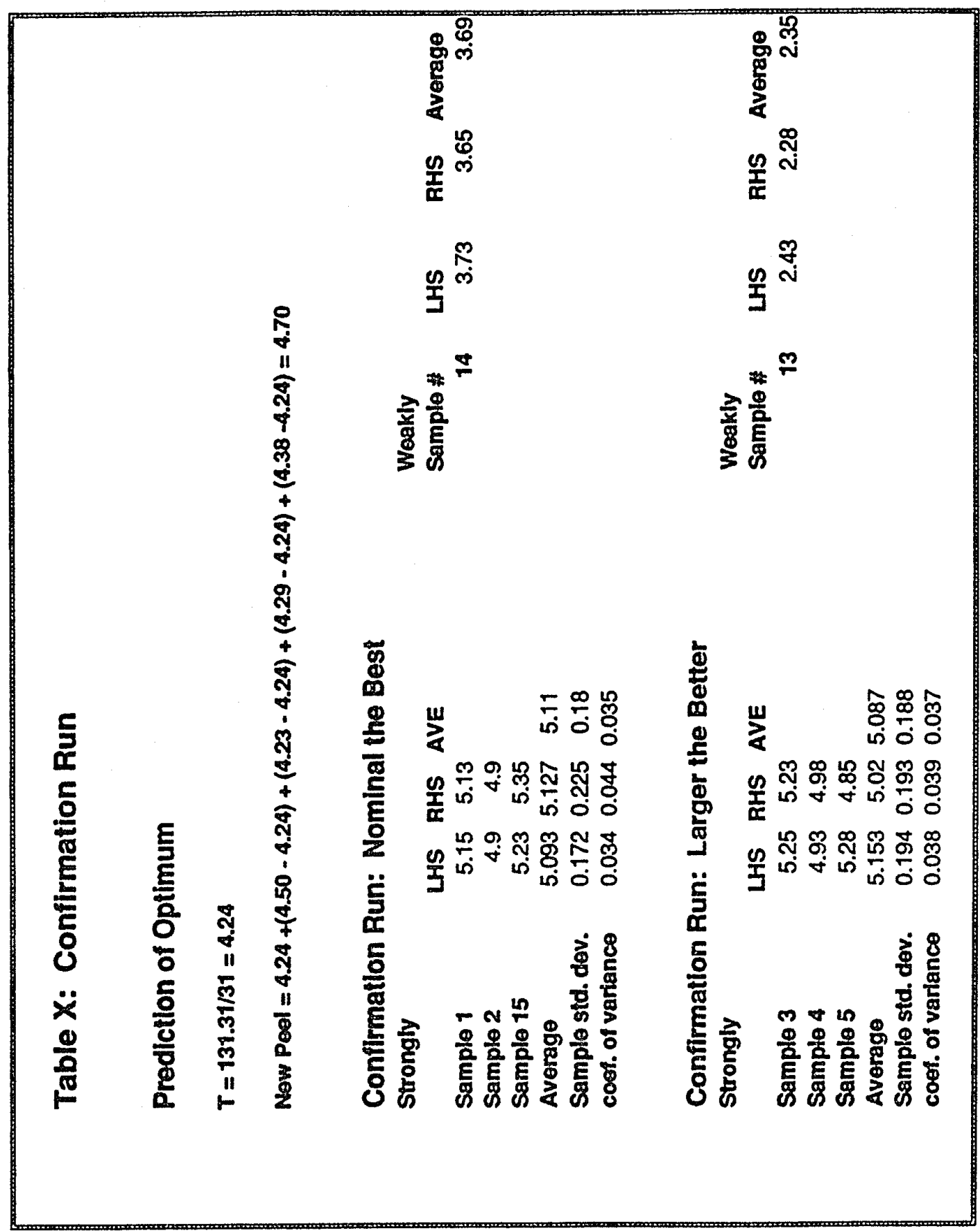


are significant, but that there was an added benefit from some interaction, most likely from power and time, as will be explained below. This other interaction helped give better than predicted results. The low variance between experiments, i.e., from batch run one through batch three, indicates good reproducibility; the variance between experiments was lower than 5 per-cent. The three runs under each condition resulted in good results and thus confirmed the experiment. What is meant by this confirmation statement is that flowrate and chamber pressure are the most significant factors influencing adhesion. For example, the average for all plasma etching experiments investigated was 4.24 $\mathrm{Kg} / \mathrm{cm}$. However, by predicting optimal setting and then using those settings to obtain peel strengths, the peel strength was improved to over $5 \mathrm{Kg} / \mathrm{cm}$, a 15 per cent improvement over peel values obtained from samples etched based on the original orthogonal array. An important fact can be noted when viewing the confirmation run result of the weakly suggested factors. These weakly suggested factors are the opposite levels than those chosen for the confirmation experiments described above. In Taguchi analysis, weakly suggested means selection of the factors that should give the poorest result in peel strength. The confirmation run based on weakly suggested experiments indicated that power is indeed an important factor. Power was the only factor different in each type of run. For example, the sample $\# 13$ from Table $X$ had results 36 per cent lower than sample \#14. To check for the role of power in adhesion, an interaction table and graph using the other suggested interaction triangular table was evaluated. Figure 26 shows this result. The only interaction that is different from those previously looked at is the interaction: time versus power. The linear graph confirms that these interact strongly. It was for this reason, 10 


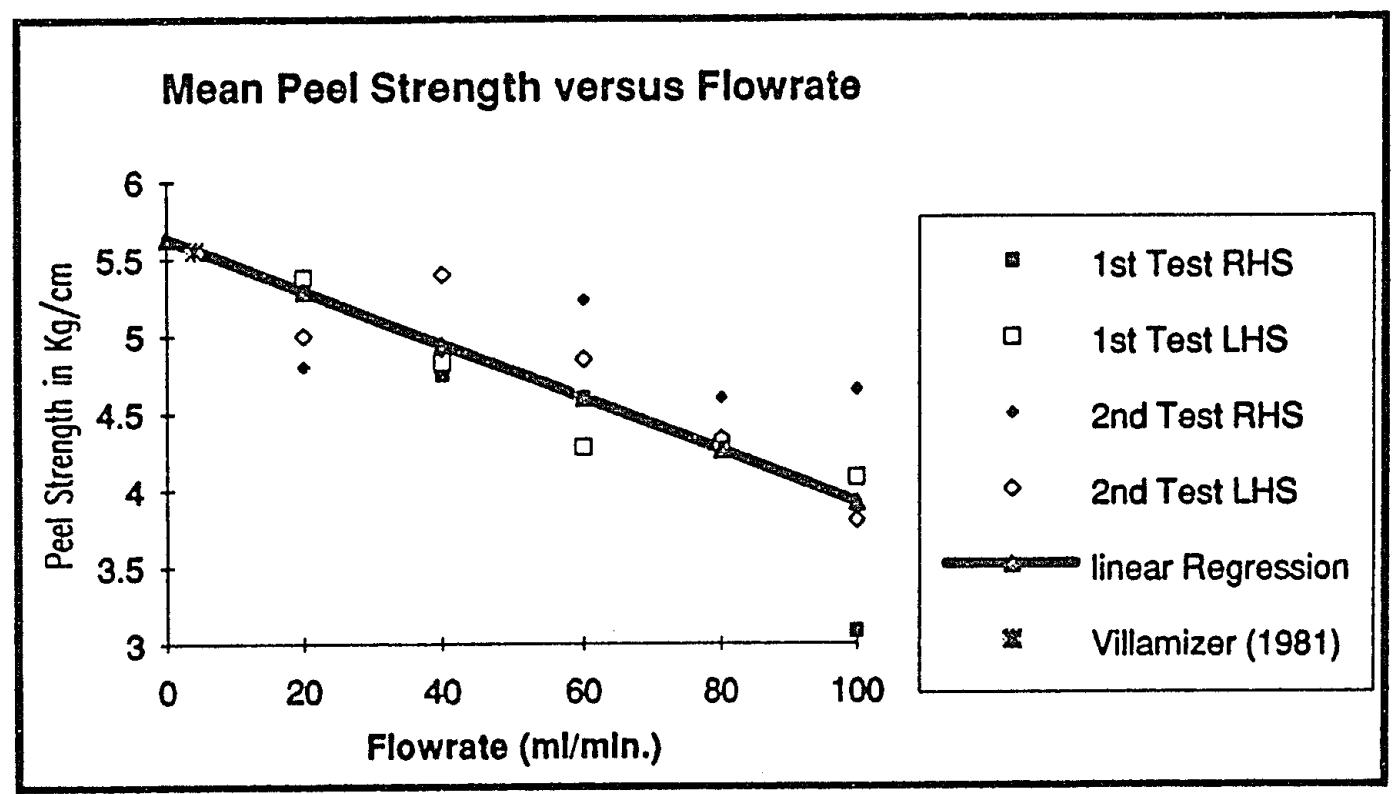

Figure 27: Flowrate Versus Adhesion: Calculated Results 
minute etch times were selected for additional one variable testing to be discussed later.

\subsection{One Variable Testing: The Main Objective}

As defined by the previously mentioned experiments, it was established that flowrate and chamber pressure were the main plasma factors that influenced adhesion. Thus, these effects were studied in more detail using traditional one variable experimental techniques.

The results of the one variable tests were presented in Section 5.6. Results indicated that flowrate was the main factor affecting peel. This effect can be quantified since the linear regression was closely correlated, correlation of -0.99 . A least squares analysis of this data would be:

$$
\text { Where: } \quad \begin{aligned}
& y=0.0171 x+5.628 \\
& y=\text { peel strength in } \mathrm{Kg} / \mathrm{cm} \\
& x=\text { oxygen flowrate in } \mathrm{ml} / \mathrm{min} .
\end{aligned}
$$

This equation is valid under these conditions: 10 minute etch time, 50 Watts RF power, and 380 millitorr chamber pressure.

A graph of this equation along with data obtained from this study and from that of Villamizer (1981) is shown in Figure 27. It is noteworthy that results from 


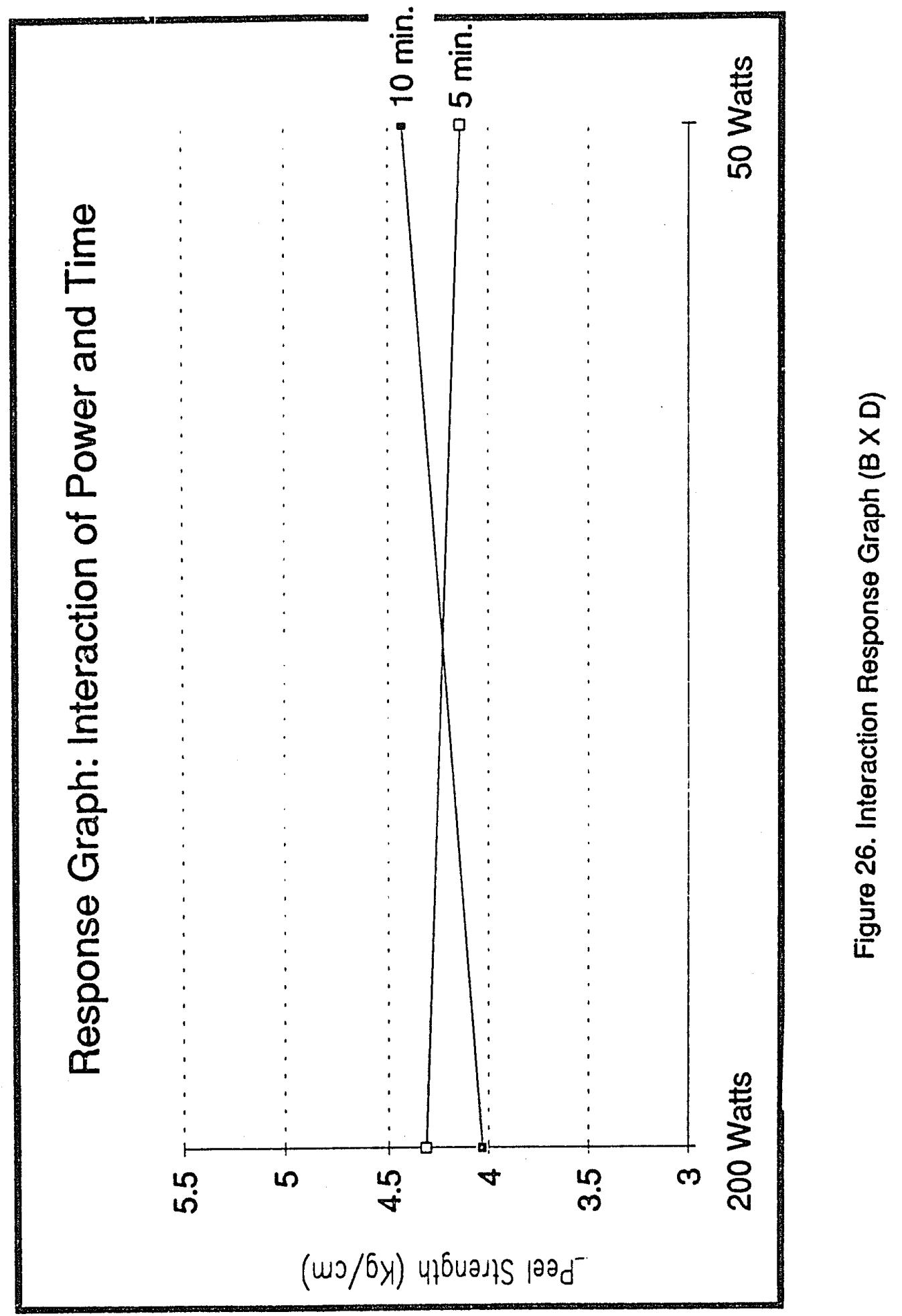


Villamizer in 1981 fit the above correlation. This equation is useful to predict the effect of flowrate under the conditions stated above.

At relatively high flowrates, $80 \mathrm{ml} / \mathrm{min}$., increased adhesion was related to a decrease in chamber pressure. The correlation between adhesion and pressure was one of the main objectives of this study. The correlation coefficient for the average of four experiments was -0.94 . Although not as good as the flowrate correlation, it is adequate to describe the results obtained. No equation was generated since the $y$ intercept was not repeatable. The $y$ intercept was not repeatable most likely since the power level was low, 50 Watts. Experiments at power levels over 125 Watts could confirm this hypothesis.

Results of the $20 \mathrm{ml} / \mathrm{min}$. testing showed adhesion peaked at 270 millitorr. Attempts to fit the data to linear, power, and exponential functions ended with poor results. The SEM photos revealed topography comparable to that from the results shown in photograph 15 . This topography was one which looks as though the plastic surface is melted. The conditions under which this sample was etched resulted in high peel strength results. At chamber pressures less than 270 millitorr, either a point of unsaturation occurred where-in the etching was dramatically changed or some other phenomena occurred. It is interesting that SEM photographs from the varied flowrate experiment, namely those for flow of $40 \mathrm{ml} / \mathrm{min}$. and $20 \mathrm{ml} / \mathrm{min}$., showed the same kind of appearance as those done under these conditions. This characteristic is that the surface appears dirty. This dirty appearance could be from polymeric material reforming on the surface since the flowrate is not large enough to sweep the surface of 
these species. Another possibility is that the flowrate is too low and therefore unsaturated radical species from the surface recombine with the surface to form a film such as described by Flamm (1981). Further testing would have to be performed to verify this unsaturated condition or other phenomena. Since these samples were etched at 50 Watts further tests should to be performed at 125 Watts or higher. This starting point for further testing is suggested by the interaction between power and time pointed out in section 6.4. 


\subsection{CONCLUSIONS}

Taguchi methods were useful in establishing plating conditions using industry standard plating baths. Times within the plating baths were standardized to obtain good and repeatable peel strength results. The results indicated that peel strength increases with decreased time in the chromic acid bath, as well as, decreased time in the accelerator bath. In addition, an interesting interaction between time in the accelerator and time in the catalyst bath was discovered.

Four plasma etch parameters, oxygen flowrate, time, RF power, and chamber pressure were varied to determine each parameter's role in modification of the plastic (ABS) surface. Taguchi experimental design was employed to establish trends and set etching conditions for satisfying the main objective. The main objective was to establish how plasma etching conditions affect adhesion. Taguchi statistical methods have not previously been used in this application. Results showed that ultimate peel strength is effectively increased by a reduction in flow rate. A mathematical correlation was determined for this relationship within the investigated etching regime. A correlation between flow rate of oxygen and the number of pores per unit area on the substrate was noted. It was also determined that peel strength is somewhat increased by a reduction in chamber pressure.

Taguchi methods were useful in determining the main objective of relating plasma etch conditions to adhesion. The complete study found that each etch method, chromic and plasma, produced good adhesion results, better than 4.0 
$\mathrm{Kg} / \mathrm{cm}$, but with different topography. On chromic acid etched coupons, the topography which met the critical pore size requirement, but had the least amount of surface damage, gave the best result for this etch method. Similarly, good adhesion on relatively smooth surfaces for plasma etched samples gave good results. Some plasma etched samples which gave better than $4.0 \mathrm{Kg} / \mathrm{cm}$ peel strengths had topography outside of the critical pore size region. This fact leads to the conclusion that mechanical interlocking in the reported critical pore size regime may not necessarily be the only factor for high quality plating on plastic. This fact might have been over looked if a more traditional method of experimental design was used. That is, previous to this study mechanical interlocking was considered the most important factor influencing adhesion. Therefore, maximizing this interlocking seemed the best course to study. To do this, chamber pressure experiments alone would have been initially attempted to duplicate chromic acid topography with plasma etched coupons. Duplicated topography may have produced good adhesion; however, the fact that flowrate was an important factor in achieving good adhesion would not have been determined through these chamber pressure experiments. Further, though the used of Taguchi design, it was found that excellent adhesion results for plasma etched samples can be found outside of the previously believed necessary critical pore size region. 


\section{REFERENCES}

1.) Krulik, G.A., Electroless Plating of Plastics, Journal of Chemical Education, Volume 55, No. 6, June 1978, p. 361-365.

2.) Jameson, M.N., New and Improved Pre-plate Chemicals and Technology, A.S.E.P. Sixth Annual Conference of the American Society of Electroplated Plastics, Nov. 10, 1973.

3.) Saubestre, E.B.; Hajdu, J.; Leibowitz, G., The Nature of the Corrosion of Electroplated Plastics, Plating, Oct., 1968, p. 341346.

4.) Brockmann, W., Durability of Adhesion Between Metals and Polymers, Journal of Adhesion, 29 (1989) pp 53-61.

5.) Hansen, G.P.; Rushing, R.A.; Warren, R.W.; Kaplan, S.L.; Kolluri, O.M., Achieving Optimum Bond Strength with Plasma Treatment, Society of Mechanical Engineers Technical Paper AD89-537 (1989).

6.) Villamizar, C.A.; Rojas, J.; Frias, P.; Chemical Etching Versus Plasma Etching in Electroplating ABS Resin Surfaces, Metal Finishing, 3 (1981) pp 27-33.

7.) Chapman, B., Glow Discharge Processes, John Wiley and Sons, New York 1980.

8.) Hollahan, J.R.; Bell, A.T., Techniques and Applications of Plasma Chemistry, John Wiley and Sons, Inc., New York 1974.

9.) Poa, S. P.: Wan, C. C.: Wu, C. J.; A Study of the Etching Effect in the Metal-to ABS Surface Adhesion in Electroless Plating, Metal Finishing, August, 1977.

10.) Heymann, K.; Reidel. W.; Woldt, G.; Electroplating of Plastics in Theory and Practice, Agnew. Chem. internat. Edit., Vol. 9, No. 6, 1970 , p. $425-433$.

11.) H. M. Ghorashi, Chromium Affects Metal Polypropylene Adhesion, Plating and Surface Finishing, April (1977). 
12.) Kaplan, S.L.; Rose, P.W., Plasma Surface Treatment of Plastics to Enhance Adhesion: An Overview, Plasma Science Technical Notes, No. 9 (1990).

13.) Ho, P.S., Chemistry and Adhesion of Metal -- Polymer Interfaces, Applied Surface Science 41/42 (1989) pp 559-566.

14.) Hall, J.R.; Westerdahl, C.A.L.; Bodnar, M.J.; Levi, D.W., Effect of Activated Gas Plasma Treatment Time on Adhesive Bondability of Polymers, Journal of Applied Polymer Science, Vol. 16 (1972) p. $1465-1477$.

15.) Flamm, D. L.; Donnelly, V. M., The Design of Plasma Etchant, Plasma Chemistry and Plasma Processing, Vol. 1, No. 4, 1981 pp 317-363.

16.) Mance, A. M.; Waldo, R. A. Dow, A. A., Interactions of Electroless Catalysts with Plasma-Oxidized Surfaces of Polystyrene-Based Resins, J. Electrochem.. Soc., Vol. 136, No. 6, June 1989. 


\section{APPENDIX A}

\section{Description of Equipment and Procedures:}

\section{Sebastian Five}

The Sebastian Five is a simple and precise system for strength testing of materials. The basic load application system is contained entirely within an instrument enclosure. All tests, as with this experiment, are completed using a variety of interchangeable platens which are installed atop the pull stack of the instrument.

Electrically the unit has been modified to contain a precision linear potentiometer and electronic circuitry which are capable of continuously measuring the travel of the lower platen. A DC output jack in the back of the unit can be used to monitor the output voltage. An output voltage of $0-10.00$ VDC represents $220 \mathrm{Kg}$.

Plotting of the peel strength tests was readily accomplished by connecting the two output jacks in the rear panel to a high impedance $X Y$ recorder. Unfortunately, the Sebastian Five unit at the school did not include a micro-range feature available through the vendor. Without the micro-range feature the machine could only record the maximum attained peel value. Other words, 
continuous peel values were recorded until an ultimate value was attained, after which no lesser value was recorded.

Mechanically all peel tests were executed using a "Gallows Structure," which was attached to the side of the Sebastian Five via two self-retaining thumb screws. A the top of the gallows is a German Wheel. The purpose of this wheel is to take up the peel at a precisely measured rate, here 1 inch per minute. The sample is mounted on a sliding stage. This sliding stage is installed into the gripper part of the tower. The tower contains the load cell which measures the resistance from the film as it is being pulled normal to the surface. The slide moves to keep the film peeling edge perpendicular to the gallows structure.

\section{ASTM Procedure B 533-85: Standard Test Method for Peel Strength of Metal Electroplated Plastics}

Summary: A properly prepared standard test specimen called a coupon, is copper plated. The plated coupon is either tested as is, or it is conditioned by a low-temperature bake and then tested. The coating is cut through to the plastic substrate using a sharp chisel or knife (a Stanley knife was used) in a way that forms two strips of coating (See Figure 1. Appendix A) An approximate $15 \mathrm{~mm}$ tab is peeled back on the strips at the end adjacent to the mold tab. 3M number 250 tape was applied to the tab. The free end of the tape was inserted into the take up slot on the German Wheel. Each strip is peeled from the substrate at a right angle using an instrument that indicates the force required to separate it 


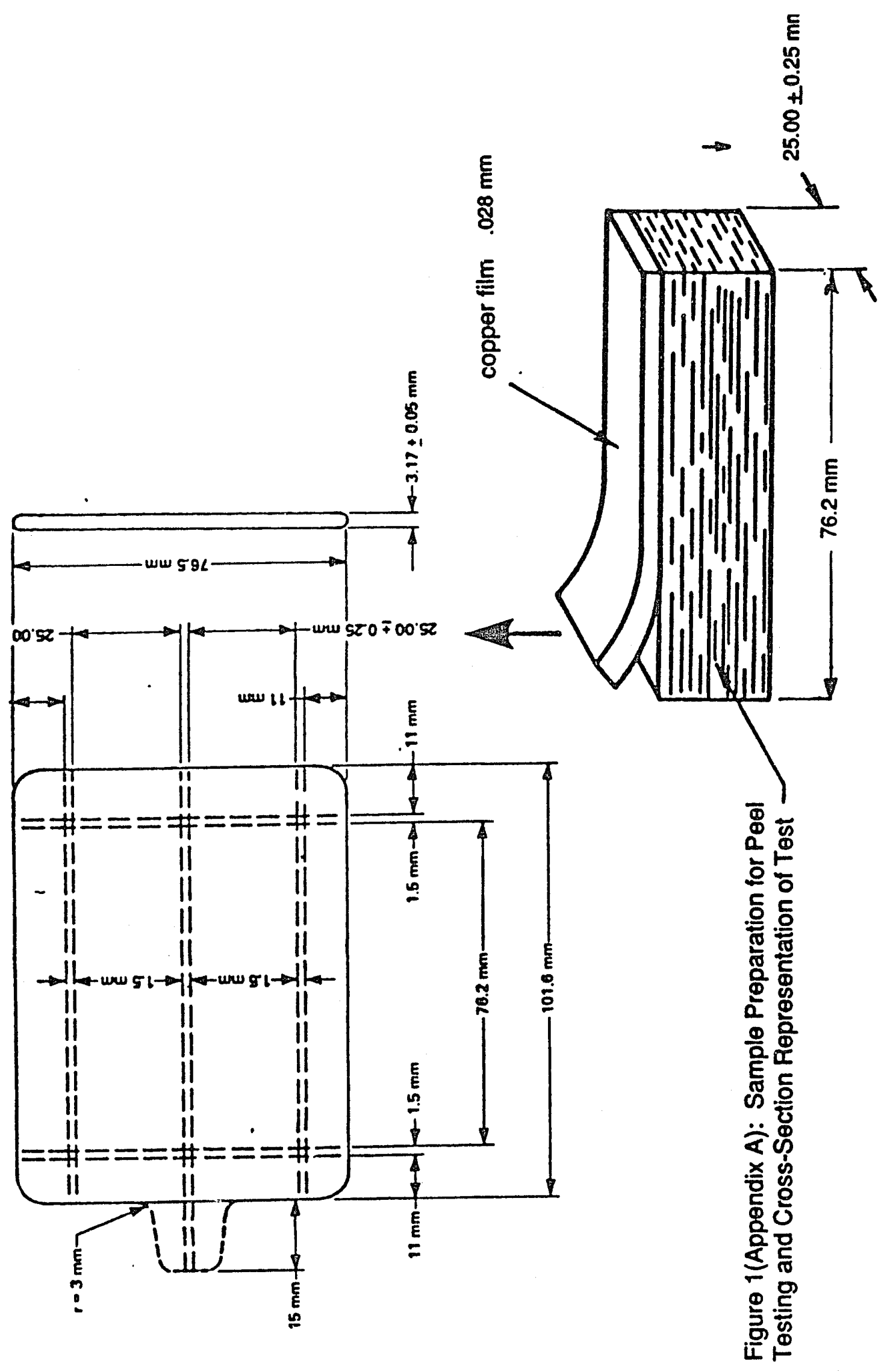


from its substrate. The speed of separation of the crossarms of the machine shall be adjusted to give a separation rate of $25 \pm 3 \mathrm{~mm} / \mathrm{min}$. The machine shall automatically and continuously record on a chart the load on one coordinate. The test is repeated on each strip, called in the experiment RHS and LHS, respectively. The amount of peel was obtained from calculations using a known chart speed. $70 \%$ of the length of the copper strip must be pulled without tearing in the copper film to be considered a valid test.

\section{March CS 1701 Plasma Etcher}

The CS-1701 plasma system is a parallel plate/Reactive Ion Etcher. It consists of two modules: the main unit and the solid state RF generator. The chamber internal dimensions are $254 \mathrm{~mm}$ Dia. X $38 \mathrm{~mm}$ high and will hold up to one $150 \mathrm{~mm}$ wafer. It is constructed of hard anodized aluminum and has a ceramic ring which concentrates the plasma on the bottom electrode.

The CS-1701 comes equipped with Z80 based computer which controls all of the processing functions, the system has 8 analog channels which control the 6 gas channels, the Pressure, and the RF Power. These process parameters are programmed by the front panel. 
Operation of the CS 1701 plasma system uses a 11 CFM vacuum pump. This pump was capable of pulling down to approximately 40 millitorr pressure with no gas flow load. The machine had an independent pressure feature which as a bleed line from the chamber to the suction side of the vacuum pump. There were limitations to the effectiveness of this feature. For example, at flow rates of $100 \mathrm{ml} / \mathrm{min}$. the pressure could be controlled between 350 and 580 millitorr. At $20 \mathrm{ml} / \mathrm{min}$. the chamber pressure could be controlled at 150 to 380 millitorr. The RF generator had a 600 Watt maximum at a constant $13.56 \mathrm{MHz}$. The generator was run at 200 and 50 Watts in the experiment and had a maximum of 2 Watts reflective power. 
APPENDIX B

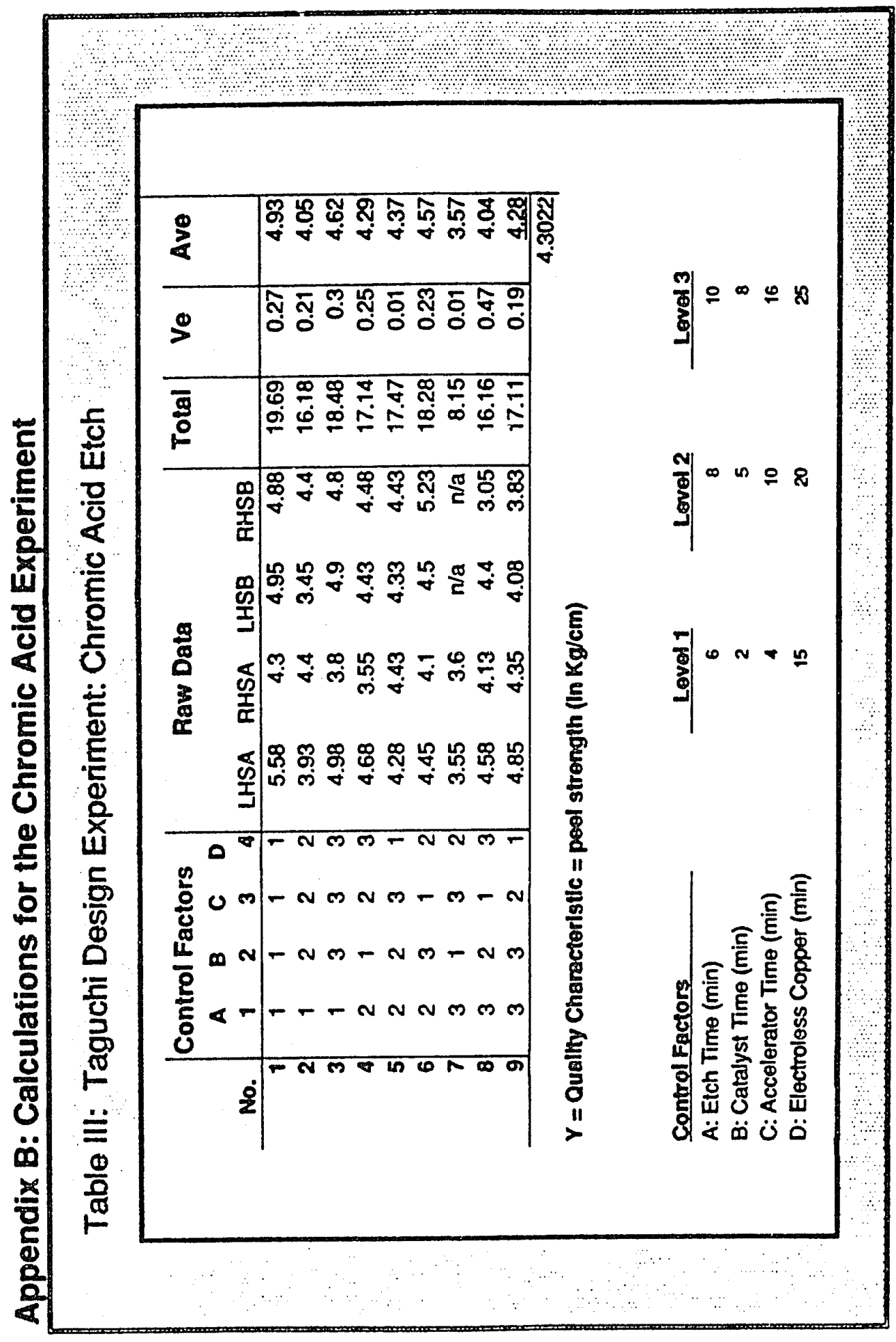




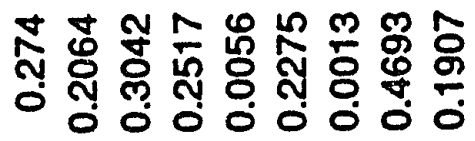

" " | " | " ติ ติ $\widehat{ต}$ ติ ง ตั पं \% \&

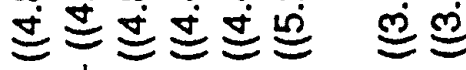
$++++++t+$

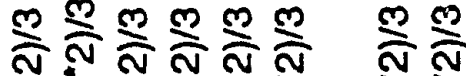

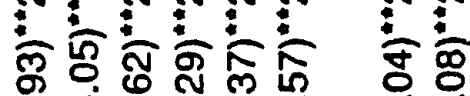

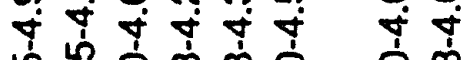
녕요용 용 过包过导 $++++++1+t$

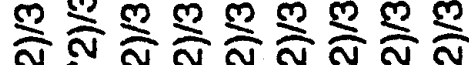
:

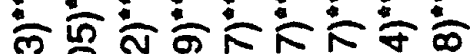

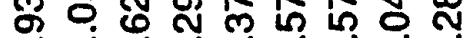

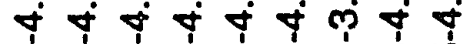

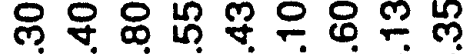

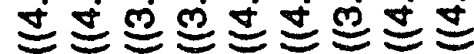
$++++++++t$

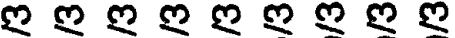
ลิ่ ลิ่ ลิ ลิ ลे

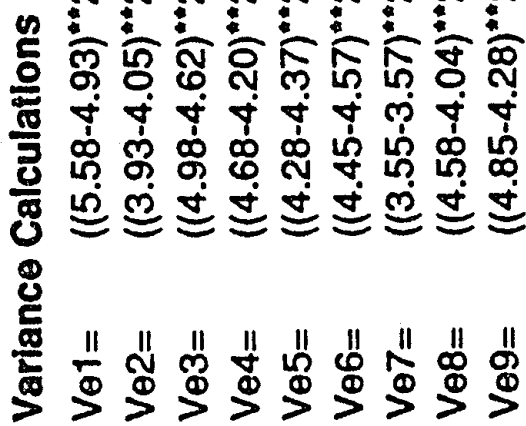



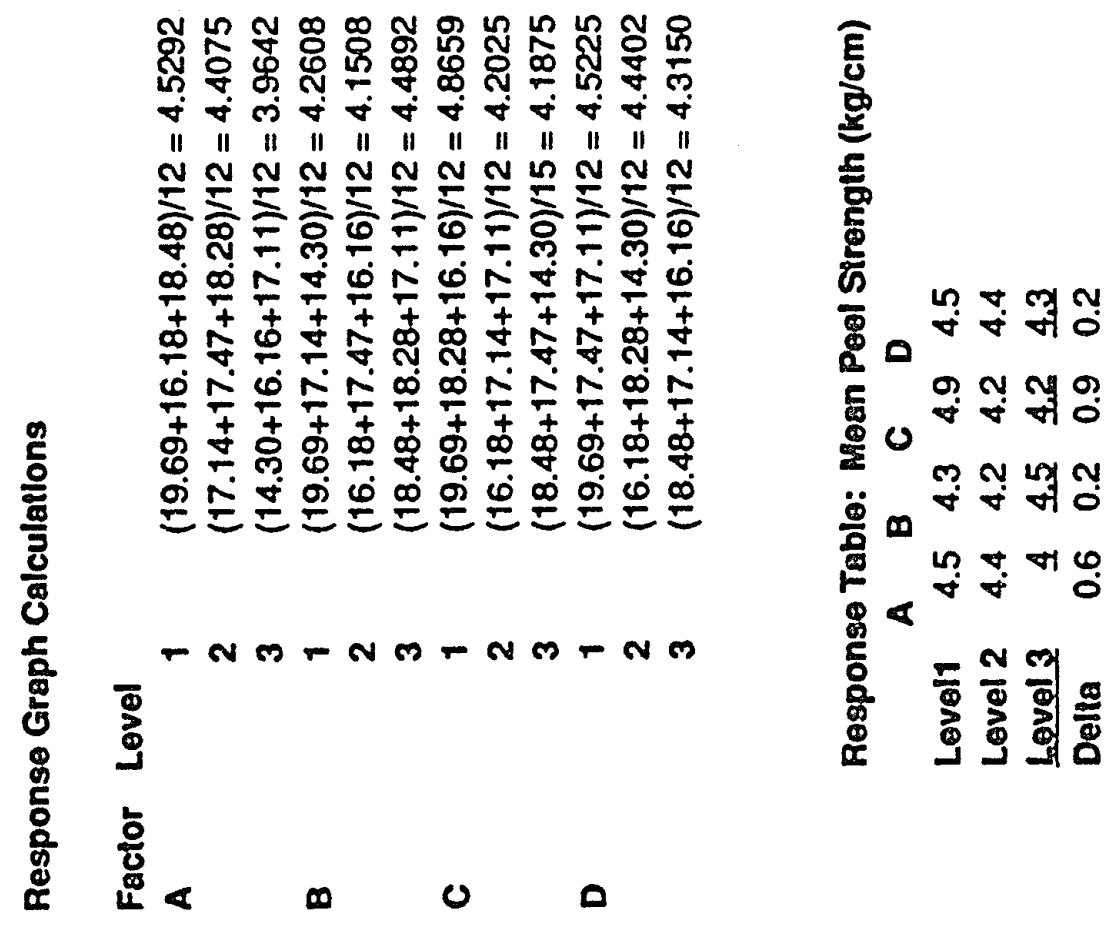


\section{APPENDIX C}

\section{Taguchi Methods}

In the preliminary design of a Taguchi experiment, a standard fishbone diagram, called a cause and effect diagram, is the most useful manner in which to generate a listing of factors to test. Initially, attempts were made to obtain plasma etched ABS topography that duplicated the chromic acid etched ABS topography, since previous work showed good results by doing so (Villamizer, 1981). To effectively etch the surface means to select factors, such as chamber pressure, which will most likely modify the surface by physically impacting the surface with high speed (energy) atoms or molecules. Plasma etching of a surface can be visualized by thinking of a meteor impacting the surface of the moon and leaving a crater.

Let's look a Figure 1C. Keeping with the theory that factors modifying the surface the most, lets choose these factors. Time has been attributed to increased ablation as is the factor RF Power. Chamber pressure has been attributed to increased etching through reduced mean free path and reactive ion etching. These factors seem most important for effective etching given our initial theory. All factors available were used initially since it was deemed necessary to establish the range of each factor within the plasma etcher capabilities.

Let's look at Table V. The control factors tested are listed in the lower left. The levels used are also listed in the lower left. The levels used are also listed 
there. The orthogonal array indicates the experiment number, the control factor and the levels used in each experiment. Also listed in the array are the peel strength results for 4 peel tests, the total, the variance, the mean peel strength, the sensitivity and the $\mathrm{S} / \mathrm{N}$ ratios for Larger-the-Better and Nominal-the-Best analyses. The calculation for these results follow the orthogonal array, Table V. 


\section{The Cause and Effect Diagram for the Experiment}

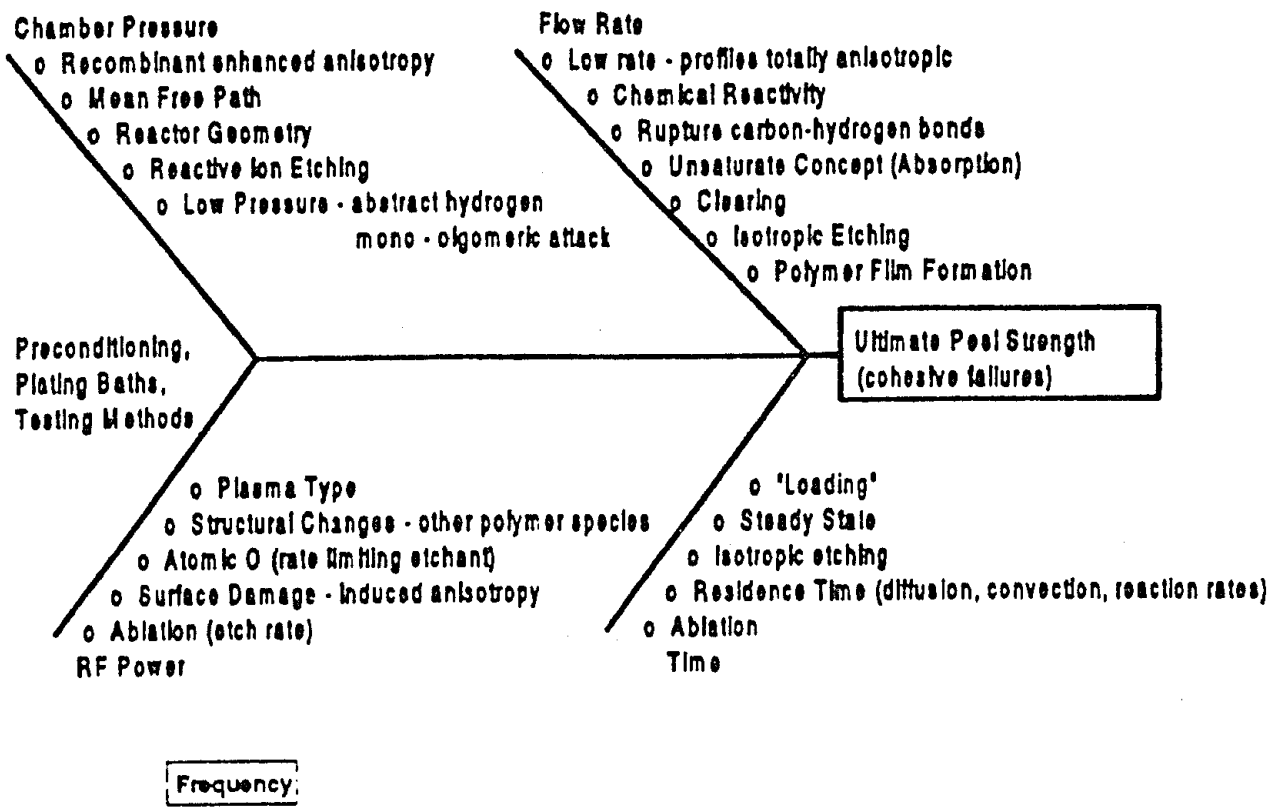

Figure 1C. Cause and Effect Diagram 


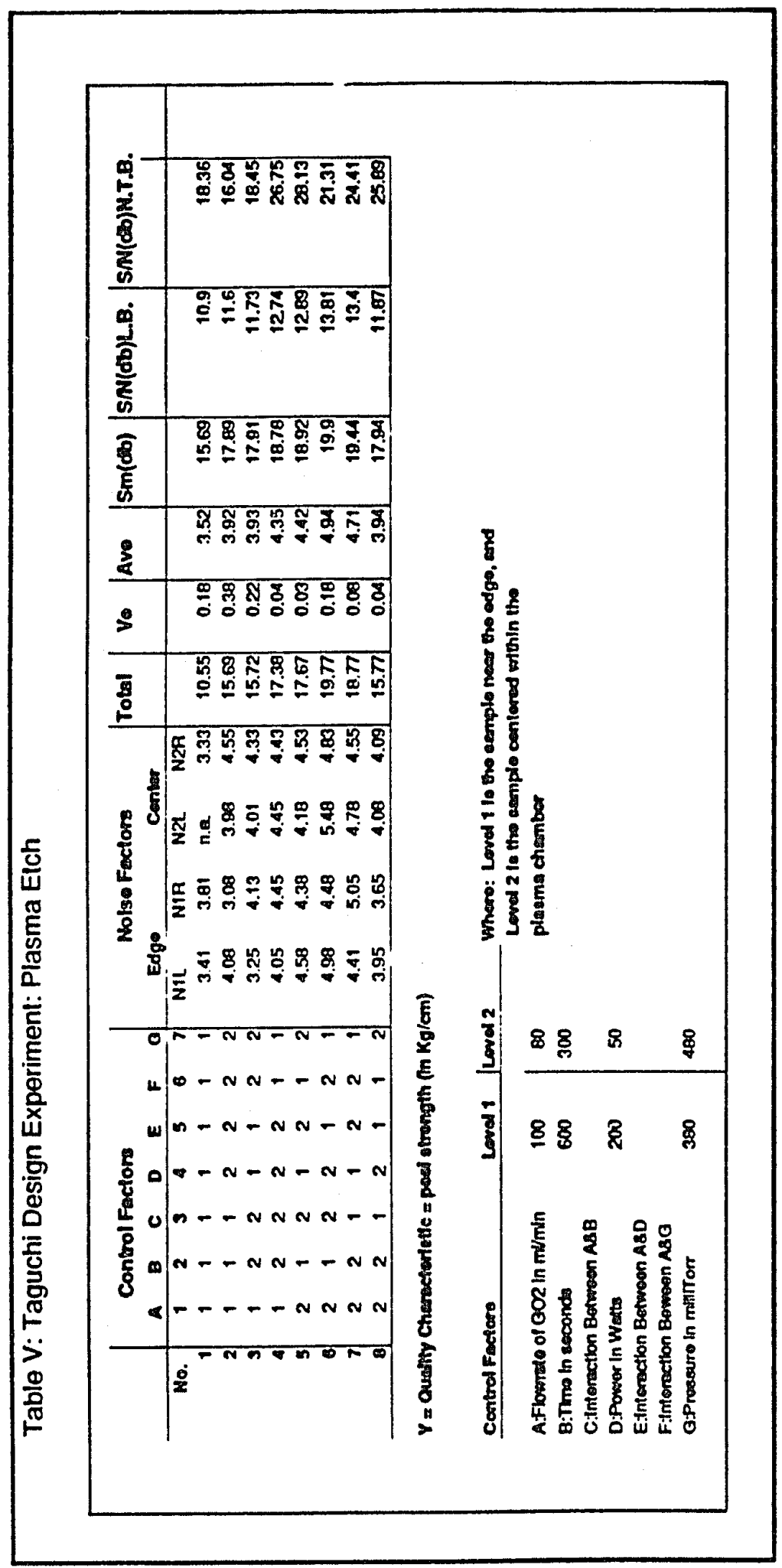




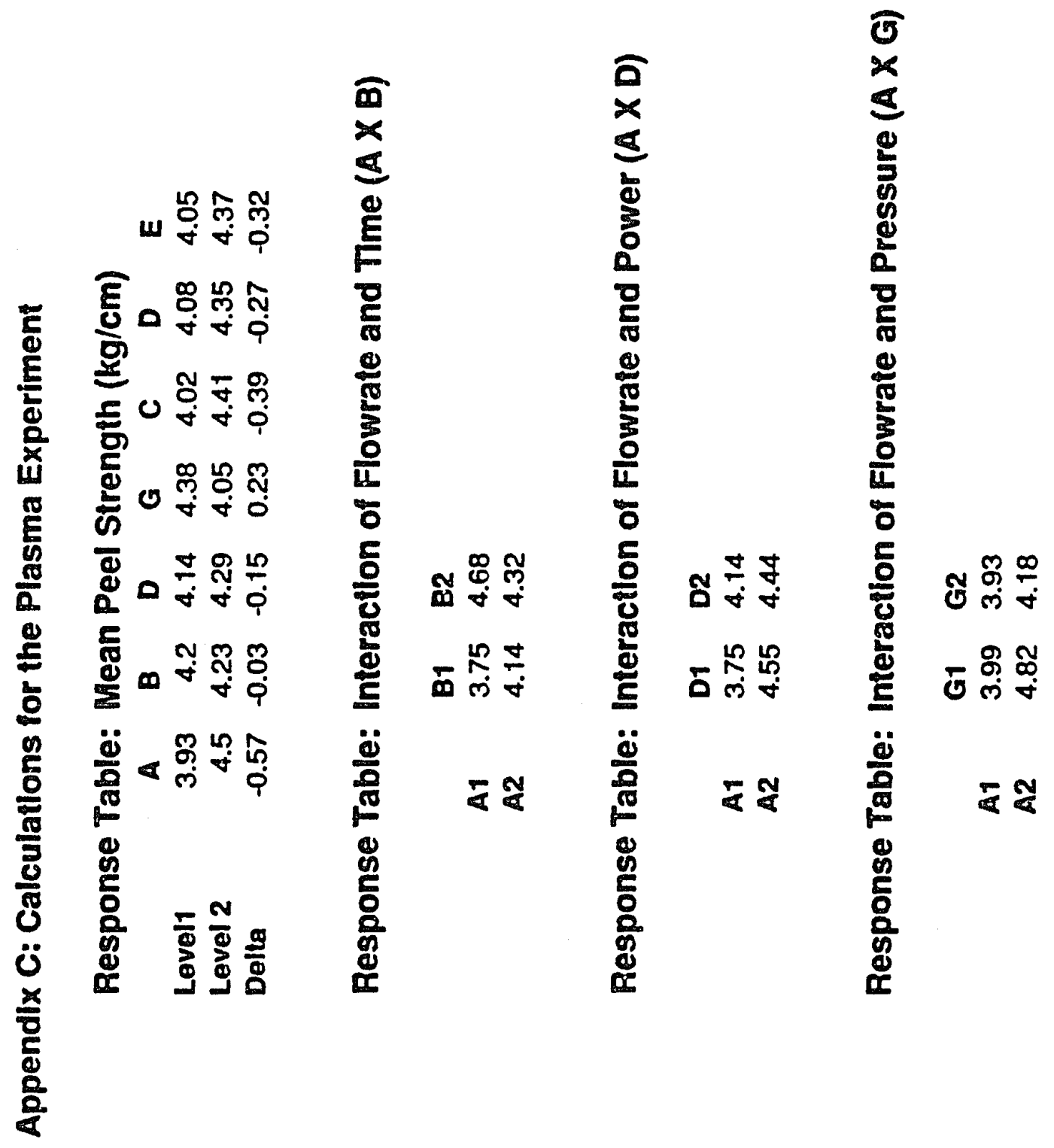



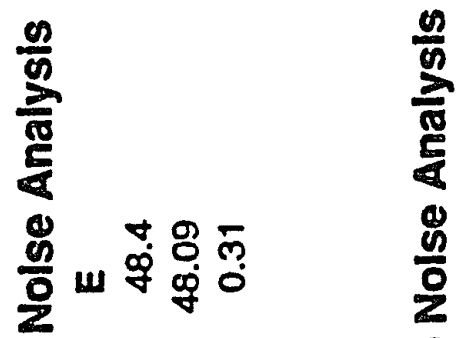

응ำ

कू

कण 0 की

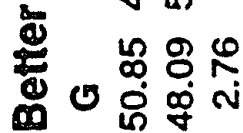

E $\pi \delta \Leftrightarrow$

-

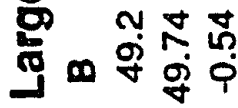

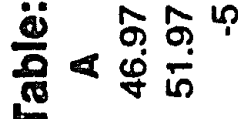

品

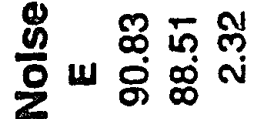

응

ब田

등 芯吉

की

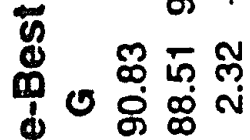

స

드잉

ह0

ஹ

吕

范

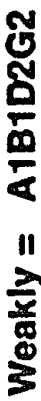

ญั

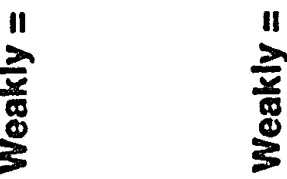

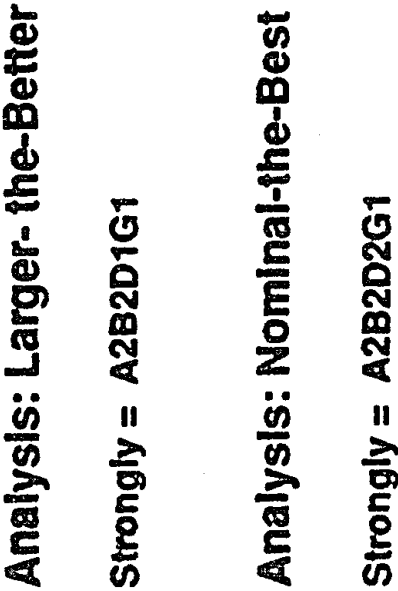

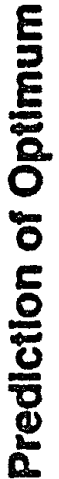




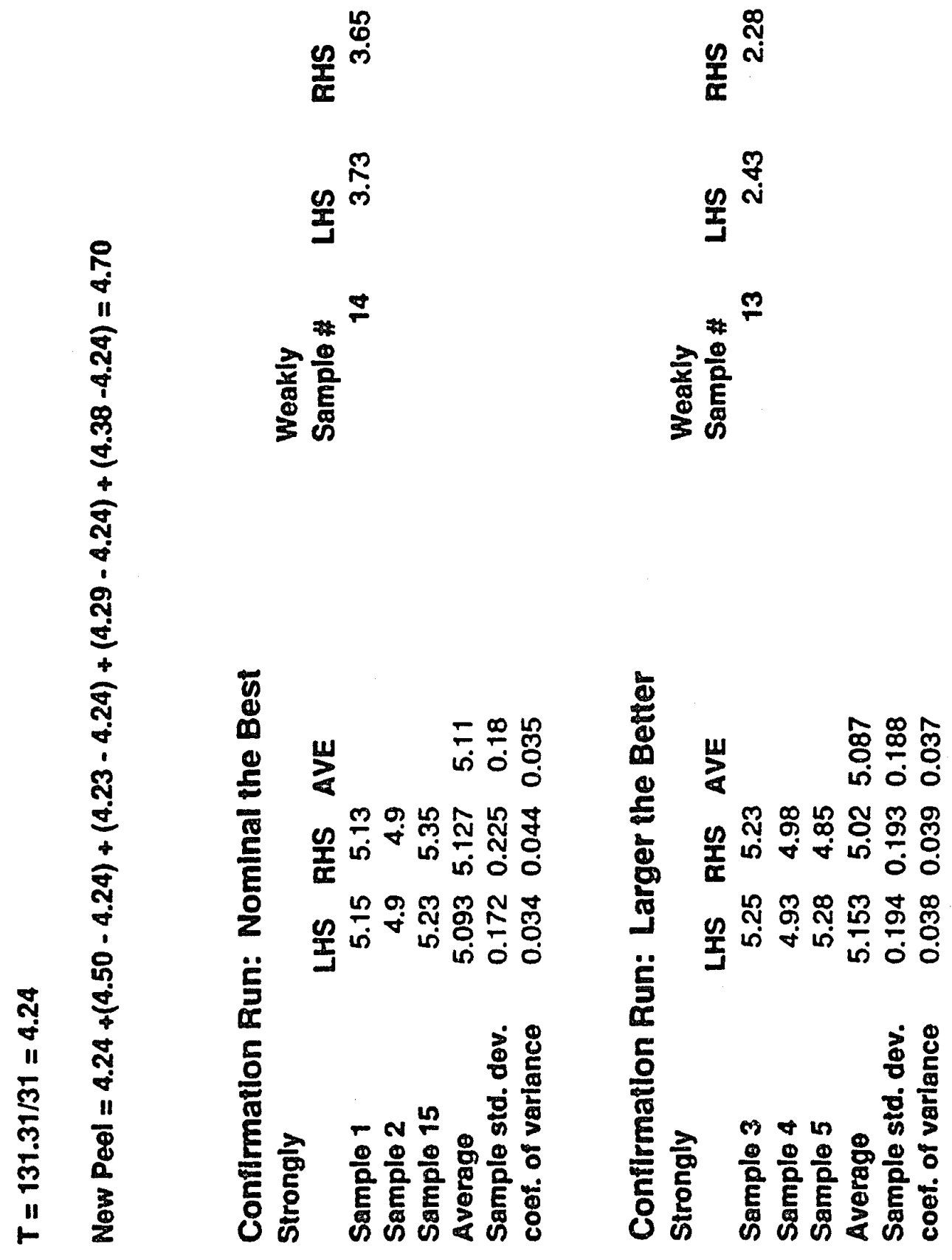




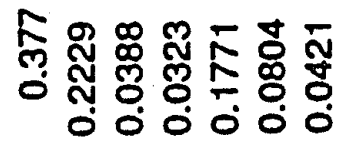

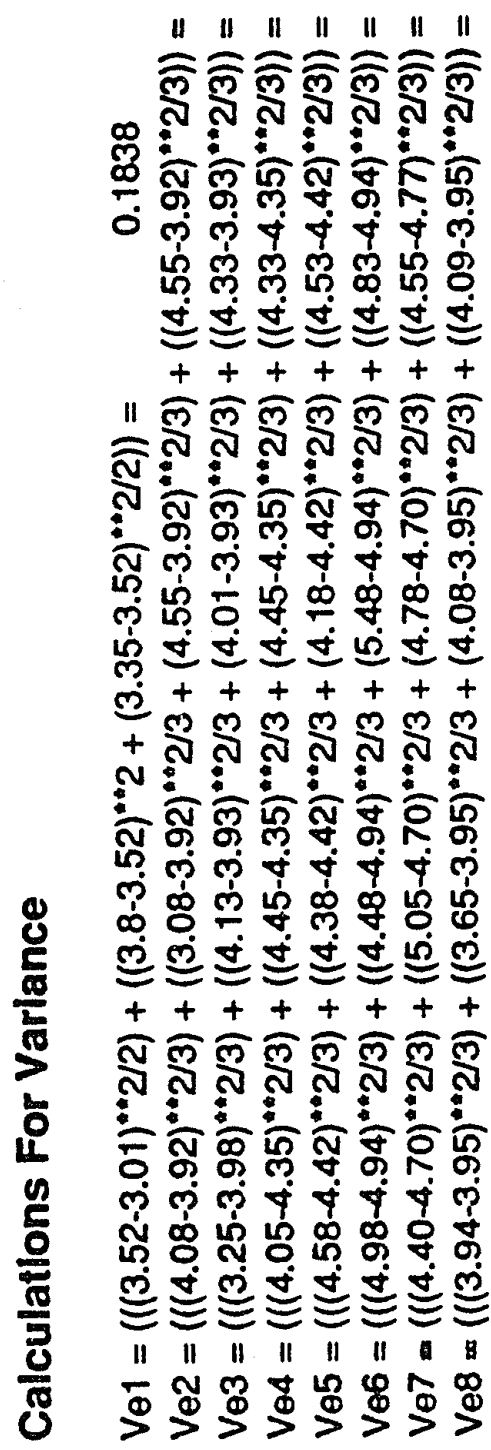

요

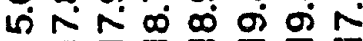
"

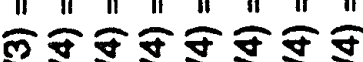
ลิ ลิ ลิ่

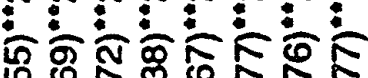
o in Un EEE 은 응 응 응 옹 응 응 응 응응으응으응으은 "I " $"$ " " Nㅜㄴ

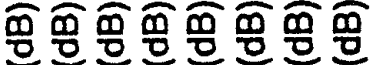

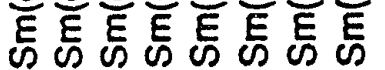




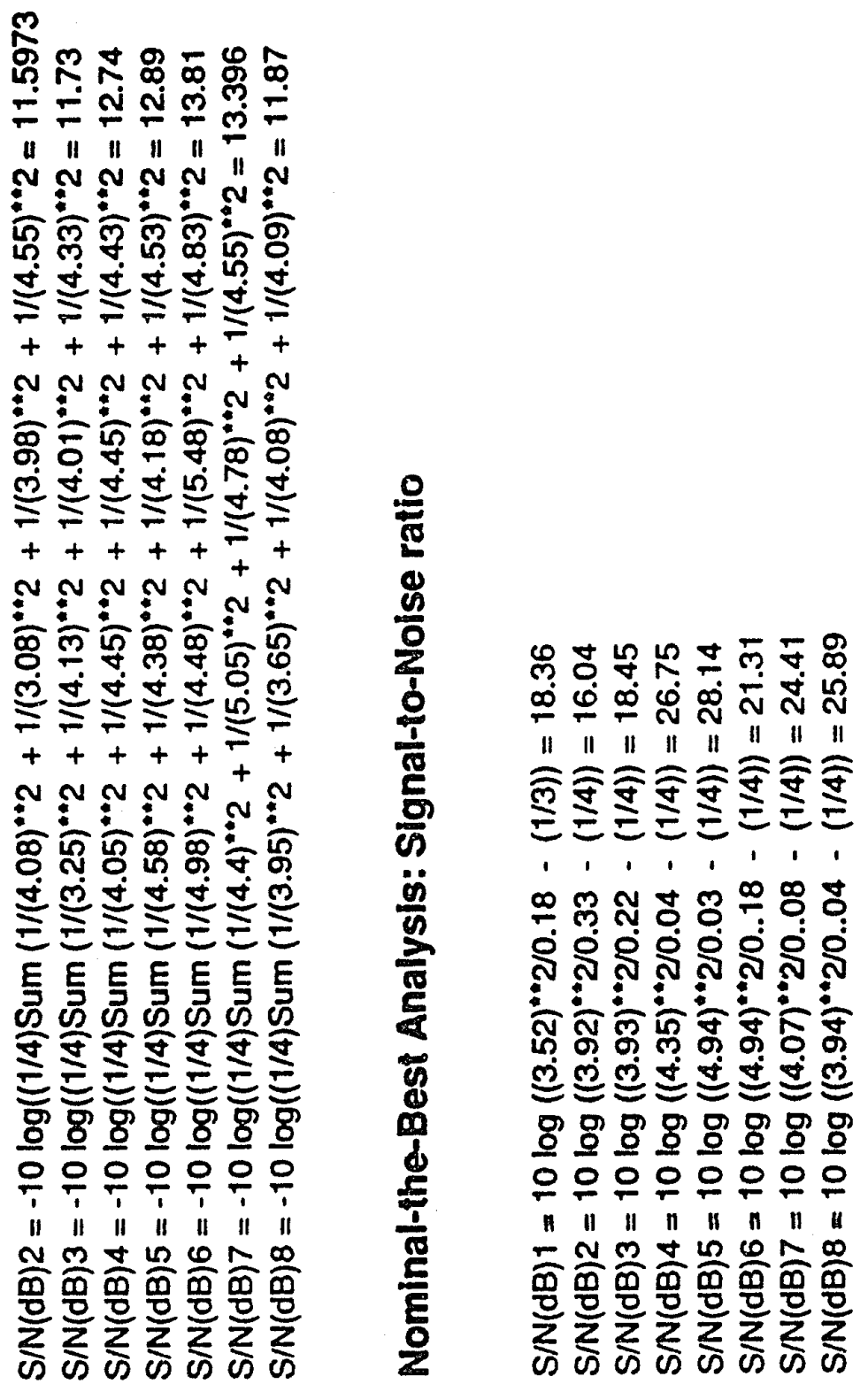


APPENDIX D

Tables of Data

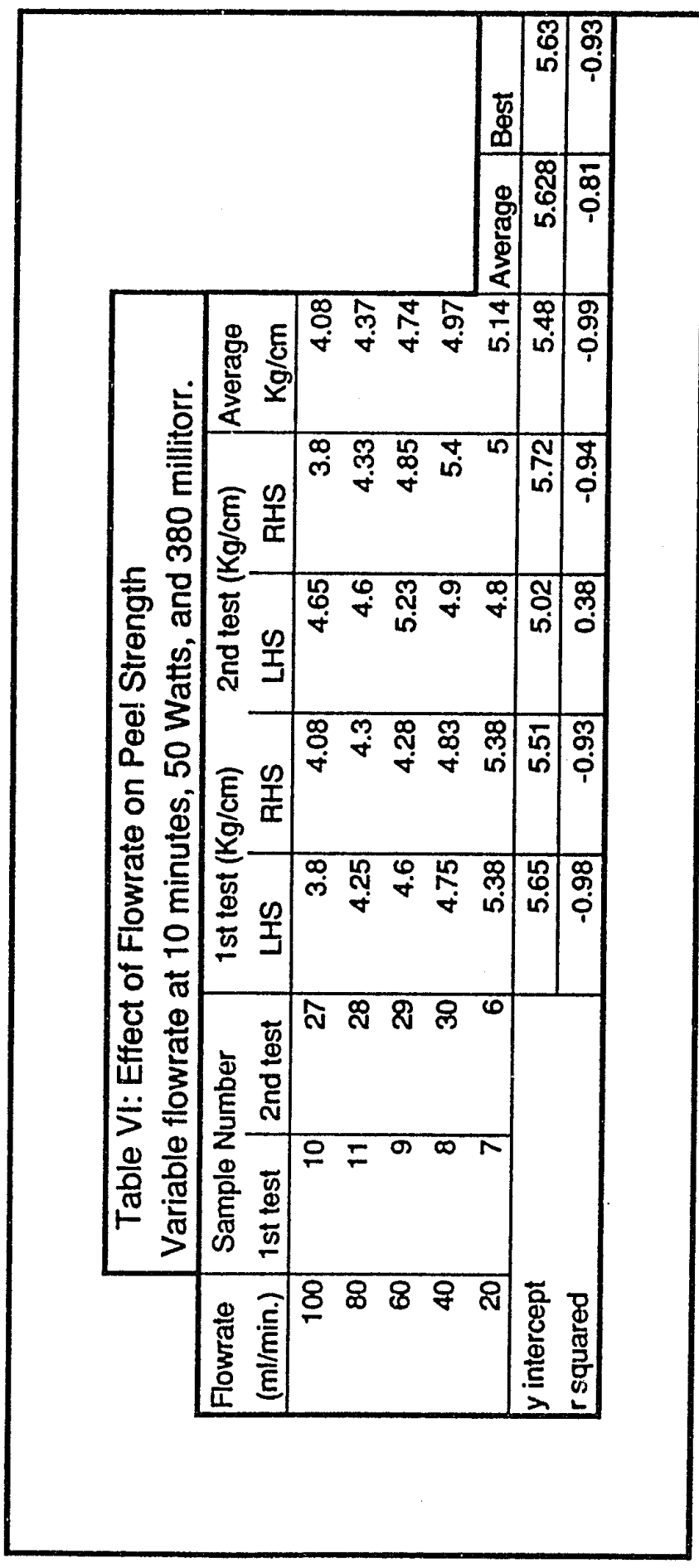




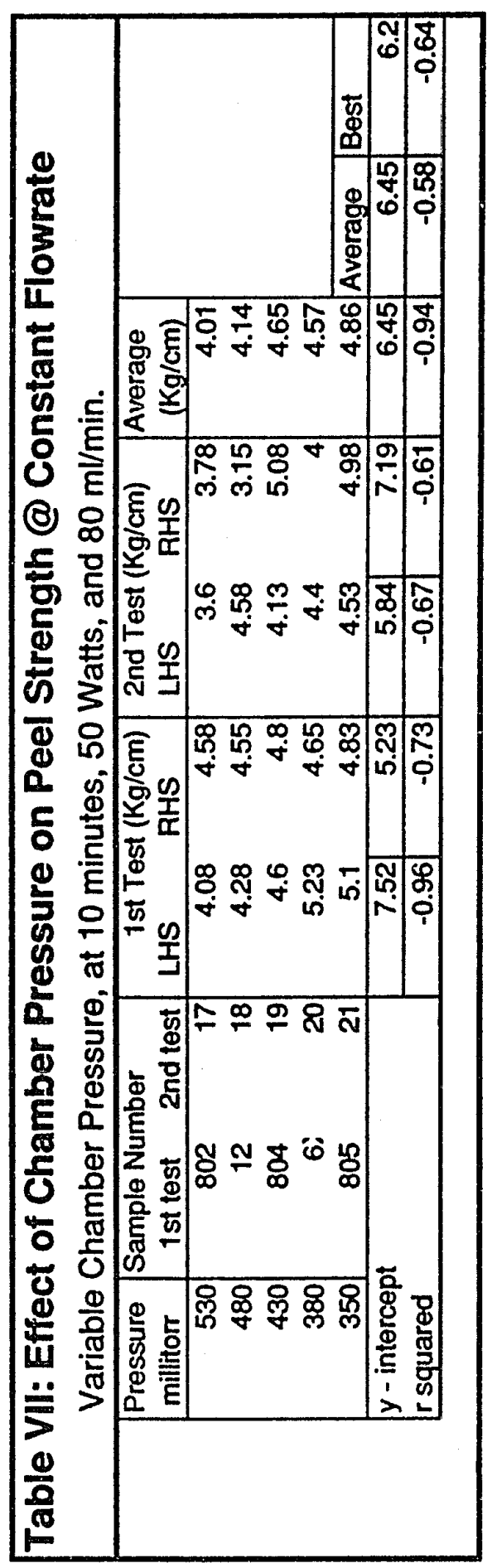




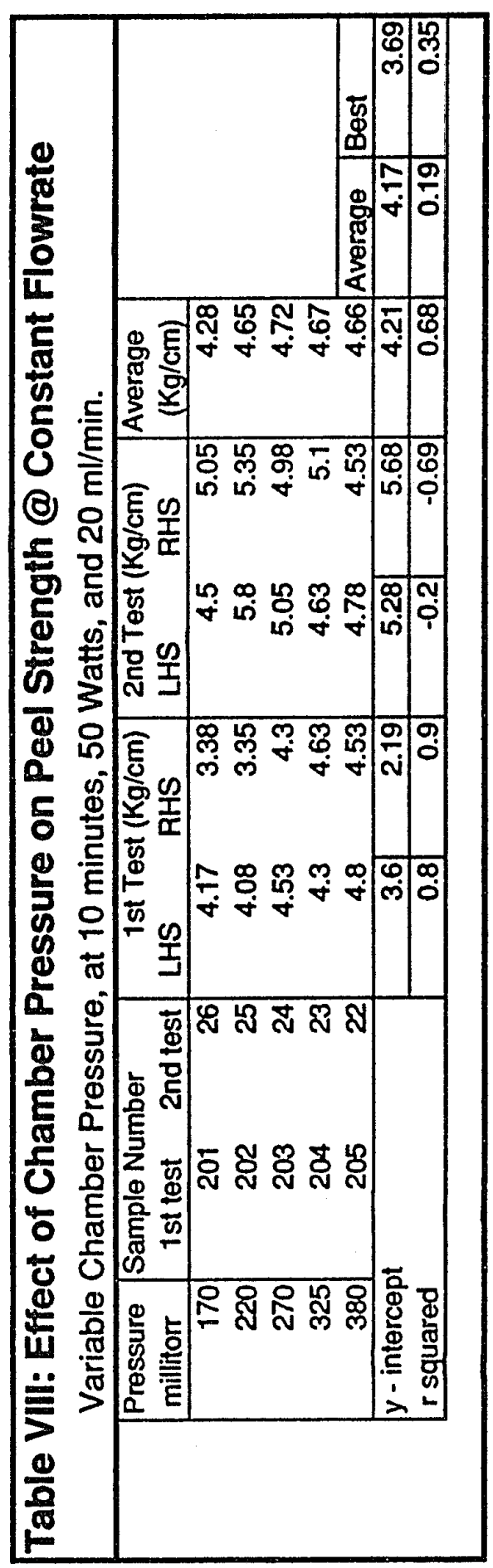




\begin{tabular}{|c|c|c|}
\hline \multicolumn{3}{|c|}{ Table IX: Copper Fllm Thickness } \\
\hline Sample Number & Thlckness (Inches) & Thickness (umeters) \\
\hline 11 & 0.0011 & 27.94 \\
\hline 12 & 0.0014 & 35.56 \\
\hline 21 & 0.0012 & 30.48 \\
\hline 22 & 0.0012 & 30.48 \\
\hline 31 & 0.0014 & 35.56 \\
\hline 32 & 0.0013 & 33.02 \\
\hline 41 & 0.0013 & 33.02 \\
\hline 42 & 0.0012 & 30.48 \\
\hline 51 & 0.0014 & 35.56 \\
\hline 52 & 0.0011 & 27.94 \\
\hline 61 & 0.0014 & 35.56 \\
\hline 62 & 0.0013 & 33.02 \\
\hline 71 & 0.0011 & 27.94 \\
\hline 72 & 0.0012 & 30.48 \\
\hline 81 & 0.0014 & 35.56 \\
\hline 82 & 0.0011 & 27.94 \\
\hline 1 & 0.001 & 25.4 \\
\hline 2 & 0.0011 & 27.94 \\
\hline 3 & 0.0011 & 27.94 \\
\hline 4 & 0.0012 & 30.48 \\
\hline 5 & 0.0012 & 30.48 \\
\hline 6 & 0.0013 & 33.02 \\
\hline 7 & 0.0011 & 27.94 \\
\hline 8 & 0.0013 & 33.02 \\
\hline 9 & 0.0011 & 27.94 \\
\hline 10 & 0.0015 & 38.1 \\
\hline 11 & 0.0013 & 33.02 \\
\hline 12 & 0.0012 & 30.48 \\
\hline 13 & 0.0011 & 27.94 \\
\hline 14 & 0.0014 & 35.56 \\
\hline 15 & 0.0015 & 38.1 \\
\hline CA & 0.0014 & 35.56 \\
\hline $\mathrm{CB}$ & 0.0013 & 33.02 \\
\hline cc & 0.001 & 25.4 \\
\hline$C D$ & 0.0018 & 45.72 \\
\hline & 0.0013 & 31.9 STD. DEV. $=4.77$ \\
\hline
\end{tabular}


APPENDIXE

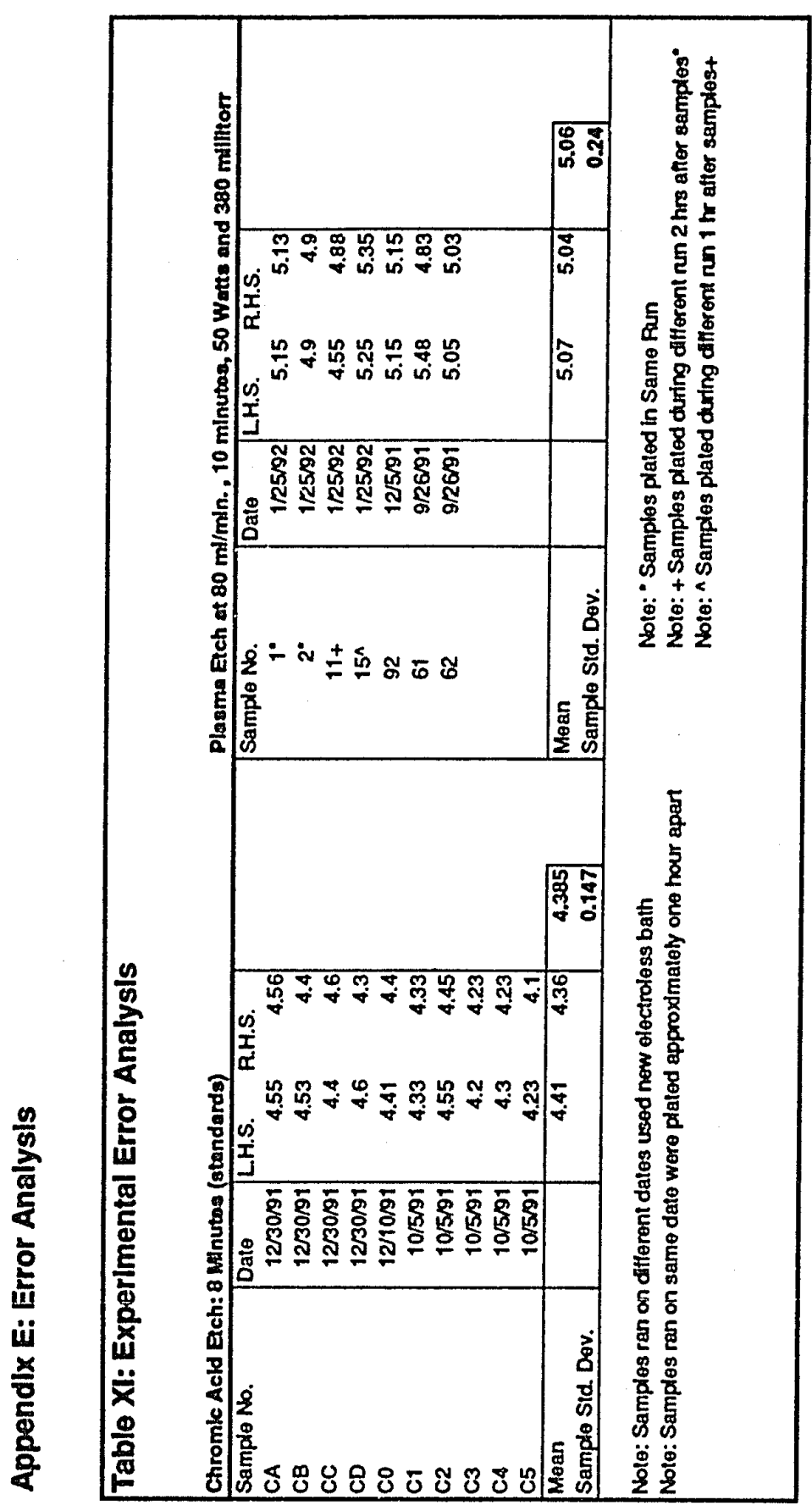

